Kenia Naara Parra

\title{
Degradação eletroquímica de tetraciclina em meio de urina artificial
}

Dissertação apresentada ao Instituto de Química de São Carlos da Universidade de São Paulo como um dos requisitos para a obtenção do título de mestre em Ciências.

Área de concentração: Físico-Química

Orientador: Prof. Dr. Artur de Jesus Motheo 

Dedido esse trabalho aos meus sobrinhos Matheus, Caio e Vinícius pelos incontáveis momentos de alegria, sinceridade e felicidade 


\section{AGRADECIMENTOS}

Meus sinceros agradecimentos:

Ao Prof. Dr. Artur de Jesus Motheo pela orientação, conhecimento compartilhado, aprendizado, discussões e amizade durante todo o mestrado;

A todos os membros do Grupo de Eletroquímica Interfacial, pela amizade, ajuda e discussões científicas;

Ao CAQI/IQSC/USP pela disponibilidade de utilização do microscópio eletrônico de varredura;

Ao Prof. Dr. Marcos R.V. Lanza pela disponibilização da bomba peristáltica;

Ao Programa de Pós-Graduação do Instituto de Química de São Carlos;

Ao amigo José Mário de Aquino pela ajuda na realização dos experimentos e na interpretação dos resultados;

A CAPES, pela bolsa de mestrado concedida;

A toda minha família, em especial meus avós Dahilson e Romilda, Vicente e Euripidina, aos meus pais Waldecir e Rosângela, aos meus irmãos Mateus, Rafael e Rúbia, e ao meu namorado Junior, pelo incentivo, carinho e apoio em todos os momentos;

A Deus por tudo acima citado e muito mais. 
Considerando a crescente contaminação da água e os vários problemas ao meio ambiente e a saúde humana decorrentes dessa contaminação, os produtos farmacêuticos e de higiene pessoal, como antibióticos e outros, constituem uma grande preocupação, pois não são completamente removidos nos sistemas de tratamento de esgoto, além de serem resistentes à biodegradação. Antibióticos como a tetraciclina $(\mathrm{TeC})$, por exemplo, são excretados em grande parte eliminados pela urina e/ou fezes, sendo cada vez mais detectados em uma grande variedade de matrizes ambientais, causando inúmeros efeitos tais como, alergias e aumento da resistência de bactérias. Assim, esse estudo visou a degradação da TeC em meio de urina artificial por método eletroquímico utilizando um ânodo dimensionalmente estável (ADE), o qual foi selecionado pela alta concentração de cloreto no meio. Foram realizados estudos de densidade de corrente e $\mathrm{pH}$ inicial, avaliando a concentração remanescente de $\mathrm{TeC}$, creatinina, uréia e COT e, comparando os resultados com os obtidos em meio aquoso contendo $\mathrm{NaCl} 0,1 \mathrm{~mol} \mathrm{~L}^{-1}$. A TeC sofreu degradação eletroquímica devido à eletrogeração de espécies oxidantes de cloro ativo a partir do cloreto presente no meio. O decaimento da concentração da TeC ajustou-se ao modelo de cinética de pseudo-primeira ordem e aumentou como o aumento da densidade de corrente aplicada. O tratamento eletroquímico pode ser realizado em valores de $\mathrm{pH}$ próximos ao neutro, em que a TeC na forma aniônica e a espécie $\mathrm{HOCl}$, favorecem a degradação, mesmo na presença de EDTA. A creatinina e a uréia interferem no processo eletroquímico, fazendo com que a degradação da TeC apresente velocidades de reação mais baixas e o consumo energético do processo seja mais elevado do que em meio aquoso contendo $\mathrm{NaCl}$.

Palavras chave: tetraciclina, urina artificial, $A D E$, tratamento eletroquímico 


\begin{abstract}
Considering the increase contamination of water and various environmental and human health problems resulting from this contamination, the pharmaceuticals and personal care products, such as antibiotics, etc., constitute a major concern because they are not removed completely from the sewage treatment systems, and they are resistant to biodegradation. Antibiotics such as tetracycline (TeC), for example, are largely excreted in the urine and/or feces increasingly being detected in a wide variety of environmental matrices and causing numerous effects such as allergies and increasing resistance to bacteria. Thus, this study aimed in degradation $\mathrm{TeC}$ amid in artificial urine medium by electrochemical method using a dimensionally stable anode (DSA), which has been selected from a highly concentrated chloride in the medium. The studies were resulted from current density and initial $\mathrm{pH}$ by assessing the remaining concentration of $\mathrm{TeC}$, creatinine, urea and TOC and comparing the results with those obtained in an aqueous medium containing $\mathrm{NaCl} 0,1 \mathrm{~mol} \mathrm{~L}^{-1}$. It was observed that, $\mathrm{TeC}$ undergoes electrochemical degradation due to the electrogeneration of oxidizing species of active chlorine from the chloride present in the medium. The decaing of TeC concentration was adjusted to a pseudo-first order kinetic model and increased as current density was increased. It was also observed that the electrochemical treatment may be performed on $\mathrm{pH}$ close to the neutral, wherein the anionic form TEC species and $\mathrm{HOCl}$ favor degradation, even in the presence of EDTA. The presence of creatinine and urea interfere in the electrochemical process, causing the degradation of $\mathrm{TeC}$ to present lowers reaction rates and highers energy consumption in the process than in aqueous medium containing $\mathrm{NaCl}$.
\end{abstract}

Keywords: tetracycline, artificial urine, DSA, electrochemical treatment 


\section{LISTA DE ILUSTRAÇÕES}

Figura 1 - Estrutura química do naftaceno, clorotetraciclina, oxitetraciclina, e TeC

Figura 1 - Célula eletroquímica para análises voltamétricas.

Figura 3 - Célula eletroquímica de fluxo: (a) célula eletroquímica, (b) visão expandida (1) suporte de aço inoxidável, (2) suporte de $\operatorname{Teflon}^{\circledR}$, (3) isolante de Viton ${ }^{\circledR}$, (4) anodo, (5) espaçador de Teflon $^{\circledR}$, (6) catodo e (7) membrana catiônica, e (c) sistema eletroquímico........ 37

Figura 4 - Reação de formação do complexo de Janovsky para determinação de creatinina.... 40

Figura 5 - Reação de formação do complexo para determinação de uréia.

Figura 6 - Micrografias de MEV do eletrodo de composição $\mathrm{Ti} / \mathrm{Ru}_{0,3} \mathrm{Ti}_{0,7} \mathrm{O}_{2}$ com ampliação de (a) 2500 X e (b) 5000 X, após as utilizações nas eletrólises.

Figura 7 - Espectro de EDX do eletrodo de composição $\mathrm{Ti} / \mathrm{Ru}_{0,3} \mathrm{Ti}_{0,7} \mathrm{O}_{2}$ (a) antes (b) após utilizações nas eletrólises

Figura 8 - (a) Voltamograma cíclico de $\mathrm{Ti} / \mathrm{Ru}_{0,3} \mathrm{Ti}_{0,7} \mathrm{O}_{2}$ em solução de $\mathrm{H}_{2} \mathrm{SO}_{4} 0,5 \mathrm{~mol} \mathrm{~L}^{-1}, \mathrm{v}=50$ $\mathrm{mV} \mathrm{s}^{-1}$. (b) análise do voltamograma em um intervalo menor de densidade de corrente. (一) antes e (---) depois do condicionamento.

Figura 9 - Voltamograma cíclico de $\mathrm{Ti} / \mathrm{Ru}_{0,3} \mathrm{Ti}_{0,7} \mathrm{O}_{2}$ em solução de $\mathrm{H}_{2} \mathrm{SO}_{4} \quad 0,5 \mathrm{~mol} \mathrm{~L}{ }^{-1}$ com diferentes velocidades de varredura, (1) 25; (2) 50; (3) 100; (4) 150 (5) $200 \mathrm{mV} \mathrm{s}^{-1}$ .46

Figura 10 - Voltamograma cíclico de $\mathrm{Ti} / \mathrm{Ru}_{0,3} \mathrm{Ti}_{0,7} \mathrm{O}_{2}$ em solução salina com diferentes velocidades de varredura,. (1) 25 ; (2) 50 ; (3) 100 ; (4) $150 \mathrm{mV} \mathrm{s}^{-1}$.

Figura 11 - Voltamograma cíclico de $\mathrm{Ti} / \mathrm{Ru}_{0,3} \mathrm{Ti}_{0,7} \mathrm{O}_{2}, \mathrm{v}=50 \mathrm{mV} \mathrm{s}{ }^{-1}$, (一) solução salina e (---) solução salina e $200 \mathrm{mg} \mathrm{L}^{-1} \mathrm{TeC}$.

Figura 12 - Voltamograma cíclico de $\mathrm{Ti} / \mathrm{Ru}_{0,3} \mathrm{Ti}_{0,7} \mathrm{O}_{2}, \mathrm{v}=50 \mathrm{mV} \mathrm{s}{ }^{-1}$, (一) solução salina, (--) TeC $200 \mathrm{mg} \mathrm{L}^{-1}$ em solução salina (---) creatinina $1,1 \mathrm{~g} \mathrm{~L}^{-1}$ e uréia $25 \mathrm{~g} \mathrm{~L}^{-1}$ em solução salina. 50 
Figura 13 - (a) Voltamograma cíclico de $\mathrm{Ti} / \mathrm{Ru}_{0,3} \mathrm{Ti}_{0,7} \mathrm{O}_{2}, \mathrm{v}=50 \mathrm{mV} \mathrm{s}^{-1}$ (b) ampliação do voltamograma no intervalo compreendido entre 1,3 e 1,6 V, (-) solução salina, (---) TeC 200 $\mathrm{mg} \mathrm{L}^{-1}$ em solução salina 2 ㅇ ciclo (---) 5으 ciclo (‥) 10으 ciclo.

Figura 14 - (a) Voltamograma cíclico de $\mathrm{Ti} / \mathrm{Ru}_{0,3} \mathrm{Ti}_{0,7} \mathrm{O}_{2}, \mathrm{v}=50 \mathrm{mV} \mathrm{s} \mathrm{s}^{-1}$ (b) ampliação do voltamograma no intervalo compreendido entre 1,2 e 1,6 V, (-) solução salina, (---) TeC 200 $\mathrm{mg} \mathrm{L}^{-1}$, creatinina $1,1 \mathrm{~g} \mathrm{~L}^{-1}$ e uréia $25 \mathrm{~g} \mathrm{~L}^{-1}$ em solução salina 2ㅇ ciclo (---) 5으 ciclo (‥) 10으 ciclo.

Figura 15 - Espectro de absorção no UV da TeC $50 \mathrm{mg} \mathrm{L}^{-1}$ (---) meio aquoso, (-) meio de urina artificial. 54

Figura 16 - Espectro de absorção no UV da $\mathrm{TeC}$ em meio de urina artificial em diferentes tempos de eletrólise. $\left([\mathrm{TeC}]_{\mathrm{i}}=200 \mathrm{mg} \mathrm{L}^{-1}, \mathrm{~T}=25^{\circ} \mathrm{C}, \mathrm{pH}_{\mathrm{i}}=6,0\right.$ e j $\left.=30 \mathrm{~mA} \mathrm{~cm}{ }^{-2}\right)$. .54

Figura 17 - Aspecto visual das soluções de $\mathrm{TeC}$ em meio de urina artificial. (a) antes do tratamento eletroquímico (b) depois do tratamento eletroquímico. ([TeC $]_{i}=200 \mathrm{mg} \mathrm{L}^{-1}, \mathrm{j}=30$ $\left.\mathrm{mA} \mathrm{cm}{ }^{-2}, \mathrm{~T}=25^{\circ} \mathrm{Ce} \mathrm{pH}_{\mathrm{i}}=6,0\right)$.

Figura 18 - Decaimento da $\mathrm{TeC}$ ao longo do tempo de eletrólise em diferentes densidades de

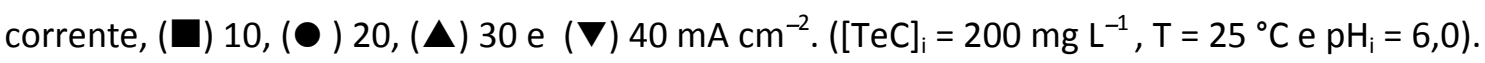

Figura 19 - Constante de velocidade de pseudo-primeira ordem em função da densidade de corrente. 57

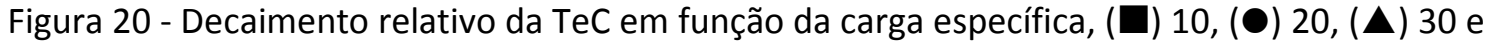
( $\boldsymbol{\nabla}) 40 \mathrm{~mA} \mathrm{~cm}^{-2}$. ([TeC $\left.]_{\mathrm{i}}=200 \mathrm{mg} \mathrm{L}^{-1}, \mathrm{~T}=25^{\circ} \mathrm{Ce} \mathrm{pH}_{\mathrm{i}}=6,0\right)$. 59

Figura 21 - Análise do teor de COT para todas as densidades de corrente com diluição automática, símbolos cheios: tempo total $=180 \mathrm{~min}$; símbolos vazios: tempo total $=360 \mathrm{~min}$. $(\boldsymbol{\square}, \square) 10,(\bullet, O) 20,(\boldsymbol{\Delta}, \triangle) 30$ e $(\boldsymbol{\nabla}, \nabla) 40 \mathrm{~mA} \mathrm{~cm}{ }^{-2}$. $\left([\mathrm{TeC}]_{\mathrm{i}}=200 \mathrm{mg} \mathrm{L}^{-1}, \mathrm{~T}=25^{\circ} \mathrm{Ce} \mathrm{pH}_{\mathrm{i}}=\right.$ $6,0)$. 
Figura 22 - Decaimento ao longo do tempo de eletrólise para j = $30 \mathrm{~mA} \mathrm{~cm}{ }^{-2}$, ( $\left.\mathbf{\square}\right)$ uréia,

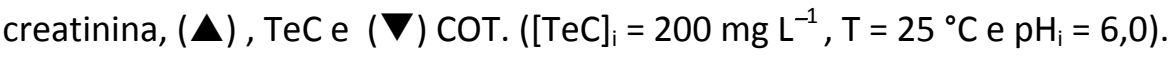

Figura 23 - Consumo energético para todas as densidades de corrente, $(\boldsymbol{\square}) 10,(\mathbf{O}) 20,(\boldsymbol{\Delta}) 30$

e ( $\boldsymbol{\nabla}) 40 \mathrm{~mA} \mathrm{~cm}^{-2} .\left([\mathrm{TeC}]_{\mathrm{i}}=200 \mathrm{mg} \mathrm{L}^{-1}, \mathrm{~T}=25^{\circ} \mathrm{Ce} \mathrm{pH}_{\mathrm{i}}=6,0\right)$.

Figura 24 - Decaimento relativo da $\mathrm{TeC}$ ao longo do tempo de eletrólise em meio de $\mathrm{NaCl}$ 0,1

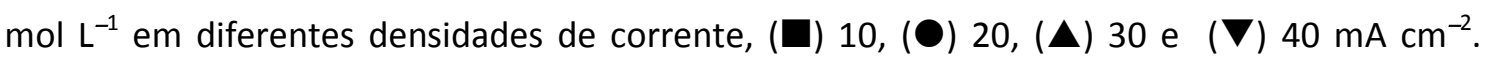

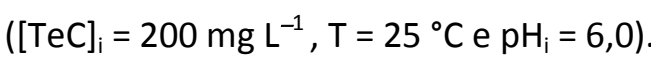

Figura 25 - Constante de velocidade de pseudo-primeira ordem em função da densidade de corrente em meio de $\mathrm{NaCl} 0,1 \mathrm{~mol} \mathrm{~L}^{-1}$. ([TeC $\left.]_{\mathrm{i}}=200 \mathrm{mg} \mathrm{L}^{-1}, \mathrm{~T}=25^{\circ} \mathrm{Ce} \mathrm{pH}_{\mathrm{i}}=6,0\right)$.

Figura 26 - ( $\mathbf{\square})$ CE e (O) EC em função da densidade de corrente após duas horas de eletrólise em meio de $\mathrm{NaCl} \mathrm{0,1} \mathrm{mol} \mathrm{L}^{-1}\left([\mathrm{TeC}]_{i}=200 \mathrm{mg} \mathrm{L}^{-1}, \mathrm{~T}=25^{\circ} \mathrm{Ce} \mathrm{pH}_{\mathrm{i}}=6,0\right)$.

Figura 27 - Cromatogramas com deteç̧ão no UV em diferentes densidades de corrente e em meio de $\mathrm{NaCl} 0,1 \mathrm{~mol} \mathrm{~L}^{-1}$. ([TeC $\left.]_{i}=200 \mathrm{mg} \mathrm{L}^{-1}, \mathrm{~T}=25^{\circ} \mathrm{C}, \mathrm{pH}_{\mathrm{i}}=6,0\right)$.

Figura 28 - Cromatogramas com deteç̧ão no UV em diferentes densidades de corrente e em meio de urina artificial. ([TeC $\left.]_{i}=200 \mathrm{mg} \mathrm{L}^{-1}, \mathrm{~T}=25^{\circ} \mathrm{C}, \mathrm{pH}_{\mathrm{i}}=6,0\right)$. 70

Figura 29 - Variação do pH ao longo do tempo de eletrólise em diferentes densidades de

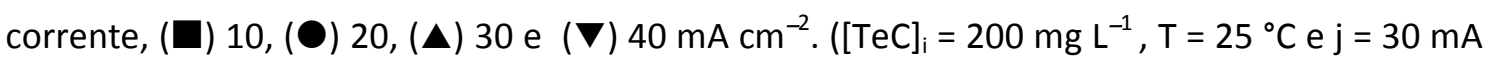
$\left.\mathrm{cm}^{-2}\right)$.

Figura 30 - Aspecto visual das soluções de TeC em meio de urina artificial. (a) pH =6,0. (b) pH = 7,0 antes de decantar o precipitado. (c) pH = 7 após decantação em fundo preto. (d) pH =7,0 após adição de $\mathrm{Na}_{2} \mathrm{EDTA}$.

Figura 31 - Representação esquemática do quelato formado entre EDTA e um cátion bivalente $\left(\mathrm{M}=\mathrm{Ca}^{2+}, \mathrm{Mg}^{2+}, \mathrm{Zn}^{2+}\right.$ etc. $)$ .76 
Figura 32 - Espectro de absorção no UV da $\mathrm{TeC}$ em meio de urina artificial em diferentes valores de $\mathrm{pH}$ inicial, $(-) \mathrm{pHi}=6,0,(--)$ pHi $=7,0$ antes da adição de $\mathrm{Na}_{2}$ EDTA (---) pHi $=7,0$ após adição de $\mathrm{Na}_{2}$ EDTA. $\left([T e C]_{i}=200 \mathrm{mg} \mathrm{L}^{-1}, \mathrm{~T}=25^{\circ} \mathrm{C}\right)$. .76

Figura 33 - Decaimento da $\mathrm{TeC}$ ao longo do tempo de eletrólise em diferentes valores de $\mathrm{pH}$ inicial, $(\boldsymbol{\square}) \mathrm{pHi}=5,0,(\mathbf{O}) \mathrm{pHi}=6,0$ e $(\boldsymbol{\Delta}) \mathrm{pHi}=7,0$ após adição de $\mathrm{Na}_{2} \mathrm{EDTA}$. ([TeC $]_{\mathrm{i}}=200 \mathrm{mg}$ $\mathrm{L}^{-1}, \mathrm{~T}=25^{\circ} \mathrm{Ce} \mathrm{j}=30 \mathrm{~mA} \mathrm{~cm}{ }^{-2}$ ).

Figura 34 - Ajuste da constante cinética de pseudo-primeira ordem para as concentrações relativas em diferentes valores de $\mathrm{pH}$ inicial, $(\mathbf{\square}) \mathrm{pHi}=5,0,(\square) \mathrm{pHi}=5,0 \mathrm{com}$ adição de $\mathrm{Na}_{2}$ EDTA, (O) pHi = 6,0 e (O) pHi = 6,0 com adição de $\mathrm{Na}_{2}$ EDTA. .78

Figura 35 - Perfil das espécies de cloro ativo em função do pH. 80

Figura 36 - Efeito do pH e modelo cinético para as constantes de velocidade de reação entre TeC e espécies de cloro ativo 80

Figura 37 - Variação do pH ao longo do tempo de eletrólise a partir de diferentes valores de pH inicial. Símbolos cheios: sem adição de $\mathrm{Na}_{2} \mathrm{EDTA}$; símbolos vazios: com adição de $\mathrm{Na}_{2} \mathrm{EDTA}$, $(\square, \square) \mathrm{pHi}=5,00,(\bullet, \bigcirc) \mathrm{pHi}=6,00,(\triangle) \mathrm{pHi}=7,00 .\left([\mathrm{TeC}]_{\mathrm{i}}=200 \mathrm{mg} \mathrm{L}^{-1}, \mathrm{~T}=25^{\circ} \mathrm{C}\right.$ e j $=30 \mathrm{~mA}$ $\left.\mathrm{cm}^{-2}\right)$.

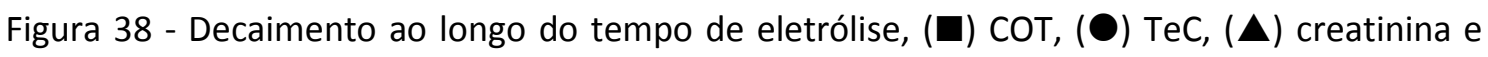
( $\nabla$ ) uréia. ([TeC $]_{i}=200 \mathrm{mg} \mathrm{L}^{-1}, \mathrm{~T}=25^{\circ} \mathrm{C}, \mathrm{j}=30 \mathrm{~mA} \mathrm{~cm}^{-2}$ e pHi $\left.=7,00\right)$. 


\section{LISTA DE TABELAS}

Tabela 1 - Poder de oxidação de vários ânodos ativos e não ativos em processos de oxidação eletroquímica em meio ácido

Tabela 2 - Composição da solução de urina artificial. 34

Tabela 3 - Variação da carga anódica e catódica para diferentes velocidades de varredura no intervalo de potencial compreendido entre 0,4 e 1,4 V vs ENH em solução de $\mathrm{H}_{2} \mathrm{SO}_{4} 0,5 \mathrm{~mol} \mathrm{L-}^{1}$

Tabela 1 - Variação da carga anódica e catódica para diferentes velocidades de varredura no intervalo de potencial compreendido entre 0,4 e 1,4 V vs ENH em solução salina

Tabela 5 - Percentagem remanescente de uréia e creatinina para cada densidade de corrente

Tabela 6 - Constantes de velocidade e consumo energético $\left(\mathrm{kW} \mathrm{h} \mathrm{m}^{-3}\right)$ para remoção de $50 \%$ de TeC para cada uma das densidades de corrente estudadas em meio de urina artificial e de $\mathrm{NaCl} 0,1 \mathrm{~mol} \mathrm{~L}^{-1}$. (Condições: $[\mathrm{TeC}]_{\mathrm{i}}=200 \mathrm{mg} \mathrm{L}^{-1}, \mathrm{~T}=25^{\circ} \mathrm{C}, \mathrm{pH}_{\mathrm{i}}=6,0$ ) 68 
ADE - Ânodo Dimensionalmente Estável

CE - Consumo Energético

$\mathrm{Cl}$ - Carbono Inorgânico

COT - Teor de Carbono Orgânico Total

CT - Carbono Orgânico Total

DDB - Diamante Dopado com Boro

DQO - Demanda Química de Oxigênio

EC - Eficiência de Corrente

ENH - Eletrodo Normal de Hidrogênio

pH - Potencial Hidrogeniônico

$\mathrm{Q}$ - Carga

RDO - Reação de Desprendimento de Oxigênio

TeC - Tetraciclina

v - Velocidade de Varredura

$\mathrm{V}-$ Volt

VC - Voltametria Cíclica

W - Watt 


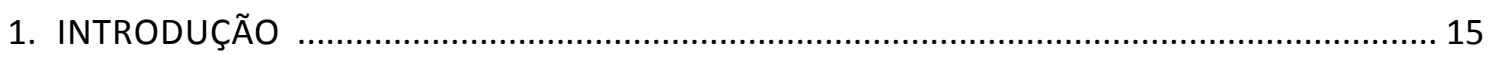

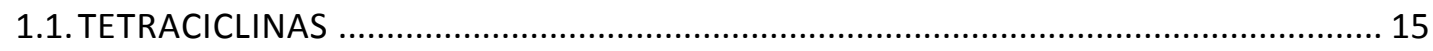

1.2. MÉTODOS PARA TRATAMENTO DE EFLUENTES AQUOSOS .................................... 19

1.3. MECANISMOS DA OXIDAÇÃO ELETROQUÍMICA EM ÂNODOS DE ÓXIDOS

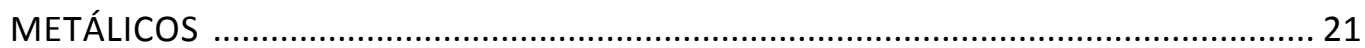

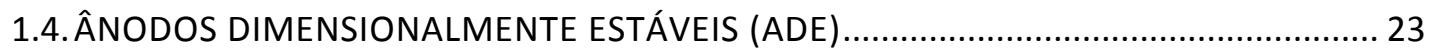

1.5. OXIDAÇÃO POR ESPÉCIES DE CLORO ATIVO ELETROGERADAS .................................. 24

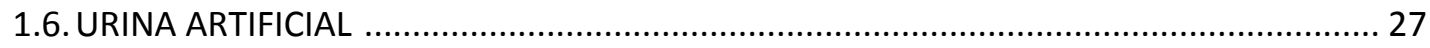

1.7.TÉCNICAS E PARÂMETROS UTILIZADOS PARA ANÁLISE DE UM PROCESSO

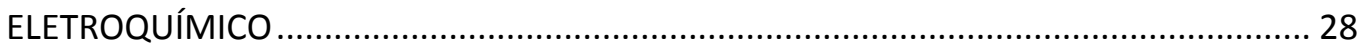

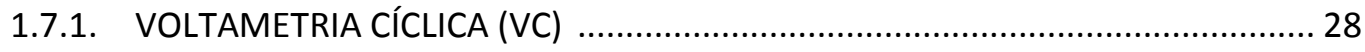

1.7.2. CROMATOGRAFIA LÍQUIDA DE ALTA EFICIÊNCIA (CLAE) ............................... 29

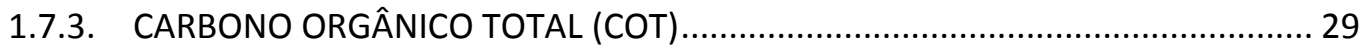

1.7.4. ESPECTROFOTOMETRIA NO ULTRAVIOLETA-VISÍVEL (UV-VIS) ....................... 30

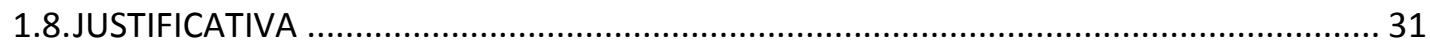

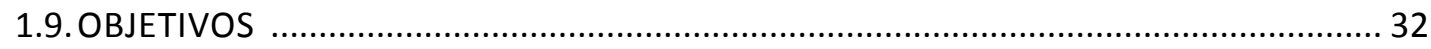

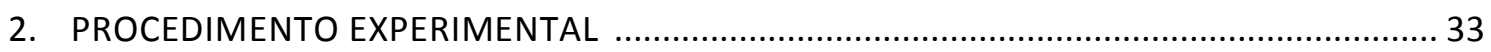

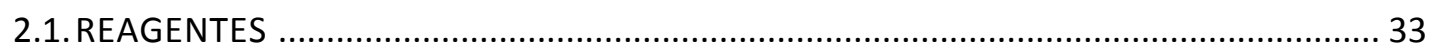

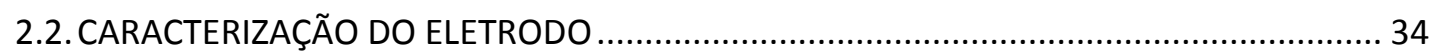

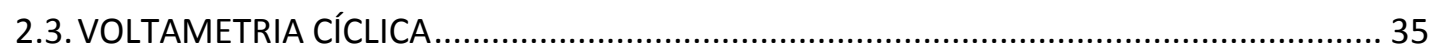

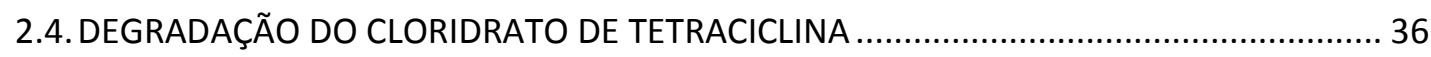

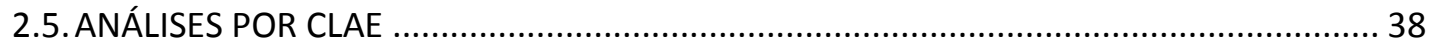

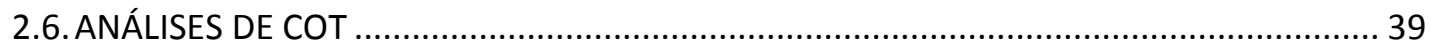

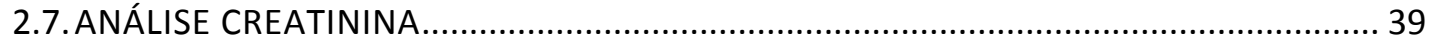

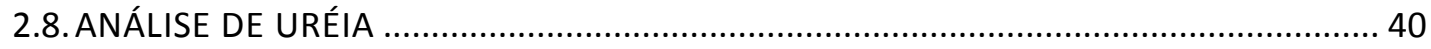

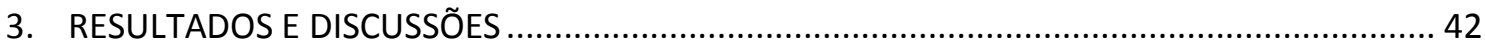

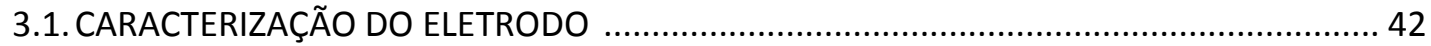

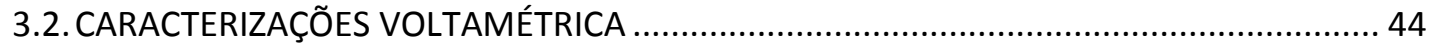

3.2.1. CARACTERIZAÇÃO ELETROQUÍMICA NA PRESENÇA DE TEC ............................. 48

3.2.2. CARACTERIZAÇÃO ELETROQUÍMICA NA PRESENÇA DOS DEMAIS COMPOSTOS

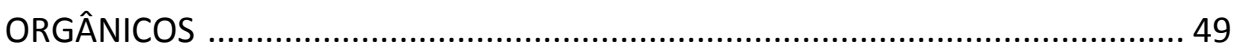

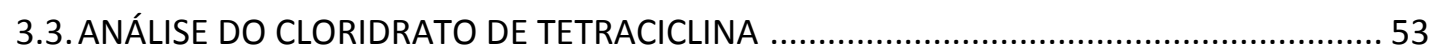

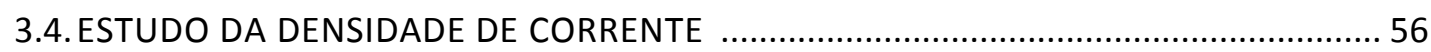


3.5.COMPARAÇÃO DO ESTUDO DA DENSIDADE DE CORRENTE EM DIFERENTES MEIOS.... 63

3.6. ANÁLISE DOS PRODUTOS DE DEGRADAÇÃO POR CLAE ................................................ 68

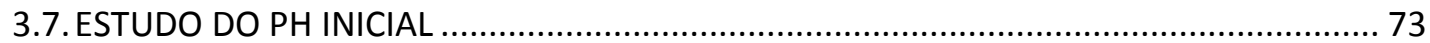

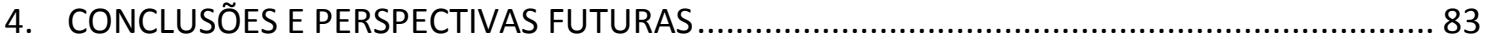

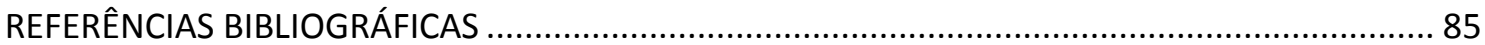




\section{CAPÍtulo 1}

INTRODUÇÃO

\subsection{Tetraciclinas}

Nos últimos anos o uso de produtos de cuidados pessoais e farmacêuticos tem aumentado consideravelmente. Essa ampla classe de produtos químicos com destaque para analgésicos, antibióticos, anticancerígenos, anticonvulsivos, antidepressivos, antissépticos, fragrâncias, hormônios sintéticos e estimulantes ${ }^{1}$ é formada por medicamentos prescritos, ou não, e que podem ser aplicados na área industrial, doméstica, agrária e na criação de animais² ${ }^{2}$.

De acordo com a literatura, antibióticos são substâncias orgânicas produzidas pelo metabolismo secundário de micro-organismos ou sintetizadas artificialmente ou semi-artificialmente, podendo matar outros micro-organismos ou inibir o crescimento ou metabolismo através de ações bioquímicas, mesmo em concentrações diminutas ${ }^{3,4}$.

Dentre os antibióticos mais consumidos, destaca-se a tetraciclina (TeC) que, juntamente com a clorotetraciclina, oxitetraciclina, demeclociclina, entre outros, formam a família das tetraciclinas, antibióticos de largo espectro de ação contra vários micro-organismos 5 .

Em aplicações terapêuticas, as tetraciclinas são comumente empregadas como agentes bacteriostáticos. Mostram-se eficientes no tratamento de infecções causadas por muitas espécies de bactérias Gram-positivas e Gram-negativas, espiroquetas, Rickettsiae e alguns vírus maiores. Também podem ser consumidas em aplicações não terapêuticas, como ativadores de crescimento de gado, em conservação de alimentos e controle microbiológico de fermentações ${ }^{4}$.

No Reino Unido em 2000, as tetraciclinas foram os compostos mais usados na medicina veterinária como promotores de crescimento animal ${ }^{6}$. Na República do Quênia na África Oriental, as tetraciclinas contribuíram com aproximadamente 55 \% do consumo de todos os antimicrobianos empregados na produção de animais para consumo alimentício entre 1995 e $1999^{7}$. 
No início da década de 1940, Lederle descobriu a primeira tetraciclina, que recebeu o nome de Aureomicina devido sua coloração amarela e a coloração dourada das Streptomices do qual o antibiótico foi extraído, porém, a primeira publicação da descoberta foi realizada em 1948 após estudos comprobatórios de sua ação contra bactérias. Dois anos mais tarde foi aprovado um novo composto de cor similar, porém com maior bioatividade e solubilidade em água, sendo denominado Terramicina. Em 1952, com o surgimento de novos equipamentos, as estruturas químicas dos dois compostos foram elucidadas e a nova família de antibióticos se tornou conhecida como tetraciclinas ${ }^{8}$.

Essa classe de moléculas é caracterizada por um esqueleto carbônico composto por quatro anéis de seis membros linearmente fundidos, denominados de $A$ até $D$, formando o naftaceno, parte central da molécula (Figura 1). Ligados a este centro existem grupos funcionais similares, com pequenas diferenças em estrutura que the conferem variações em atividade farmacêutica ${ }^{8,9}$. Confirmada a diferença entre as estruturas químicas da Aureomicina e Terramicina, estas receberam o nome de clorotetraciclina e oxitetraciclina, respectivamente (Figura 1).

Em 1954, foi aprovado um composto obtido pela hidrogenação catalítica da clorotetraciclina resultando em um derivado desclorado, de maior potência, solubilidade e favorável atividade farmacológica, denominado TeC (Figura 1). Essa foi a primeira tetraciclina obtida a partir da modificação de um produto natural, sendo o primeiro antibiótico semi-sintético usado na medicina. A partir daí, uma série de outros derivados semi-sintéticos surgiram, como metaciclina, doxiciclina, demeclociclina, sanciclina, minociclina, entre outros ${ }^{8}$.

As tetraciclinas são caracterizadas por possuírem grupos multifuncionais que Ihes conferem propriedades ácido-base. Possuem quatro constantes de dissociação sendo que o grupo hidroxila do sistema tricarbonil do anel A é responsável pelo primeiro pKa em aproximadamente 3,3. O grupo hidroxila do sistema dicarbonil entre os anéis $B$ e C é o responsável pelo segundo pKa por volta de 7,6. O terceiro pKa, em aproximadamente 9,7, é atribuído ao grupo amino (dimetilamino) no anel A. Por fim, a quarta constante entre 10,7 e 12,0 é associada ao grupo hidroxila do fenol no anel $D^{10,11}$. 


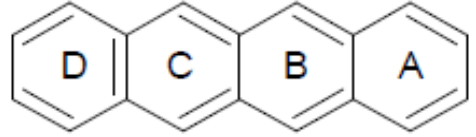

naftaceno<smiles>CN(C)[C@@H]1C2=CC3C(=C(O)[C@]2(O)C(=O)C(C(N)=O)=C1O)C(=O)c1c(O)ccc(Cl)c1[C@@]3(C)O</smiles>

clorotetraciclina

Aureomicina

1948

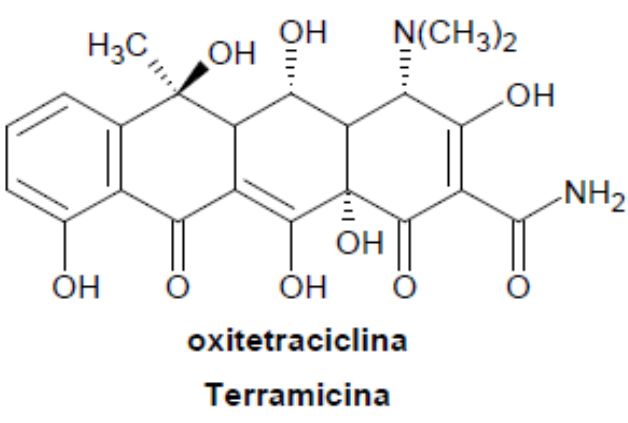

1951<smiles>CN(C)[C@H]1C(O)=C(C(N)=O)C(=O)[C@@]2(O)C(O)=C3C(=O)c4c(O)cccc4[C@@](C)(O)C3CC12</smiles>

tetraciclina

Teracina

1954

Figura 2 - Estrutura química do naftaceno, clorotetraciclina, oxitetraciclina, e $\mathrm{TeC}^{8}$.

A maioria das tetraciclinas possuem caráter anfótero, existindo na forma catiônica em pHs mais ácidos, aniônica em pHs mais alcalinos e na forma zeuteriônica em pHs próximos ao ponto isoelétrico que varia de 4 a $6^{10}$.

A TeC é comercializada tanto na forma livre quanto na de cloridrato ou fosfato. É caracterizada por ser um pó amarelo, inodoro, pouco solúvel em água, estável ao ar, mas a exposição à luz solar forte provoca seu escurecimento ${ }^{4}$.

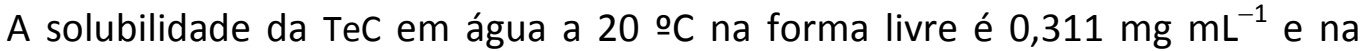
forma de cloridrato, comumente utilizada em pesquisas e formulações farmacêuticas, é $17,8 \mathrm{mg} \mathrm{mL}^{-1}$. Tal comportamento provavelmente está relacionado com a presença do grupo cloridrato, que em água forma espécies iônicas e a protonação do grupo amino, cuja interação com a água é do tipo íon-dipolo aumentando a solubilidade em água ${ }^{12,13}$.

As doses desse antibiótico variam de acordo com a via de administração: oral (todas as formas) - 250 a 500 mg a cada 6 horas; intramuscular (como sal de cloridrato ou fosfato) - $200 \mathrm{mg}$ a $1 \mathrm{~g}$ diários divididos em duas a três doses; intravenosa 
(cloridrato) - 250 a $500 \mathrm{mg}$, duas vezes ao dia $^{4}$. Quando indicado para o tratamento de infecções vaginais causadas por fungos e bactérias, é utilizado na forma de creme vaginal com aplicações contendo cerca 100 mg de TeC cada uma até duas vezes diárias num período de 7 a 15 dias $^{14,15}$.

Devido à presença de funções ácidas, as tetraciclinas em geral são capazes de formar complexos insolúveis através da quelação com cátions bivalentes ou trivalentes em pHs neutros. Portanto, a administração simultânea da TeC, por exemplo, com antiácidos, suplementos de cálcio, salicilatos de colina e magnésio, ferro e laxantes contendo magnésio pode levar à formação de complexos estáveis não absorvíveis. Leite e laticínios não devem ser ingeridos durante 1 ou 2 horas antes ou depois da administração do antibiótico, pois podem diminuir a eficácia do tratamento e a absorção em aproximadamente 50\%. Assim, tetraciclinas não são normalmente aplicadas a gestantes e crianças até 12 anos, pois podem comprometer a formação dos ossos e coloração dos dentes, uma vez que, complexadas com cálcio, podem ser depositadas nesses tecidos ${ }^{16,17}$.

Antibióticos em geral são fracamente absorvidos pelo intestino e em sua maior parte são eliminados pelas fezes ou urina. Sendo grande parte deles hidrossolúveis, até $90 \%$ de uma dose de um antibiótico pode ser excretada pela urina de forma não metabolizada ${ }^{6}$.

Em ratos, aproximadamente $60 \%$ da TeC administrada é encontrada na urina ${ }^{18}$. Em humanos, a maioria das tetraciclinas é absorvida incompletamente pelo sistema gastrointestinal. A absorção da clorotetraciclina varia de 25 a $30 \%$, da oxitetraciclina, demeclociclina e TeC de 58 a $80 \%$, sendo que da parte eliminada, de 60 a $70 \%$ é excretada pela urina sob forma não-metabolizada ${ }^{19}$.

Nas últimas décadas, bactérias causadoras de doenças humanas tem desenvolvido resistência a antibióticos comumente utilizados em tratamentos medicinais ${ }^{20}$. A aquisição de mecanismos de resistência é consequência da capacidade natural de adaptação das populações bacterianas quando expostas a antibióticos usados indiscriminadamente na medicina, na produção de alimentos para animais e na agricultura, sendo assim um problema mundial ${ }^{21}$.

Du et $a .^{3}$ também relacionaram tal fato à quantidade significativa de antibióticos e seus metabólitos bioativos, ou produtos de degradação, que são 
introduzidos em agro-ecosistemas através da fertilização e irrigação com adubos, biosólidos, água de esgoto, sedimentos e água poluídos por antibióticos.

Em um estudo sobre a ocorrência e comportamento ambiental de resíduos de antibióticos de uso veterinário ${ }^{22}$, foi discutido a capacidade de determinados antibióticos serem lixiviados, devido a alta mobilidade no solo, e assim, serem encontrados em várias matrizes aquosas, enquanto outros, possuem baixa mobilidade, com tendência em se acumularem nas camadas superficiais do solo, como é o caso das tetraciclinas, consideradas imóveis. Tais características estão relacionadas a fatores como extensão da contaminação e tipo de matriz contaminada, em processos dependentes do solo, $\mathrm{pH}$, força iônica, presença de íons metálicos, metabólitos e carbono orgânico dissolvido (COD).

Wei et $a .^{23}$ realizaram um estudo que investigou os efeitos adversos da TeC no solo. Para os autores, a presença desta molécula causa distúrbios significativos na estrutura das comunidades microbiais e inibe as atividades microbiais no solo em termos de urease, ácido fosfatase e dehidrogenase. Raízes apresentaram redução de $40 \%$ de biomassa e houve queda de assimilação de fósforo pela planta. Assim, os resultados demonstram que o uso de adubos ou sedimentos de tanques de peixes, que contêm quantidade considerável de antibióticos, pode elevar os riscos ecológicos.

Uma vez que baixa quantidade desse antibiótico é metabolizada ou absorvida pelo organismo, retornando assim ao meio ambiente através da excreção, resíduos de TeC têm sido detectados em águas superficiais bem como em ovos, leite, mel, frutas, vegetais, peixes e carnes ${ }^{24,25}$ em concentrações acima da concentração máxima permitida para todas as tetraciclinas $\left(1 \mu \mathrm{g} \mathrm{L}^{-1}\right)^{26}$. Desse modo, tem aumentado o número de estudos que através de variadas técnicas visam à degradação da $\mathrm{TeC}$ e eliminação desse antibiótico da natureza.

\subsection{Métodos para tratamento de efluentes aquosos}

Os métodos convencionais de tratamento de efluentes são os químicos, físicoquímicos, ou biológicos. Os métodos químicos são baseados na oxidação dos compostos orgânicos por meio de fortes agentes oxidantes como ozônio, peróxido de hidrogênio e cloro, por exemplo. O emprego de tais oxidantes torna muitas vezes esse 
método desvantajoso devido à dificuldade de transporte e armazenamento. São consumidos em altas quantidades, elevando ainda mais os custos e, além disso, estudos indicam que, em alguns casos, produzem compostos e gases mais tóxicos do que o composto de partida ${ }^{27}$. Os métodos físico-químicos por sua vez, são mais comuns em estações de tratamento de efluentes, sendo que dentre eles, destacam-se a precipitação, filtração e adsorção. Embora sejam muito empregados, eles não são suficientes para atingir os limites de descarte, não removendo por completo o poluente do meio a ser tratado, sendo que na maioria das vezes ocorre simplesmente a transferência de compostos orgânicos para um meio físico distinto, não solucionando o problema ${ }^{27}$.

O método biológico possui, de modo geral, baixo custo, podendo ser anaeróbio, aeróbio ou a combinação de ambos. Esse processo pode ser limitado à compostos biodegradáveis e por isso, muitas vezes é necessário tratamento prévio para seu posterior emprego. Além disso, esse método demanda grandes áreas, produz lodo como subproduto e, o tempo de tratamento pode variar muito, tendo como consequência uma variação também do custo final, o que o torna muitas vezes inadequado ${ }^{28}$.

Nesse contexto, os métodos eletroquímicos representam alternativa viável, podendo ser efetivamente usados como tratamento prévio ao tratamento biológico de efluentes aquosos e para degradação e purificação de águas residuais poluídas com compostos orgânicos, oferecendo como principais vantagens: versatilidade, segurança, facilidade de automação e uma boa relação custo/benefício, em termos tecnológicos, econômicos e ambientais ${ }^{29,30}$. São considerados versáteis porque são passíveis de adaptações e variações, de acordo com o efluente que se deseja tratar, a capacidade do reservatório e o eletrodo utilizado, por exemplo. São mais seguros, pois, embora seja utilizado corrente elétrica, elétrons são considerados "reagentes limpos" e não há necessidade de se empregar substâncias tóxicas. Possuem facilidade de automação uma vez que os parâmetros corrente e potencial são fáceis de controlar. Apresentam boa relação custo/benefício, pois, embora a dependência de energia elétrica em alguns casos possa resultar em custos consideráveis, os equipamentos e operações necessários são geralmente simples e em muitos estudos apresentam maior eficiência 
na degradação de compostos orgânicos, sem a geração de substâncias mais tóxicas que a de partida $27,29,31$.

\subsection{MECANISMOS de OXIDAÇÃo ELETROQUímICA EM ÂNOdOS DE ÓXIDOS METÁlicos}

Simond et al. ${ }^{32}$ discute que em oxidações eletroquímicas, o material pelo qual o ânodo é composto é um importante parâmetro a ser considerado, uma vez que em reações anódicas os mecanismos e produtos são dependentes da natureza e composição do ânodo.

Considerando os mecanismos propostos na literatura, para ânodos de óxidos metálicos tem-se inicialmente a formação de radicais hidroxila adsorvidos na superfície do ânodo através da descarga de $\mathrm{H}_{2} \mathrm{O}$ (em meio ácido) ou $\mathrm{OH}^{-}$(em meio básico) (Eq. 1).

$\mathrm{MO}_{\mathrm{x}}(\mathrm{s})+\mathrm{H}_{2} \mathrm{O}(\mathrm{l}) \rightarrow \mathrm{MO}_{\mathrm{x}}(\mathrm{OH}) \mathrm{ads}+\mathrm{H}^{+}(\mathrm{aq})+\mathrm{e}^{-}$

Enquanto vários ânodos favorecem oxidação parcial e seletiva de compostos orgânicos, como os ânodos de carbono, grafite, $\mathrm{IrO}_{2}, \mathrm{RuO}_{2}$ e platina, outros como 0 diamante dopado com boro (DDB) e $\mathrm{PbO}_{2}$, por exemplo, favorecem a oxidação completa com a formação de $\mathrm{CO}_{2}$, sendo assim, caracterizados por ânodos ativos e não ativos, respectivamente. Em ânodos ativos, devido à forte interação entre o óxido e os radicais hidroxila adsorvidos ocorre a transferência do oxigênio do radical hidroxila para a estrutura do óxido metálico formando os óxidos superiores (Eq. 2).

$\mathrm{MO}_{\mathrm{x}}\left({ }^{\circ} \mathrm{OH}\right)$ ads $\rightarrow \mathrm{MO}_{\mathrm{x}+1}(\mathrm{~s})+\mathrm{H}^{+}(\mathrm{aq})+\mathrm{e}^{-}$

O par redox $\mathrm{MO}_{\mathrm{x}} / \mathrm{MO}_{\mathrm{x}+1}$, conhecido por oxigênio ativo quimicamente adsorvido pode atuar como mediador da oxidação seletiva em ânodos ativos (Eq. 3).

$\mathrm{MO}_{\mathrm{x}+1}(\mathrm{~s})+\mathrm{R}(\mathrm{aq}) \rightarrow \mathrm{MO}_{\mathrm{x}}(\mathrm{s})+\mathrm{RO}(\mathrm{aq})$

Em ânodos não ativos em que não há formação de óxidos superiores, radicais hidroxilas fracamente adsorvidos conhecidos por oxigênio ativo fisicamente adsorvido, 
e os íons metálicos oxidados podem provocar a oxidação não seletiva de orgânicos e levar à completa mineralização (Eq. 4).

$\mathrm{MO}_{\mathrm{x}}\left({ }^{\circ} \mathrm{OH}\right)_{\mathrm{z}}(\mathrm{ads})+\mathrm{R}(\mathrm{aq}) \rightarrow \mathrm{MO}_{\mathrm{x}}(\mathrm{s})+\mathrm{CO}_{2}(\mathrm{~g})+\mathrm{zH}^{+}(\mathrm{aq})+\mathrm{ze}^{-}$

Entretanto, ambos os mecanismos podem competir com a reação de desprendimento de oxigênio (RDO), por exemplo, reduzindo a eficiência da oxidação anódica (Eqs. 5 e 6$)^{30}$.

$$
\begin{aligned}
& \mathrm{MO}_{\mathrm{x}}(\mathrm{OH})(\mathrm{ads}) \rightarrow \frac{1}{2} \mathrm{O}_{2}(\mathrm{~g})+\mathrm{H}^{+}(\mathrm{aq})+\mathrm{e}^{-}+\mathrm{MO}_{\mathrm{x}}(\mathrm{s}) \\
& \mathrm{MO}_{\mathrm{x}+1}(\mathrm{~s}) \rightarrow \mathrm{MO}_{\mathrm{x}}(\mathrm{s})+\frac{1}{2} \mathrm{O}_{2}(\mathrm{~g})
\end{aligned}
$$

De acordo com o exposto, ânodos com pequenos sobrepotenciais para a RDO possuem um comportamento ativo, ou seja, participam efetivamente da oxidação eletroquímica de compostos orgânicos favorecendo oxidações parciais enquanto que, ânodos com altos sobrepotenciais, exibem comportamento não ativo e favorecem a oxidação completa de poluentes $(R)^{27}$, sendo assim classificados de acordo com o poder de oxidação em meio ácido como mostra a Tabela $1^{33}$. 
Tabela 2 - Poder de oxidação de vários ânodos ativos e não ativos em processos de oxidação eletroquímica em meio ácido

\begin{tabular}{|c|c|c|c|c|}
\hline Eletrodo & $\begin{array}{l}\text { Potencial de } \\
\text { oxidação / V }\end{array}$ & $\begin{array}{l}\text { Sobrepotencial } \\
\text { para a RDO / V }\end{array}$ & $\begin{array}{c}\text { Entalpia de } \\
\text { adsorção da } \\
\text { espécie M(־ } \mathrm{OH})\end{array}$ & $\begin{array}{c}\text { Poder de } \\
\text { oxidação do } \\
\text { ânodo }\end{array}$ \\
\hline $\begin{array}{l}\mathrm{RuO}_{2}-\mathrm{TiO}_{2} \\
\left(\mathrm{ADE}{ }^{*}-\mathrm{Cl}_{2}\right)\end{array}$ & $1,4-1,7$ & 0,18 & \multirow{6}{*}{$\begin{array}{l}\text { Quimissorção } \\
\text { Fisissorção }\end{array}$} & \multirow[t]{6}{*}{$\Pi$} \\
\hline $\begin{array}{l}\operatorname{IrO}_{2}-\mathrm{Ta}_{2} \mathrm{O}_{5} \\
\left(\mathrm{ADE}^{*}-\mathrm{O}_{2}\right)\end{array}$ & $1,5-1,8$ & 0,25 & & \\
\hline Ti-Pt & $1,7-1,9$ & 0,3 & & \\
\hline $\mathrm{Ti} / \mathrm{PbO}_{2}$ & $1,8-2,0$ & 0,5 & & \\
\hline $\mathrm{Ti} / \mathrm{SnO}_{2}-\mathrm{Sb}_{2} \mathrm{O}_{3}$ & $1,9-2,2$ & 0,7 & & \\
\hline $\mathrm{p}-\mathrm{Si} / \mathrm{DDB}$ & $2,2-2,6$ & 1,3 & & \\
\hline
\end{tabular}

*ADE: ânodo dimensionalmente estável

\section{4. Ânodos Dimensionalmente Estáveis (ADE)}

Os ânodos dimensionalmente estáveis são compostos por misturas de óxidos de Ti, Ru, Ir, Sn e/ou Sb capazes de apresentar alta atividade eletrocatalítica, estabilidade mecânica e química mesmo em altas densidades de corrente e soluções ácidas. Um dos $\mathrm{ADE}$ mais utilizados na literatura é o $\mathrm{Ti} / \mathrm{RuO}_{2}-\mathrm{TiO}_{2}$ obtido a partir da mistura de óxido de rutênio e titânio depositada termicamente sob um substrato de titânio, largamente usado em indústrias de cloro-soda $\left(\mathrm{ADE}-\mathrm{Cl}_{2}\right)$ como substituto dos eletrodos de grafite, considerados frágeis, menos ativos e de menor tempo de vida útil $^{34,35}$.

O titânio é empregado como metal base ou substrato em praticamente todos os ADE devido à boa relação custo/benefício que oferece. Em ADE o metal base é um metal que possui alta estabilidade mecânica, sendo que o tempo de vida do eletrodo depende diretamente da estabilidade química e eletroquímica desse metal base. 0 
material condutor depositado sobre ele é por sua vez, o responsável pela atividade eletrocatalítica do eletrodo ${ }^{36}$.

Eletrodos de ADE vêm sendo muito empregados em estudos de degradações de fármacos. Em dois trabalhos distintos, Wu et $a l^{37}$ e Zhang et al. ${ }^{38}$ estudaram a degradação eletroquímica da TeC usando um ânodo dimensionalmente estável (ADE) em solução aquosa contendo $\mathrm{Na}_{2} \mathrm{SO}_{4}$ como eletrólito suporte e concluiram que a TeC é eficientemente degradada pelo processo eletroquímico, sendo que no segundo estudo a toxicidade dos intermediários formados inicialmente aumentou e em seguida decaiu com um tratamento exaustivo.

Como anteriormente discutido, esses eletrodos são considerados ativos e quando empregados, o processo de oxidação pode ocorrer por oxidação direta e pela geração indireta de espécies de alto poder oxidativo como espécies de cloro ativo ${ }^{34}$.

\subsection{OXIDAÇÃo POR ESPÉCIES DE CLORO ATIVO ELETROGERADAS}

As espécies de cloro ativo são agentes oxidantes largamente utilizados como desinfetantes em tratamentos de águas poluídas. Vários estudos têm revelado que ao utilizar $A D E$ em meios que contenham íons cloreto, a eficiência de remoção aumenta consideravelmente devido a eletrogeração de espécies de cloro ativo de alto poder oxidante $^{39}$ (Eqs. 7 a 11), num processo dependente do $\mathrm{pH}$ e temperatura do meio e conhecido por oxidação indireta ${ }^{40,41}$.

Ânodo: $2 \mathrm{Cl}^{-}(\mathrm{aq}) \rightarrow \mathrm{Cl}_{2}(\mathrm{aq})+2 \mathrm{e}^{-}$

Cátodo: $2 \mathrm{H}_{2} \mathrm{O}(\mathrm{l})+2 \mathrm{e}^{-} \rightarrow \mathrm{H}_{2}(\mathrm{~g})+2 \mathrm{OH}^{-}(\mathrm{aq})$

Solução: $\mathrm{Cl}_{2}(\mathrm{aq})+\mathrm{H}_{2} \mathrm{O}(\mathrm{l}) \rightarrow \mathrm{HClO}(\mathrm{aq})+\mathrm{H}^{+}(\mathrm{aq})+\mathrm{Cl}^{-}(\mathrm{aq})$

$$
\mathrm{HClO}(\mathrm{aq}) \leftrightarrow \mathrm{H}^{+}(\mathrm{aq})+\mathrm{ClO}^{-}(\mathrm{aq})
$$

Orgânicos $+\mathrm{OCl}^{-}(\mathrm{aq}) \rightarrow$ intermediários $\rightarrow \mathrm{CO}_{2}(\mathrm{~g})+\mathrm{Cl}^{-}(\mathrm{aq})+\mathrm{H}_{2} \mathrm{O}(\mathrm{l})$

Essas reações podem competir com outras reações que ocorrem simultaneamente (reações parasitas) que diminuem a eficiência do processo, como a 
RDO (Eqs. 12a e 12b) e formação química e eletroquímica de íons cloratos (Eqs. 13 e 14). Além disso, em células com único compartimento pode haver consumo de íons hipoclorito a partir de sua redução no cátodo (Eq. 15).

$$
\begin{aligned}
& 4 \mathrm{OH}^{-}(\mathrm{aq}) \rightarrow 2 \mathrm{H}_{2} \mathrm{O}(\mathrm{l})+\mathrm{O}_{2}(\mathrm{~g})+4 \mathrm{e}^{-} \\
& 2 \mathrm{H}_{2} \mathrm{O}(\mathrm{l}) \rightarrow 4 \mathrm{H}^{+}(\mathrm{aq})+\mathrm{O}_{2}(\mathrm{~g})+4 \mathrm{e}^{-} \\
& \mathrm{OCl}^{-}(\mathrm{aq})+2 \mathrm{HClO}(\mathrm{aq}) \rightarrow \mathrm{ClO}_{3}^{-}(\mathrm{aq})+2 \mathrm{HCl}(\mathrm{aq}) \\
& 6 \mathrm{OCl}^{-}(\mathrm{aq})+3 \mathrm{H}_{2} \mathrm{O}(\mathrm{l}) \rightarrow 2 \mathrm{ClO}_{3}^{-}(\mathrm{aq})+4 \mathrm{Cl}^{-}(\mathrm{aq})+6 \mathrm{H}^{+}(\mathrm{aq})+1,5 \mathrm{O}_{2}(\mathrm{~g})+6 \mathrm{e}^{-} \\
& \mathrm{OCl}^{-}(\mathrm{aq})+\mathrm{H}_{2} \mathrm{O}(\mathrm{l})+2 \mathrm{e}^{-} \rightarrow \mathrm{Cl}^{-}(\mathrm{aq})+2 \mathrm{OH}^{-}(\mathrm{aq})
\end{aligned}
$$

O esquema proposto por Comninellis pode ser estendido para casos em que espécies de oxicloro adsorvidas sobre a superfície do eletrodo estão envolvidas no processo de degradação a partir da transferência de oxigênio para o composto orgânico (Eqs. 16 e 17$)^{31}$.

$$
\begin{aligned}
& \mathrm{MO}_{\mathrm{x}}(\mathrm{OH}) \text { ads }+\mathrm{Cl}^{-}(\mathrm{aq}) \rightarrow \mathrm{MO}_{\mathrm{x}}(\mathrm{HOCl}) \text { ads }+\mathrm{e}^{-} \\
& \text {Orgânicos }+\mathrm{MO}_{\mathrm{x}}(\mathrm{HOCl})(\text { ads }) \rightarrow \text { intermediários } \rightarrow \mathrm{MO}_{\mathrm{x}}(\mathrm{s})+\mathrm{CO}_{2}(\mathrm{~g})+\mathrm{Cl}^{-}(\mathrm{aq}) \\
& +\mathrm{H}_{2} \mathrm{O}(\mathrm{l})+\mathrm{H}^{+}(\mathrm{aq})
\end{aligned}
$$

Assim, em ADE, embora possa ocorrer oxidação seletiva do composto orgânico na superfície do ânodo, a eletrólise indireta ocorre em maior proporção e é mediada por espécies de cloro ativo na presença de íons cloreto ${ }^{41}$.

Scialdone et al. $^{42}$ estudaram os parâmetros operacionais da oxidação eletroquímica do ácido oxálico em diamante dopado com boro (DDB) e $1 \mathrm{IO}_{2}-\mathrm{Ta}_{2} \mathrm{O}_{5}$ $\left(\mathrm{ADE}-\mathrm{O}_{2}\right)$ na presença e ausência de cloreto de sódio. Os autores observaram que na presença de cloreto a oxidação ocorre em maior parte pelo processo homogêneo, ou seja, entre o composto orgânico e as espécies de cloro ativo eletrogeradas e, no caso do $A D E$, aumenta a eficiência de corrente. Entretanto, esse mesmo estudo mostrou que o DDB não é um eletrodo eficiente para a produção de espécies de cloro ativo mesmo em condições ácidas, que de acordo com os autores, é devido ao rápido e 
constante consumo das espécies de cloro ativo formadas pelos radicais hidroxilas adsorvidos ou peróxido, gerando íons cloreto e clorato.

Uma desvantagem em relação ao emprego de íons cloretos em eletrólises de compostos orgânicos é que quando a completa mineralização não ocorre, há a possibilidade de formação de organoclorados. Esses compostos podem eventualmente oferecer riscos maiores do que o próprio composto original, devido sua elevada toxicidade ${ }^{31}$.

Malpass et al. ${ }^{43}$ estudaram o efeito do tratamento eletroquímico $\mathrm{e}$ eletroquímico foto-assistido em escala de bancada, bem como os efeitos de $\mathrm{NaCl}$ e $\mathrm{Na}_{2} \mathrm{SO}_{4}$ como eletrólito suporte na toxicidade de soluções contendo o pesticida atrazina. Os autores observaram que a velocidade de remoção da atrazina no tratamento eletroquímico foi maior quando $\mathrm{NaCl}$ foi utilizado como eletrólito suporte, provavelmente devido à geração in situ de $\mathrm{Cl}_{2}$ no ânodo, e subsequente formação de espécies de cloro livres que continuaram a remoção da matéria orgânica. Quando o método foto-assistido foi aplicado, ocorreu aumento substancial na remoção da atrazina e do carbono orgânico para ambos os eletrólitos estudados. No estudo da toxicidade das soluções empregando organismo tolerante a meios salinos (crustáceo Artemia nauplii), foi observado que tanto o uso do $\mathrm{NaCl}$ quanto do $\mathrm{Na}_{2} \mathrm{SO}_{4}$ durante o tratamento eletroquímico provocou aumento dos efeitos tóxicos nas soluções finais, o que no caso do $\mathrm{NaCl}$ foi mais uma vez atribuído à formação de produtos organoclorados. No tratamento foto-assistido, porém, a toxicidade para ambos os eletrólitos foi reduzida a zero devido à possível formação de radicais com alto poder oxidante, originados a partir da interação entre intermediários da reação eletroquímica e a luz UV. Tais resultados provaram que a combinação do método eletroquímico e fotoquímico é promissora para remoção de poluentes devido o sinergismo entre eles, mesmo em presença de $\mathrm{NaCl}$ como eletrólito suporte.

Desse modo, devido à possibilidade de aumento da toxicidade, muitos pesquisadores evitam a adição de cloretos ao meio em tratamentos eletroquímicos, trabalhando com sulfatos, carbonatos ou nitratos como eletrólitos suporte. Entretanto, deve-se considerar que íons cloreto estão naturalmente presentes em várias matrizes ambientais podendo assim, aumentar a eficiência do processo ${ }^{37,38}$. 


\subsection{URINA ARTIFICIAL}

Considerando alguns fatores até aqui citados como: a importância de meios salinos para estudos eletroquímicos, o fato de matrizes aquosas naturais e residuais possuírem naturalmente sais dissolvidos capazes de atuar como eletrólito suporte; o efeito de cloretos em degradações utilizando ADE e, sabendo ainda que grande parte dos antibióticos como as tetraciclinas são eliminados através da urina, esse meio possibilitaria avanços nos estudos de degradações eletroquímicas, uma vez que possui maior concentração da $\mathrm{TeC}$ comparado à outros meios e elevada concentrações de sais como sulfatos, fosfatos e cloretos, capaz de elevar a degradação desse antibiótico por meio da oxidação indireta.

Nesse contexto, urina constituída artificialmente têm se mostrado um interessante meio para estudos que pretendam simular um determinado comportamento em urina natural. Como principais vantagens elas possuem composição constante, próxima a da urina natural e não propiciam contaminações, podendo ter de uma para outra, algumas variações com relação aos componentes empregados devido as diferentes aplicações e objetivos específicos de cada área de pesquisa $^{44}$.

Em pesquisas na área de urologia, por exemplo, Norbert et al. ${ }^{45}$ estudaram a formação e crescimento de pedras urinárias de oxalato de cálcio, a partir da adição de oxalato de amônio em soluções padrões de cloreto de cálcio, e em urina artificial, para induzir a formação de cristais de oxalato de cálcio, o cristal mais comum no trato urinário, observando que a distribuição do tamanho das partículas dependem da composição da solução sendo a cristalização menos pronunciada em urina artificial.

Opalko et $a .^{46}$ avaliaram em urina artificial o crescimento de cristais de oxalato de cálcio tri-hidratado através da reação entre cloreto de cálcio e oxalato de potássio. Neste caso os autores observaram que o oxalato de cálcio pode ser mais estável em urina do que até então se pensava.

A urina artificial também foi utilizada em estudo para desenvolvimento e aplicação de novos procedimentos analíticos para determinação do diurético furosemida em amostras comerciais do medicamento em fluidos biológicos ${ }^{47}$. 
Mais recentemente a urina artificial foi empregada em um estudo ${ }^{48}$ que visava a remoção do nitrogênio nela presente por método eletroquímico utilizando eletrodo de $\mathrm{IrO}_{2}$. Para tanto foram utilizadas duas composições de urina artificiais com diferentes concentrações de nitrogênio simulando urina fresca e urina estocada. 0 tratamento removeu eficientemente o nitrogênio da urina fresca através da oxidação mediada por espécies de cloro ativo eletrogeradas a partir do cloreto presente na urina artificial. Entretanto, na urina estocada a oxidação da amônia é inibida devido a presença de carbonato nesse meio.

Embora sejam reconhecidas as vantagens de se trabalhar com urinas artificiais, na literatura ainda não foram reportados estudos de degradações eletroquímicas de antibióticos em semelhante meio. Assim, a urina artificial é um interessante meio para o estudo de degradação da TeC, uma vez que quantidade considerável do mesmo é eliminada pelas vias urinárias e esse meio possui alta concentração de íons cloreto que presentes em um tratamento que empregue um ADE podem atuar na remoção do antibiótico.

\subsection{TÉCNICAS E PARÂMETROS UtILIZAdos PARA ANÁLISE DE UM PROCESSO ELETROQUímico}

Durante os processos de degradação eletroquímica de compostos orgânicos se faz necessário o uso de algumas técnicas analíticas para avaliações qualitativas e quantitativas do processo. Dentre as várias técnicas utilizadas esse estudo fez uso da voltametria cíclica (VC), cromatografia líquida de alta eficiência (CLAE), carbono orgânico total (COT), espectrofotometria no ultravioleta-visível (UV-Vis).

\subsubsection{Voltametria Cíclica (VC)}

As técnicas voltamétricas fornecem informações sobre concentração, identidade e comportamento da amostra analisada. Na voltametria cíclica mede-se a corrente em função do potencial aplicado ao sistema, sendo que este último varia de modo linear até um valor máximo e a partir deste, ocorre a inversão do sentido da varredura e o potencial retorna ao valor inicial. Esse ciclo pode ser repetido inúmeras vezes ao longo do tempo, e assim é possível obter informações sobre processos de 
oxidação e redução em vários meios, de adsorção em superfícies, reversibilidade da reação e de mecanismo de transferência de elétrons.

\subsubsection{Cromatografia Líquida de Alta Eficiência (CLAE)}

Cromatografia líquida de alta eficiência é um método físico-químico utilizado na separação dos componentes de uma mistura. A base para esta separação é a distribuição diferencial dos analitos entre duas fases: uma fase estácionária e a fase móvel líquida ${ }^{49}$. Métodos baseados em CLAE são bastante aplicados em análises de poluentes orgânicos emergentes, presentes tanto em amostras aquosas, quanto em várias matrizes ambientais, sendo adequados para uma variedade de compostos orgânicos e adaptado de acordo com a polaridade, volatilidade e instabilidade térmica.

\subsubsection{CARBONO ORGÂNICO TOTAL (COT)}

A análise de COT é uma medida indireta da presença de átomos de carbono em matrizes aquosas, sendo que essa medida não fornece informações sobre a natureza e estrutura da matéria orgânica. Em grande parte dos instrumentos o COT é obtido a partir da subtração do carbono inorgânico (IC) presente na amostra $\left(\mathrm{CO}_{2}\right.$ dissolvido, carbonatos e bicarbonatos), do carbono total (CT):

$\mathrm{COT}=\mathrm{CT}-\mathrm{CI}$

Os métodos para análise de COT são baseados na detecção do $\mathrm{CO}_{2}$ produzido a partir da oxidação quantitativa de compostos orgânicos presentes na solução a ser analisada. $\mathrm{O} \mathrm{CO}_{2}$ produzido é estequiometricamente relacionado ao valor de COT. Em geral, o COT depende do tipo de água analisada e fatores como temperatura, salinidade, $\mathrm{pH}$, atividade microbial e vegetação vizinha. Em águas poluídas, o COT também provém de produtos como fertilizantes, pesticidas, produtos farmacêuticos e de cuidados pessoais, surfactantes, solventes provindos do uso direto e de tratamentos de água ineficientes em estações de tratamento de água e esgoto. 
Diferentes procedimentos analíticos podem ser empregados para detecção do $\mathrm{CO}_{2}$ produzido, exemplos de deteç̧ões são espectrometria no infravermelho, titulação ácido-base, condutividade térmica e eletrodos sensíveis a $\mathrm{CO}_{2}{ }^{50}$.

\subsubsection{ESPECTROFOTOMETRIA NO ULTRAVIOLETA-VISÍVEL (UV-VIS)}

A técnica de espectrometria no UV-Vis é largamente utilizada em várias áreas científicas como química e bioquímica devido a certas vantagens que oferece, como simplicidade, economia, robustez, fácil operação e flexibilidade, podendo ser empregada para análise de grande variedade de amostras, como água, produtos alimentícios e farmacêuticos ${ }^{51}$.

A espectrofotometria é fundamentada na lei de Lambert-Beer, que é a base matemática para medidas de absorção de radiação por amostras no estado sólido, líquido ou gasoso, nas regiões ultravioleta, visível e infravermelho do espectro eletromagnético. Para medidas de absorção de radiação em determinado comprimento de onda, tem-se: $A=\log (\mathrm{Io} / \mathrm{I})=\varepsilon b c$, onde $A$ é a absorbância, Io é a intensidade da radiação monocromática que incide na amostra e I é a intensidade da radiação que emerge da amostra. A absortividade molar $\varepsilon$ é uma grandeza característica da espécie absorvente, cuja magnitude depende do comprimento de onda da radiação incidente. O termo c é a concentração da espécie absorvente e $b$, $a$ distância percorrida pelo feixe através da amostra.

A oxidação eletroquímica de compostos orgânicos depende de muitos fatores como o material pelo qual o eletrodo é constituído, eletrólito de suporte, presença de cloreto, densidade de corrente, concentração inicial, fluxo, $\mathrm{pH}$ da solução, temperatura, configuração da célula e presença de outras espécies orgânicas na solução a ser tratada ${ }^{42}$. Assim, uma das vantagens que o processo eletroquímico fornece é a possibilidade de variar esses fatores e avaliar o efeito produzido em função de parâmetros como eficiência de remoção, carga aplicada, eficiência de corrente aparente ou de mineralização, eficiência de corrente instantânea, consumo energético e tempo demandado para se atingir determinada remoção.

A eficiência de remoção fornece a porcentagem removida após determinado tempo da cor, do composto orgânico, do COT ou COD. Comparando essas remoções 
pode-se avaliar se o composto foi degradado a intermediários, se tais intermediários são recalcitrantes, se foi completamente mineralizado, ou se as duas coisas ocorreram, qual a proporção entre elas.

A carga aplicada também é calculada na avaliação dos melhores fatores, pois para variações de um determinado valor, como temperatura, por exemplo, pode-se para uma determinada carga aplicada, comparar a remoção do composto orgânico e selecionar aquele que apresenta a maior remoção, levando-se em conta também o tempo que se leva para atingir determinadas cargas para cada caso.

A eficiência de corrente aparente é obtida pela remoção experimental do COT em um determinado tempo e o COT calculado teoricamente considerando que a carga elétrica aplicada seja consumida apenas na reação de mineralização do composto e assim, quanto mais próximo de $100 \%$, mais eficiente foi o processo, pois maior foi a mineralização do composto durante o tratamento eletroquímico.

O consumo energético está diretamente relacionado à carga aplicada, assim quanto maior o tempo e/ou a corrente aplicada demandada para te atingir determinada remoção, maior será o consumo energético. Esse parâmetro auxilia na seleção do melhor fator, pois às vezes uma degradação eletroquímica realizada sob baixos valores de corrente e que demanda assim longo tempo, pode ser mais onerosa que degradação realizada sob altos valores de corrente porém em tempo muito mais curto.

\subsection{JUSTIFICATIVA}

Considerando o crescente uso de produtos de cuidados pessoais e farmacêuticos, e mais especificamente o uso de antibióticos, que devido à ineficiência dos tratamentos de efluentes convencionais têm persistido na natureza e causado males como o aumento da resistência de bactérias, o estudo de novos métodos de tratamento de efluentes é de grande importância tanto para o meio ambiente quanto para a garantia de uma vida saudável.

Assim, a proposta do tratamento eletroquímico para degradação do antibiótico TeC, sob a forma de cloridrato, em urina artificial tem como objetivo analisar a degradação desse composto no principal meio pelo qual é eliminado, a urina. Esse 
meio possui naturalmente alta concentração de íons cloretos, tornando interessante e economicamente viável o estudo de degradação de antibióticos em eletrodo $A D E$, com geração in situ de espécies de cloro ativo.

A partir disso, considera-se a futura aplicação desse tratamento em hospitais, clínicas veterinárias e fazendas de criação de animais de corte, eliminando a possibilidade do contato desse antibiótico e similares com águas superficiais e subterrâneas.

\subsection{OBJETIVOS}

Esse projeto teve como objetivo analisar a degradação do antibiótico TeC em meio de urina artificial por método eletroquímico utilizando um ADE.

Para tanto, foram estabelecidas as metas a seguir especificadas:

$\checkmark$ Investigação do efeito da densidade de corrente;

$\checkmark$ Investigação do efeito do $\mathrm{pH}$;

$\checkmark$ Análise das concentrações de creatinina e uréia durante as eletrólises;

$\checkmark$ Comparação de alguns resultados obtidos com estudos simultâneos do grupo sobre a degradação da $\mathrm{TeC}$ em meio aquoso na ausência de creatinina e uréia. 


\section{CAPÍtulo 2}

\section{Procedimento EXPERIMENTAL}

Nesse capítulo são apresentados os reagentes e equipamentos utilizados nesse estudo bem como os métodos empregados para análise do $A D E$, remoção $e$ determinação da TeC, determinação de creatinina, uréia e COT.

\subsection{REAGENTES}

Cloridrato de tetraciclina $\left(\mathrm{C}_{22} \mathrm{H}_{24} \mathrm{~N}_{2} \mathrm{O}_{8} . \mathrm{HCl}, 95 \%\right)$, creatinina anidra (P.A.), uréia (99,0-100,5 \%), p-dimetilaminobenzaldeído (99\%) e os demais sais componentes da urina artificial foram obtidos da Sigma-Aldrich. O ácido pícrico (P.A.) foi adquirido da Merck. Todos os reagentes foram utilizados como recebidos, ou seja, nenhuma purificação adicional foi realizada. Água deionizada (sistema Milli- ${ }^{\circledR}$ Academic Millipore $-18,2 \mathrm{M} \Omega \mathrm{cm}$ ) foi utilizada para o preparo de todas as soluções.

A Tabela 2 fornece a composição da urina artificial de oito componentes utilizada neste estudo ${ }^{45}$. Além dos compostos inorgânicos, a uréia e creatinina foram empregadas na composição como principais representantes dos compostos orgânicos nitrogenados, sendo ambas usualmente monitoradas em análises clínicas para avaliação de algumas disfunções renais, musculares e tiroidais ${ }^{52,53}$. A creatinina é o produto metabólico resultante da conversão entre creatina e fosfocreatina durante a transferência de energia nos músculos. É eliminada pela urina e sua produção no organismo é constante e proporcional à massa muscular do indivíduo ${ }^{54}$.

Na urina artificial utilizada no presente estudo, a concentração de creatinina é $1,1 \mathrm{~g} \mathrm{~L}^{-1}$. De acordo com Mazzachi et al. ${ }^{55}$ a concentração de creatinina na urina varia de 0,28 - 2,17 $\mathrm{g} \mathrm{L}^{-1}$ em mulheres e de 0,39 - 2,59 $\mathrm{g} \mathrm{L}^{-1}$ em homens quando analisada na primeira urina recolhida pela manhã. A uréia é outro composto orgânico presente em grande quantidade na urina. É o produto final do metabolismo das proteínas e aminoácidos e responsável por $80-90 \%$ do nitrogênio excretado em humanos. $\mathrm{Na}$ urina a concentração de uréia pode variar de 19 a $35 \mathrm{~g} \mathrm{~L}^{-1}$ de acordo com Solich et al. ${ }^{56}$ e no presente estudo a concentração de uréia adotada foi de $25 \mathrm{~g} \mathrm{~L}^{-1}$. 
Tabela 3 - Composição da solução de urina artificial ${ }^{45}$

\begin{tabular}{lc}
\hline Substância & Concentração $\left(\mathbf{g ~ t}^{-1}\right)$ \\
\hline $\mathrm{CaCl}_{2} \cdot 2 \mathrm{H}_{2} \mathrm{O}$ & 1,103 \\
$\mathrm{NaCl}$ & 2,925 \\
$\mathrm{Na}_{2} \mathrm{SO}_{4}$ & 2,25 \\
$\mathrm{KH}_{2} \mathrm{PO}_{4}$ & 1,40 \\
$\mathrm{KCl}$ & 1,60 \\
$\mathrm{NH}$ & 1,00 \\
$\mathrm{Uréia}$ & 25,00 \\
$\mathrm{Creatinina}$ & 1,10 \\
$\mathrm{pH}$ & 6,0 \\
\hline
\end{tabular}

\subsection{CARActerização do Eletrodo}

A superfície do eletrodo foi analisada por microscopia eletrônica de varredura (MEV) utilizando um equipamento ZEISS LEO 440 (Cambridge, England) com detector OXFORD (model 7060), operando com feixe de elétrons de $20 \mathrm{kV}$. A análise de espectroscopia de raios $X$ por dispersão em energia (EDX da sigla em inglês) foi realizada em um equipamento EDX LINK ANALYTICAL, (Isis System Series 200), com detetor de SiLi Pentafet, janela ultrafina ATW II (Atmosphere Thin Window), de resolução de $133 \mathrm{eV}$ à 5,9 keV, acoplado a um Microscópio Eletrônico. Utilizou-se padrão de Co para calibração, feixe de elétrons de $20 \mathrm{kV}$, distância focal de $25 \mathrm{~mm}$, dead time de $30 \%$, corrente de 2,82A e probe de 950 pA . A área analisada foi de 1,0 $\mathrm{mm}^{2}$. 


\subsection{Voltametria Cíclica}

Ensaios de voltametria cíclica foram realizados para análises qualitativas das reações que se processam na superfície do eletrodo, utilizando um Potenciostato/Galvanostato PGSTAT30.

Foi empregado como eletrodo de trabalho um ADE circular de composição $\mathrm{Ti} / \mathrm{Ru}_{0,3} \mathrm{Ti}_{0,7} \mathrm{O}_{2}$ e área geométrica igual a $2,1 \mathrm{~cm}^{-2}$, dois contra-eletrodos de platina foram posicionados paralelamente ao ADE e um eletrodo normal de hidrogênio (ENH) foi utilizado como eletrodo de referência. Os ensaios foram realizados em um reservatório de $175 \mathrm{~mL}$.

Avaliou-se inicialmente o efeito do condicionamento sobre a superfície do eletrodo, obtendo-se antes e depois da ativação do eletrodo, voltamogramas em meio de $\mathrm{H}_{2} \mathrm{SO}_{4} 0,5 \mathrm{~mol} \mathrm{~L}^{-1}$ e em um intervalo de potencial de 0,4 a $1,6 \mathrm{~V}$, à velocidade de varredura de $50 \mathrm{mV} \mathrm{s}^{-1}$.

Ensaios dessa técnica também foram realizados na solução de urina artificial na ausência da TeC, denominada solução salina, em seguida na presença de $200 \mathrm{mg} \mathrm{L}^{-1}$ desse antibiótico e por fim na presença dos demais compostos orgânicos, ou seja, TeC, uréia e creatinina, sendo que a concentração de todos os componentes foram as mesmas presentes na Tabela 2.

A concentração inicial de TeC igual a $200 \mathrm{mg} \mathrm{L}^{-1}$ foi estabelecida para todas as análises, considerando a suposição de que a partir da administração oral diária de uma dose de $1000 \mathrm{mg} \mathrm{L}^{-1} 71,5 \%$ da dose é absorvida e dos $28,5 \%$ eliminados $70 \%$ (200 $\mathrm{mg} \mathrm{L}^{-1}$ ) é excretado pela urina.

A velocidade de varredura (v) foi igual a $50 \mathrm{mV} \mathrm{s}^{-1}$ e os intervalos de potencial utilizados foram de 0,4 a $1,4 \mathrm{~V}$ e 0,4 a 1,6 V. A Figura 2 mostra a montagem da célula para as análises voltamétricas. 


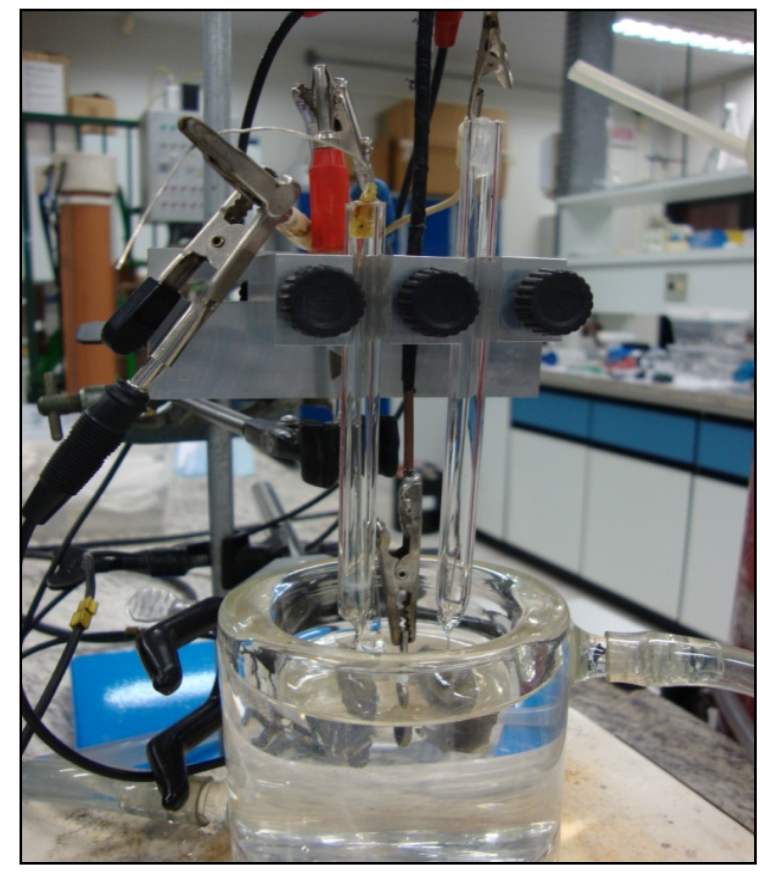

Figura 3 - Célula eletroquímica para análises voltamétricas.

\subsection{DEgRADAÇÃo do CLORIDRATO DE TETRACICLINA}

Nos estudos de eletro-oxidação, os experimentos foram feitos em batelada utilizando uma célula eletroquímica em fluxo do tipo filtro-prensa composta por um ADE comercial (ADE - DSA ${ }^{\circledR}$ da empresa De Nora do Brasil S.A.) de composição $\mathrm{Ti} / \mathrm{Ru}_{0,3} \mathrm{Ti}_{0,7} \mathrm{O}_{2}$ e área geométrica de $15,0 \mathrm{~cm}^{2}$. Uma placa de $\mathrm{Ti}$ e um $\mathrm{ENH}$ foram utilizados como contra-eletrodo e eletrodo de referência, respectivamente. O contato elétrico entre a célula eletroquímica e o eletrodo de referência foi feito com uma membrana comercial catiônica mergulhada em uma solução de $\mathrm{H}_{2} \mathrm{SO}_{4} 0,5 \mathrm{~mol} \mathrm{~L}^{-1}$. A Figura 3 (a) e (b) representa a montagem da célula e o sistema eletroquímico. 


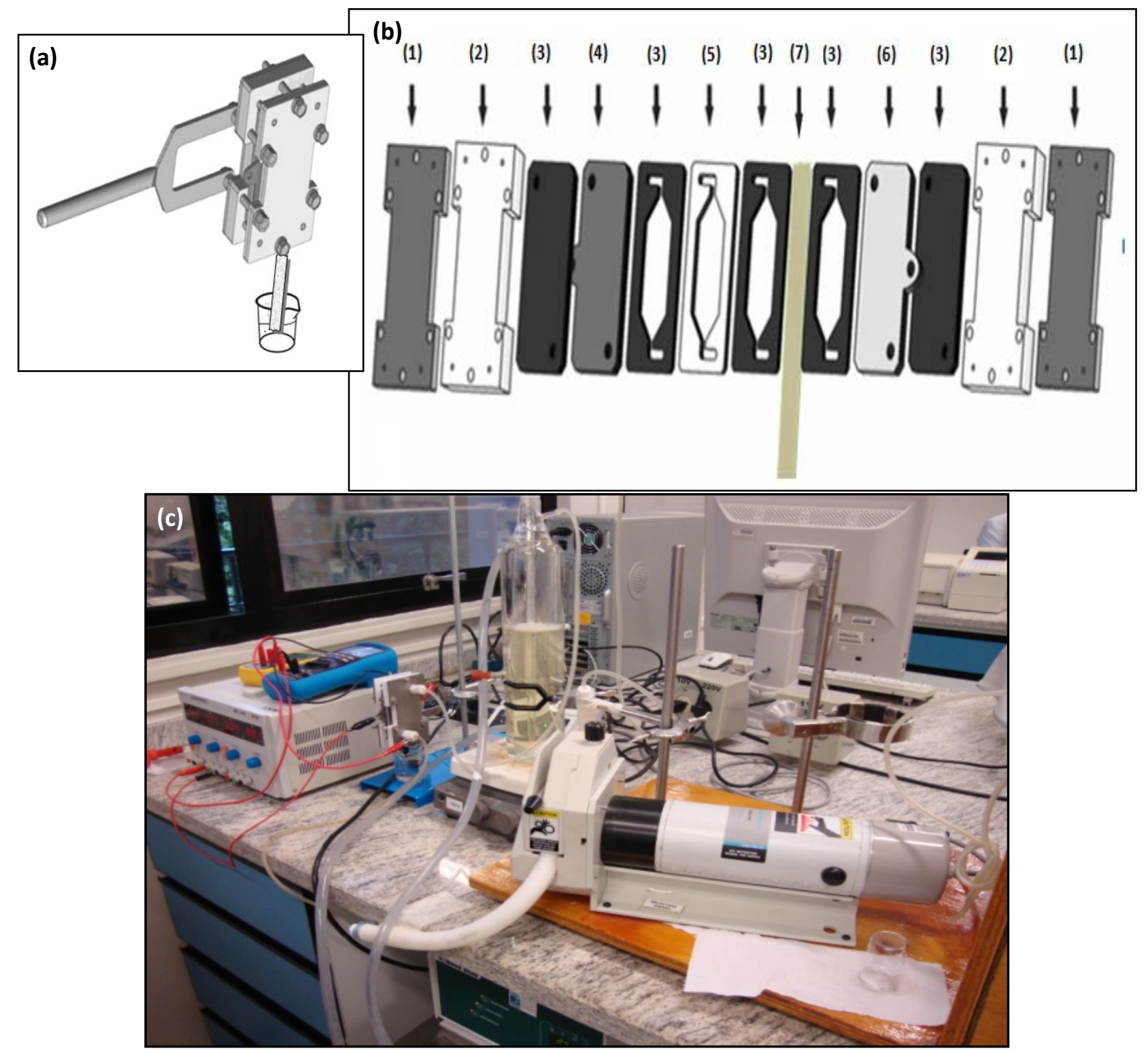

Figura 3 - Célula eletroquímica de fluxo: (a) célula eletroquímica, (b) visão expandida (1) suporte de aço inoxidável, (2) suporte de $\operatorname{Teflon}^{\circledR}$, (3) isolante de Viton ${ }^{\circledR}$, (4) anodo, (5) espaçador de Teflon $^{\circledR}$, (6) catodo e (7) membrana catiônica ${ }^{57}$, e (c) sistema eletroquímico.

No processo de eletro-oxidação a corrente aplicada através de uma fonte (modelo MPL-3303 da Minipa) foi mantida constante ao longo de todo o experimento, a vazão e temperatura foram controladas por uma bomba peristáltica (modelo 7760110 da Masterflex) e um ultratermostato (modelo 521/3D da Nova Ética), respectivamente. A agitação da solução no reservatório foi feita com um agitador 
magnético da Corning e o volume da solução de trabalho foi igual a $500 \mathrm{~mL}$. A Figura 3 (c) representa o sistema eletroquímico utilizado.

A concentração inicial da TeC (200 $\left.\mathrm{mg} \mathrm{L}^{-1}\right)$, o pH inicial (6), a vazão (460 mL $\left.\min ^{-1}\right)$ e a temperatura $\left(25^{\circ} \mathrm{C}\right)$ foram mantidos fixos, e inicialmente foi estudado $\mathrm{O}$ efeito da densidade de corrente $\left(10,20,30\right.$ e $\left.40 \mathrm{~mA} \mathrm{~cm}^{-2}\right)$. Em seguida foi avaliado o efeito do $\mathrm{pH}$ do meio $(5,6$ e 7$)$.

Antes da realização de cada ensaio, o $A D E$ foi submetido a um pré-tratamento oxidativo em solução de $\mathrm{H}_{2} \mathrm{SO}_{4} 0,5 \mathrm{~mol} \mathrm{~L}^{-1}$, aplicando-se uma densidade de corrente de $40 \mathrm{~mA} \mathrm{~cm}{ }^{-2}$ por $20 \mathrm{~min}$, para a limpeza de qualquer impureza orgânica aderida à superfície. Durante a eletrólise, e em tempos pré-determinados, alíquotas foram retiradas para determinação da concentração da $\mathrm{TeC}$ residual e o teor de carbono orgânico total (COT).

As demais substâncias orgânicos presentes na urina artificial também foram monitoradas para determinar se a carga aplicada no sistema durante a eletrólise também poderia ter sido utilizada para a oxidação da creatinina e/ou uréia

\subsection{ANÁLISES POR CLAE}

A degradação da TeC foi monitorada por cromatografia liquida de alta eficiência (CLAE) utilizando uma coluna C-18 de fase reversa (Coluna Ultra C-18 da Restek, $150 \mathrm{~mm} \times 4,6 \mathrm{~mm}$, tamanho da partícula: 5,0 $\mu \mathrm{m}$, tamanho do poro: $100 \AA$ Å). A detecção no ultravioleta (UV) foi realizada no comprimento de onda $(\lambda)$ de $360 \mathrm{~nm}$ e a fase móvel foi constituída pela mistura de ácido oxálico $0,01 \mathrm{~mol} \mathrm{~L}^{-1}$, metanol e acetonitrila na proporção volumétrica de 65: 25: $10^{58}$. A vazão e temperatura do forno foram mantidas constantes em $0,5 \mathrm{~mL} \mathrm{~min}^{-1}$ e $40^{\circ} \mathrm{C}$, respectivamente.

Previamente a injeção no equipamento de CLAE, as amostras contendo TeC foram submetidas à extração em fase sólida, utilizando cartuchos Sep-Pak ${ }^{\circledR}$ Classic C18 da Waters, para retenção da TeC e eliminação dos sais que são prejudiciais à coluna C-18 a partir da eluição das amostras em metanol. A preparação e condicionamento do cartucho consistiu na passagem pelo cartucho de $5 \mathrm{~mL}$ de metanol seguido de $5 \mathrm{~mL}$ de água, percolação de $1 \mathrm{~mL}$ da amostra e, por fim, eluição do analito do adsorvente em 1 $\mathrm{mL}$ de metanol. 


\subsection{ANÁLISES DE COT}

As análises para a determinação do teor de COT para avaliação da porcentagem de mineralização, ou seja, a porcentagem de matéria orgânica oxidada em gás carbônico, água e inorgânicos, foram feitas em um aparelho modelo TOC- $\mathrm{V}_{\mathrm{CPH}}$ da Shimadzu, utilizando-se $1 \mathrm{~mL}$ de solução que foi, previamente (automaticamente ou manualmente) diluída 20 vezes devido ao alto teor de carbono orgânico da amostra.

\subsection{ANÁLISES DE CREATININA}

A creatinina foi determinada na urina artificial pelo método da reação de Jaffé59 modificado. A determinação ocorreu em tempos pré-definidos a partir da reação entre um complexo denominado picrato alcalino com a creatinina presente na amostra coletada, formando outro complexo de coloração vermelho-alaranjado (Figura 4) que pode ser detectado por espectrofotometria em $486 \mathrm{~nm}$, sendo que a intensidade do sinal está relacionada à concentração de creatinina na amostra.

Assim, o método foi adaptado para as análises da creatinina residual durante as degradações do antibiótico em urina artificial e consistiu na reação entre $150 \mu \mathrm{L}$ de cada alíquota retirada durante a eletrólise (previamente diluída 5 vezes) e, $1 \mathrm{~mL}$ de picrato alcalino, sendo que foram adicionados $1,35 \mathrm{~mL}$ de água para obtenção de um volume final igual a $2,50 \mathrm{~mL}$. A solução de picrato alcalino por sua vez, foi obtida a partir da reação entre $\mathrm{NaOH} 5,00 \mathrm{~mol} \mathrm{~L}^{-1}$ e ácido pícrico $2,08 \times 10^{-2} \mathrm{~mol} \mathrm{~L}^{-1}$.

As determinações da absorbância do complexo vermelho-alaranjado formado foram feitas em comprimento de onda $(\lambda)=486 \mathrm{~nm}$ após $40 \mathrm{~min}$ de reação. $A$ concentração foi determinada a partir de uma curva de calibração em que a concentração da creatinina foi variada de 0,88 a $44 \mathrm{mg} \mathrm{L}^{-1}$, sendo os limites de detecção (LD) e quantificação (LQ) iguais a 0,61 e 1,85 $\mathrm{mg} \mathrm{L}^{-1}$, respectivamente.

Considerando a possibilidade da concentração da creatinina diminuir durante as eletrólises era sabido que possivelmente o volume $(150 \mu \mathrm{L})$ e a diluição (5 vezes) das alíquotas retiradas tivessem que variar para que a deteç̧ão fosse garantida até o limite de deteç̧ão do método. 
<smiles>CN1CC(=O)NC1=N</smiles>

creatinina

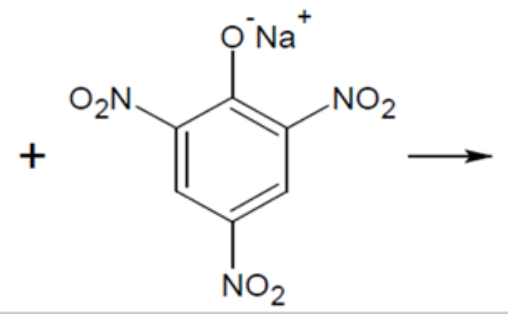

picrato alcalino

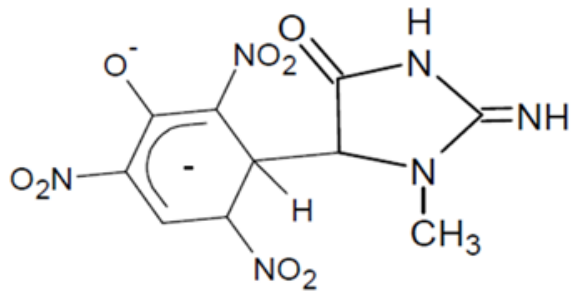

complexo Janovsky

Figura 4 - Reação de formação do complexo de Janovsky para determinação de creatinina $^{60}$.

\subsection{ANÁLISES DE URÉIA}

A uréia também foi determinada por método espectrofotométrico ${ }^{61}$ baseado na produção de um composto de coloração amarelo-esverdeado quando uma solução etanólica de p-dimetilaminobenzaldeído acidificada com ácido mineral é adicionada a uma solução de uréia (Figura 5).

Assim, no presente estudo a determinação da uréia residual consistiu na reação entre $1,50 \mathrm{~mL}$ de amostra (previamente diluída 50 vezes) e, 0,50 mL de solução alcoólica e acidificada de p-dimetilaminobenzaldeído, adicionando 0,50 $\mathrm{mL}$ de água para perfazer um volume final de 2,50 mL. Após 10 min de reação a determinação da concentração do composto amarelado formado foi realizada em $\lambda=422 \mathrm{~nm}$, utilizando como referência uma curva de calibração em que a concentração da uréia foi variada de 60 a $400 \mathrm{mg} \mathrm{L}^{-1}$, sendo LD e LQ iguais a 15,12 e 45,80 $\mathrm{mg} \mathrm{L}^{-1}$, respectivamente.

As análises da creatinina e uréia foram realizadas no espectrofotômetro MultSpec-1501 da Shimadzu, empregando uma cubeta de quartzo de caminho óptico de $1 \mathrm{~cm}$.

Os melhores parâmetros para degradação da TeC foram selecionados com base nos dados de remoção do antibiótico, e análises da carga, eficiência de corrente, consumo energético e carbono orgânico total. 


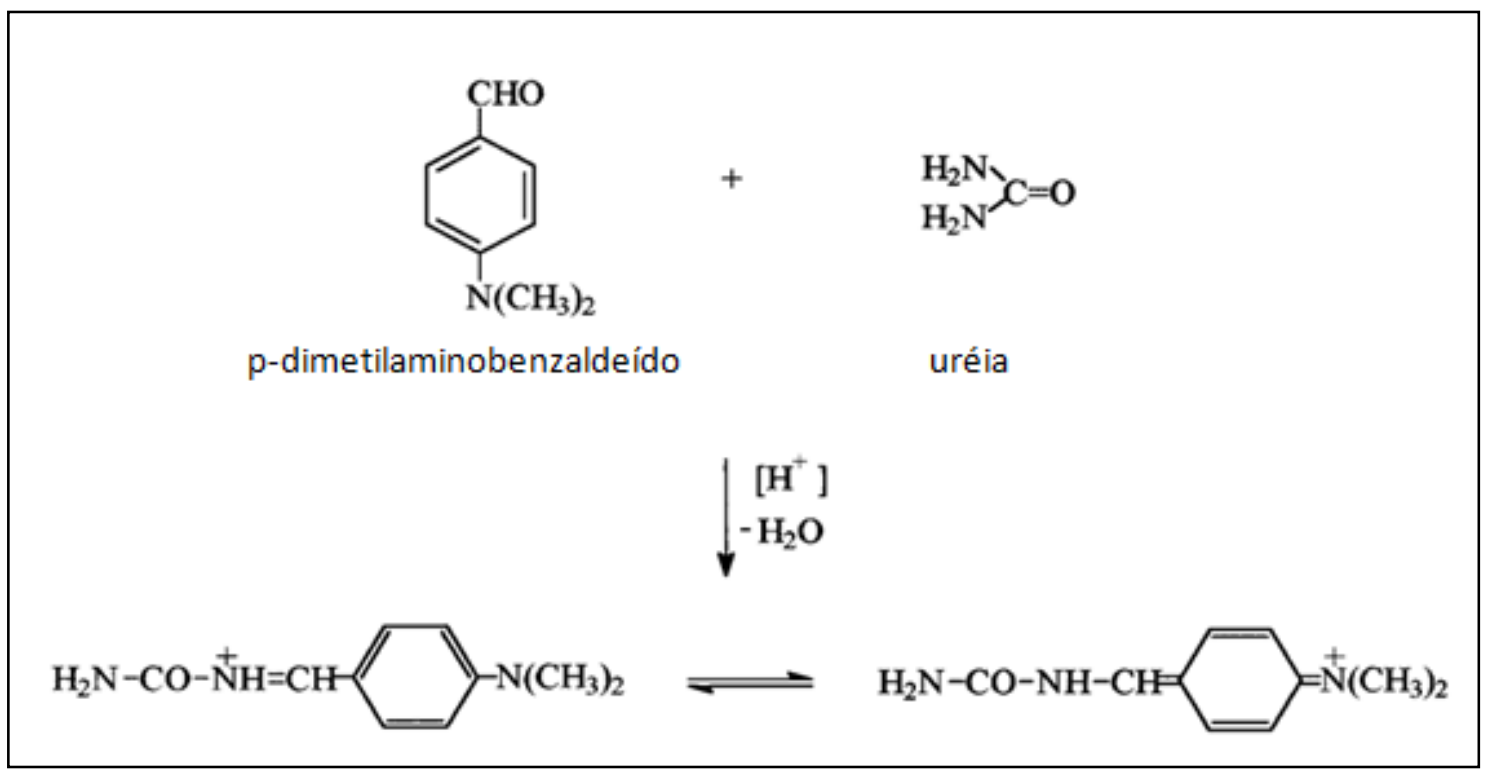

Figura 5 - Reação de formação do complexo para determinação de uréia ${ }^{61}$. 


\section{CAPÍtulo 3}

\section{Resultados e Discussões}

\subsection{CARActerização do eletrodo}

A caracterização morfológica da superfície do eletrodo de ADE composta pela mistura de óxidos de titânio e rutênio bem como a composição após as eletrólises foram analisados por meio de MEV e EDX. A Figura 6 mostra em diferentes ampliações as micrografias da superfície do eletrodo de composição $\mathrm{Ti} / \mathrm{Ru}_{0,3} \mathrm{Ti}_{0,7} \mathrm{O}_{2}$ após as realizações das eletrólises da $\mathrm{TeC}$ em meio de urina artificial.

O material eletródico apresenta a morfologia do tipo "barro rachado" - típico de materiais produzidos por decomposição térmica. Essas rachaduras e fendas resultam no aumento da área superficial e em maior facilidade de acesso a parte mais interna do ânodo ${ }^{62}$.

Para avaliação da composição do eletrodo, foram realizadas análises por EDX depois das eletrólises, sendo que os resultados são apresentados na Figura 7 (a).

A composição do eletrodo após utilização em várias eletrólises era de 70,17 \% de Ti e 29,83 \% de Ru, ou seja, muito próxima da composição nominal fornecida pela fabricante. Uma vez que o eletrodo já vinha sendo utilizado por outros membros do grupo em outras degradações eletroquímicas, possuindo um tempo de uso de aproximadamente quatro anos, não foi possível realizar uma comparação entre sua composição após a utilização e sua composição original, ou seja, logo após sua aquisição. Mas em geral e como comentado previamente, ânodos dimensionalmente estáveis possuem longo tempo de vida útil podendo variar com o fluxo da solução, os eletrólitos utilizados e as densidades de corrente aplicadas. 

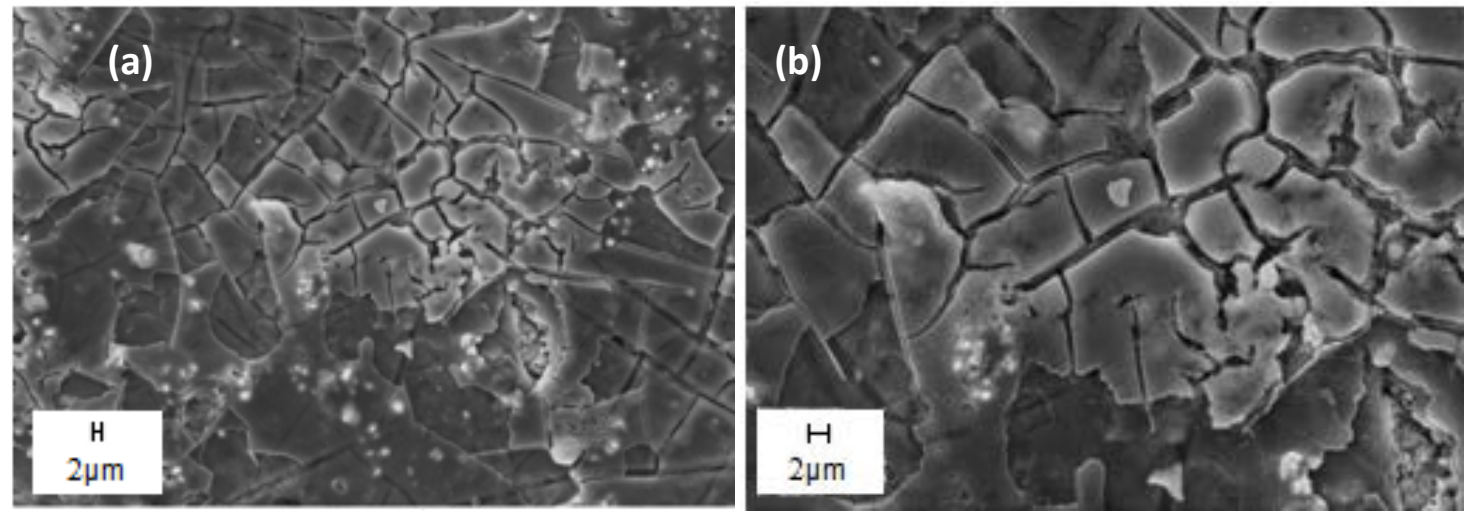

Figura 6 - Micrografias de MEV do eletrodo de composição $\mathrm{Ti} / \mathrm{Ru}_{0,3} \mathrm{Ti}_{0,7} \mathrm{O}_{2}$ com ampliação de (a) 2500 X e (b) 5000 X, após as utilizações nas eletrólises.
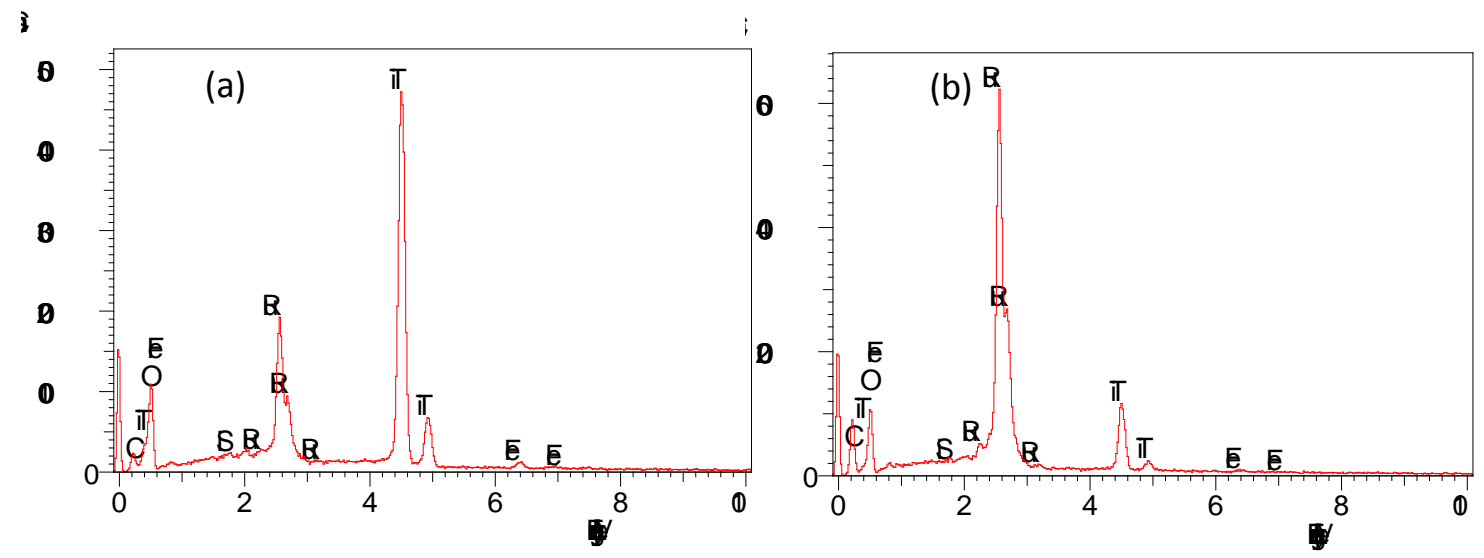

Figura 7 - Espectro de EDX do eletrodo de composição $\mathrm{Ti} / \mathrm{Ru}_{0,3} \mathrm{Ti}_{0,7} \mathrm{O}_{2}$ utilizações nas eletrólises (a) região dominante (camada de óxidos) (b) pontos brancos isolados.

Gomes $^{63}$ constatou que ao realizar degradações eletroquímicas do corante têxtil Alaranjado Remazol 3R em um ADE de composição nominal Ti/ $\mathrm{Ru}_{0,3} \mathrm{Ti}_{0,7} \mathrm{O}_{2}$ houve variação insignificante da composição, indo de 64,91 \% de Ti e 35,09 \% de Ru para $65,01 \%$ de Ti e 34,99 \% de Ru. Nesse trabalho foi verificado por MEV uma aparente remoção da camada de óxido da superfície do óxido, sendo que uma hidratação de novos sítios ativos anteriormente não alcançados pode ocorrer ao longo das eletrólises e assim, manter a composição nominal praticamente inalterada.

$\mathrm{Na}$ ampliação de 5000 vezes, pode-se perceber pontos brancos isolados, que correspondem à matéria orgânica adsorvida sob a superfície que eventualmente tenha permanecido após a limpeza do eletrodo em solução de $\mathrm{H}_{2} \mathrm{SO}_{4} 0,5 \mathrm{~mol} \mathrm{~L}^{-1}$ por $20 \mathrm{~min}$. a $40 \mathrm{~mA} \mathrm{~cm}^{-2}$. Isso pode ser confirmado por EDX que identificou maior teor de carbono 
presente nessa região, como mostra a Figura 7 (b), além disso, foi observado também que nessa região especificamente ocorreu uma inversão das proporções entre TiO $(14,59 \%)$ e RuO (85,41 \%), sendo que é possível que na região analisada tenha ocorrido maior exposição do óxido de rutênio em detrimento do óxido de titânio.

\subsection{CARACTERIZAÇões VOLTAMÉtRICA}

Previamente a cada experimento eletroquímico, o eletrodo de ADE foi ativado eletroquimicamente em solução de $\mathrm{H}_{2} \mathrm{SO}_{4} \quad 0,5 \mathrm{~mol} \mathrm{~L}^{-1}$ através da aplicação de uma corrente anódica constante com densidade igual a $40 \mathrm{~mA} \mathrm{~cm}{ }^{-2}$ durante $20 \mathrm{~min}^{64}$. Para avaliar os efeitos desse pré-tratamento sob o eletrodo, voltamogramas cíclicos foram obtidos em solução de $\mathrm{H}_{2} \mathrm{SO}_{4} 0,5 \mathrm{~mol} \mathrm{~L}^{-1}$ com velocidade de $50 \mathrm{mV} \mathrm{s}^{-1}$ antes e depois do pré-tratamento.

A Figura 8 (a) mostra os VC obtidos antes e depois do pré-tratamento. Pode se observar mais detalhadamente pela Figura 8 (b) que após o pré-tratamento houve aumento significante da área superficial eletroquimicamente ativa, aumento da corrente na RDO e um deslocamento do potencial de RDO para potenciais mais negativos, aumentando assim a eficiência do processo, devido à liberação de sítios ativos até então impedidos.

De acordo com Rossi et al. ${ }^{65}$, a ativação do eletrodo sob intensa RDO é atribuída à hidratação de sítios superficiais de regiões de difícil alcance como poros, e pequenas rachaduras. Assim, o pré-tratamento precisa ser realizado para evitar mudanças na área superficial eletroquimicamente ativa do eletrodo durante os experimentos eletroquímicos sendo também usado como um método de limpeza ou regeneração da área superficial eletroquimicamente ativa, pois os sítios do eletrodo podem ficar bloqueados por filmes orgânicos adsorvidos (polímeros).

A Figura 9 mostra o comportamento eletroquímico do eletrodo de composição $\mathrm{Ti} / \mathrm{Ru}_{0,3} \mathrm{Ti}_{0,7} \mathrm{O}_{2}$ em solução de $\mathrm{H}_{2} \mathrm{SO}_{4} \quad 0,5 \mathrm{~mol} \mathrm{~L}^{-1}$ com diferentes velocidades de varredura. 

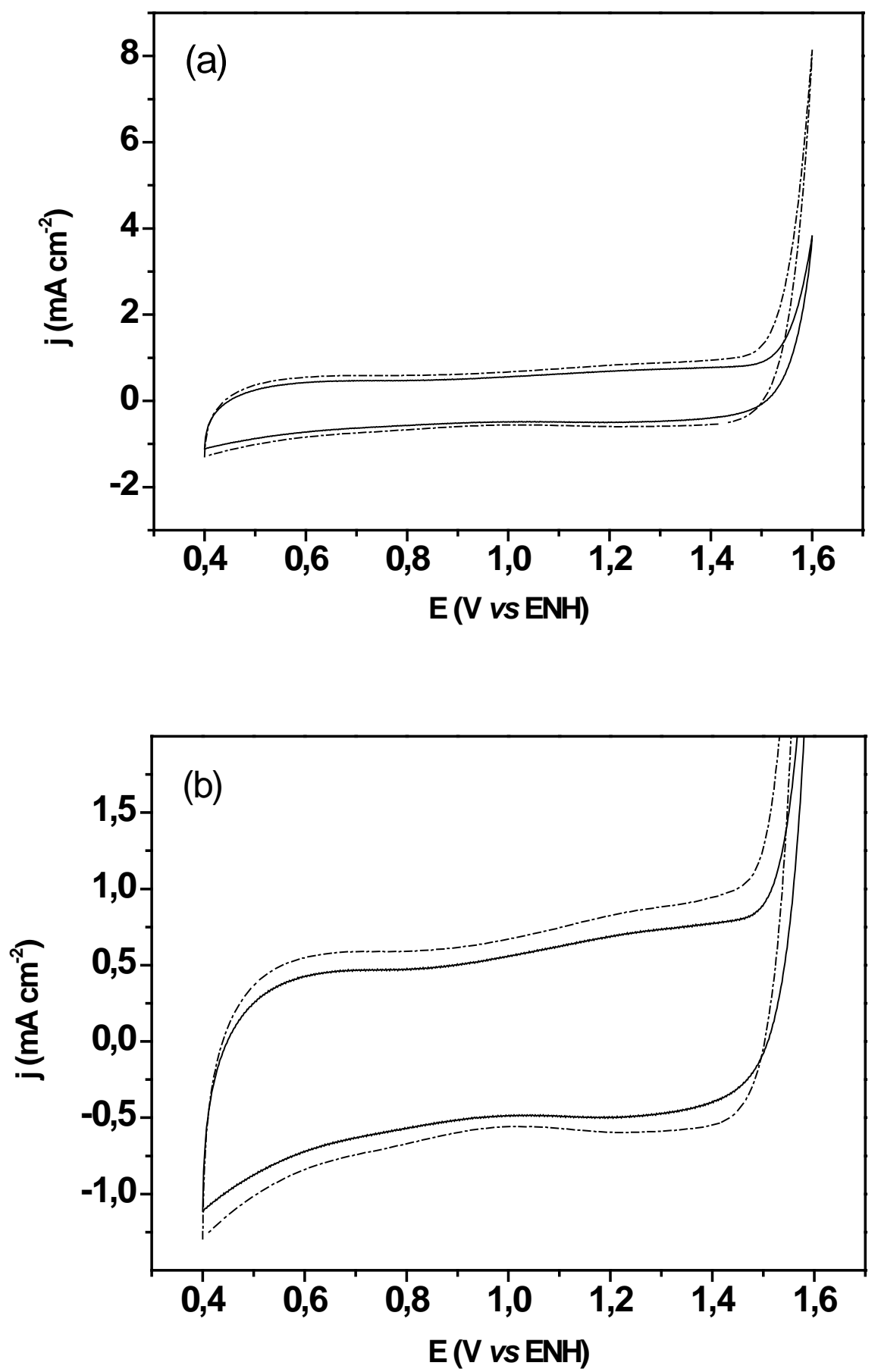

Figura 8 - (a) Voltamograma cíclico de $\mathrm{Ti} / \mathrm{Ru}_{0,3} \mathrm{Ti}_{0,7} \mathrm{O}_{2}$ em solução de $\mathrm{H}_{2} \mathrm{SO}_{4} 0,5 \mathrm{~mol} \mathrm{~L}^{-1}$, v $=50 \mathrm{mV} \mathrm{s}^{-1}$. (b) análise do voltamograma em um intervalo menor de densidade de corrente. (-) antes e (---) depois do condicionamento. 


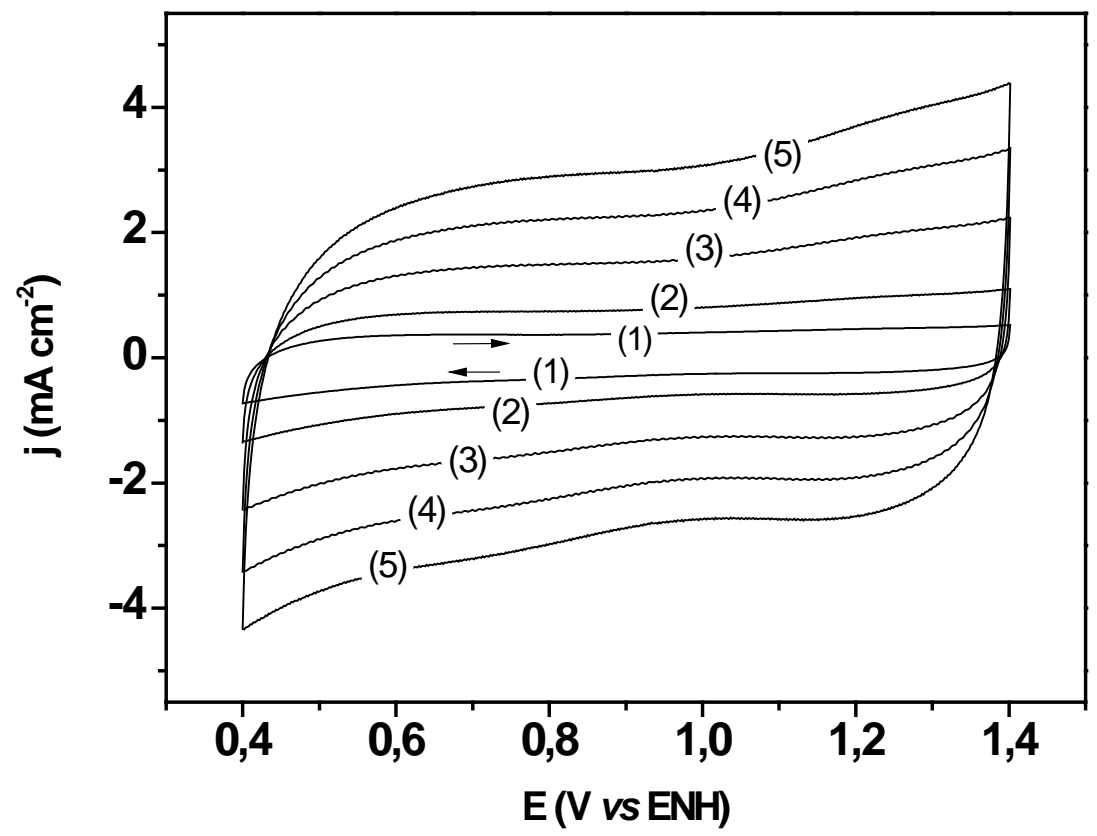

Figura 9 - Voltamograma cíclico de $\mathrm{Ti} / \mathrm{Ru}_{0,3} \mathrm{Ti}_{0,7} \mathrm{O}_{2}$ em solução de $\mathrm{H}_{2} \mathrm{SO}_{4} 0,5 \mathrm{~mol} \mathrm{~L}{ }^{-1}$ com diferentes velocidades de varredura, (1) 25; (2) 50; (3) 100 ; (4) 150 (5) $200 \mathrm{mV} \mathrm{s}^{-1}$.

Notam-se duas regiões características ${ }^{65,66}$, sendo elas:

- $\quad$ Região (I): composta por um pico largo e pouco definido entre 0,5 e 1,0 V vs ERH, associado à transição do estado sólido do par $\mathrm{Ru}(\mathrm{III}) / \mathrm{Ru}(\mathrm{IV}) \mathrm{e}$

- $\quad$ Região (II): composta por um pico entre 1,1 e 1,3 V vs ERH, relacionado à transição do par $\mathrm{Ru}(\mathrm{IV}) / \mathrm{Ru}(\mathrm{VI})$.

Nas Tabelas 3 e 4 observa-se o efeito da variação da velocidade de varredura sob as cargas anódicas e catódicas. Os valores da carga voltamétrica anódica $\left(q_{\mathrm{a}}\right)$ e catódica $\left(q_{c}\right)$ foram obtidos por integração das partes anódicas e catódicas da curva, na região em que a RDO e RDH não contribuem para a carga voltamétrica, sendo que a relação $q_{a} / q_{c}$ fornece uma indicação da reversibilidade das transições no estado sólido dos pares redox.

O aumento da velocidade de varredura provoca, de forma geral, uma diminuição nos valores de $q_{a}$ e $q_{c}$ para ambos os meios estudados. À medida que a velocidade de varredura aumenta é realizada a varredura de um intervalo de potencial maior para um mesmo intervalo de tempo, levando a exclusão de sítios ativos menos acessíveis da resposta voltamétrica e consequentemente causando a diminuição da carga voltamétrica para ambas as varreduras (catódica e anódica) em ambos os meios estudados. 
Tabela 4 - Variação da carga anódica e catódica para diferentes velocidades de varredura no intervalo de potencial compreendido entre 0,4 e 1,4 V vs ENH em solução de $\mathrm{H}_{2} \mathrm{SO}_{4} 0,5 \mathrm{~mol} \mathrm{~L}^{-1}$

\begin{tabular}{c|c|c|c}
\hline $\mathbf{v}\left(\mathbf{m V ~ s}^{-\mathbf{1}}\right)$ & $\mathbf{q}_{\mathbf{a}}\left(\mathbf{m C ~} \mathbf{~ c m}^{-\mathbf{2}}\right)$ & $\mathbf{q}_{\mathbf{c}}\left(\mathbf{m C ~} \mathbf{c m}^{-\mathbf{2}}\right)$ & $\mathbf{q}_{\mathbf{a}} / \mathbf{q}_{\mathbf{c}}$ \\
\hline 25 & 15,17 & 13,51 & 1,12 \\
\hline 50 & 15,29 & 14,43 & 1,06 \\
\hline 100 & 15,19 & 14,71 & 1,03 \\
\hline 150 & 14,91 & 14,54 & 1,02 \\
\hline 200 & 14,57 & 14,28 & 1,02 \\
\hline
\end{tabular}

Tabela 5 - Variação da carga anódica e catódica para diferentes velocidades de varredura no intervalo de potencial compreendido entre 0,4 e 1,4 V vs ENH em solução salina

\begin{tabular}{c|c|c|c}
\hline $\mathbf{v}\left(\mathbf{m V ~ ~ s ^ { - 1 }}\right)$ & $\mathbf{q}_{\mathrm{a}}\left(\mathbf{m C} \mathbf{~ c m}^{-\mathbf{2}}\right)$ & $\mathbf{q}_{\mathbf{c}}\left(\mathbf{m C ~} \mathbf{c m}^{-\mathbf{2}}\right)$ & $\mathbf{q}_{\mathrm{a}} / \mathbf{q}_{\mathbf{c}}$ \\
\hline 25 & 14,69 & 11,98 & 1,23 \\
\hline 50 & 12,74 & 11,37 & 1,12 \\
\hline 100 & 10,61 & 10,10 & 1,05 \\
\hline 150 & 9,84 & 9,54 & 1,03 \\
\hline
\end{tabular}

Os dados nas Tabelas 3 e 4 também mostram que a razão entre as cargas anódicas e catódicas permaneceram na faixa de 1,05, para todas as velocidades de varredura estudadas, mostrando boa reversibilidade das transições no intervalo de potencial estudado.

Pela Figura 10 observa-se também que na solução salina os picos referentes às transições no estado sólido dos pares redox, não ficaram bem evidentes, porém, a reversibilidade das transições foi mantida o que se comprova a partir dos valores de $q_{a}$ $/ q_{c}$ presentes avaliados. 


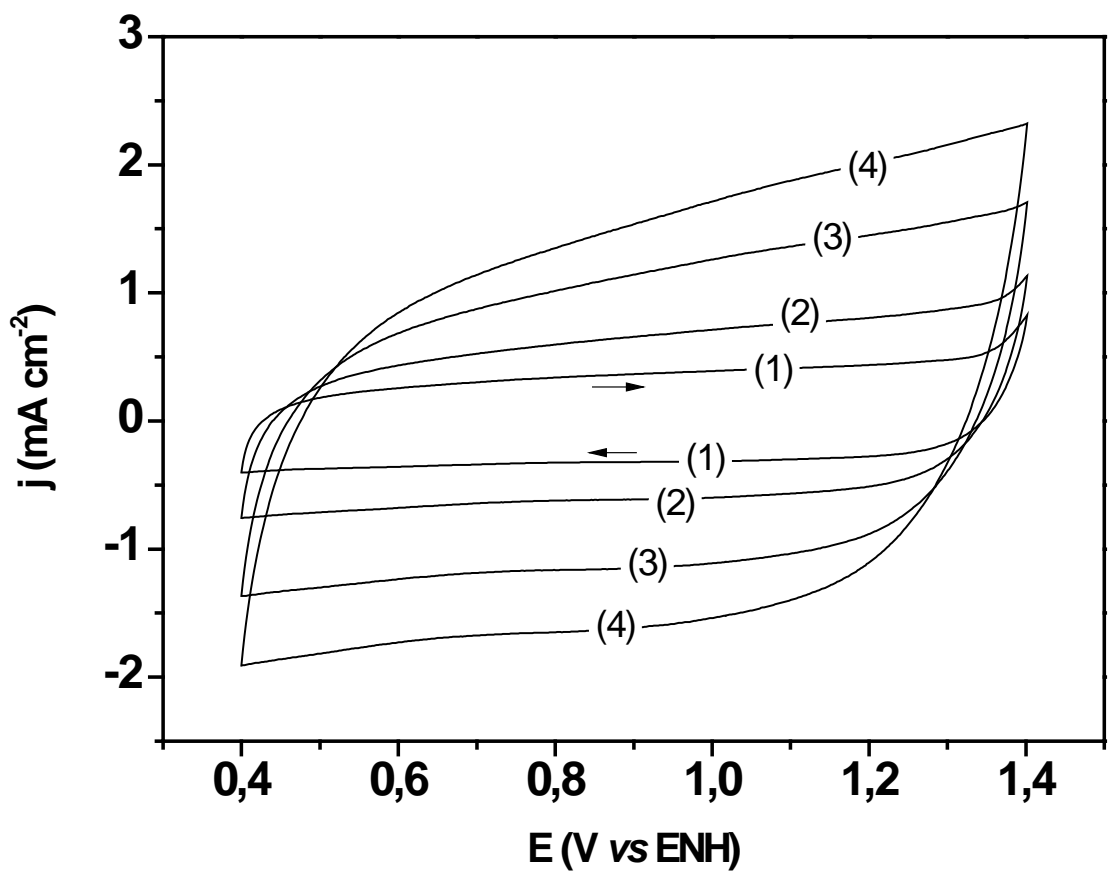

Figura 10 - Voltamograma cíclico de $\mathrm{Ti} / \mathrm{Ru}_{0,3} \mathrm{Ti}_{0,7} \mathrm{O}_{2}$ em solução salina com diferentes velocidades de varredura,. (1) 25; (2) 50; (3) 100 ; (4) $150 \mathrm{mV} \mathrm{s}^{-1}$.

Assim, é observado que o $A D E$ de composição $\mathrm{Ti} / \mathrm{Ru}_{0,3} \mathrm{Ti}_{0,7} \mathrm{O}_{2}$ mostra bom desempenho nas condições estudas, apresentando composição próxima da composição nominal mesmo após inúmeras utilizações, reversibilidade em meio salino e recuperação da área eletroquimicamente ativa após condicionamento.

\subsubsection{Caracterização eletroquímica na presença de TeC}

Através da Figura 11 foi possível observar que no intervalo de potencial estudado, o antibiótico não sofre oxidação na superfície do eletrodo, pois não ocorreu o surgimento de picos adicionais na varredura anódica ou catódica. Entretanto, houve diminuição na RDO e na reação de desprendimento de cloreto, indicando diminuição da oxidação indireta. 


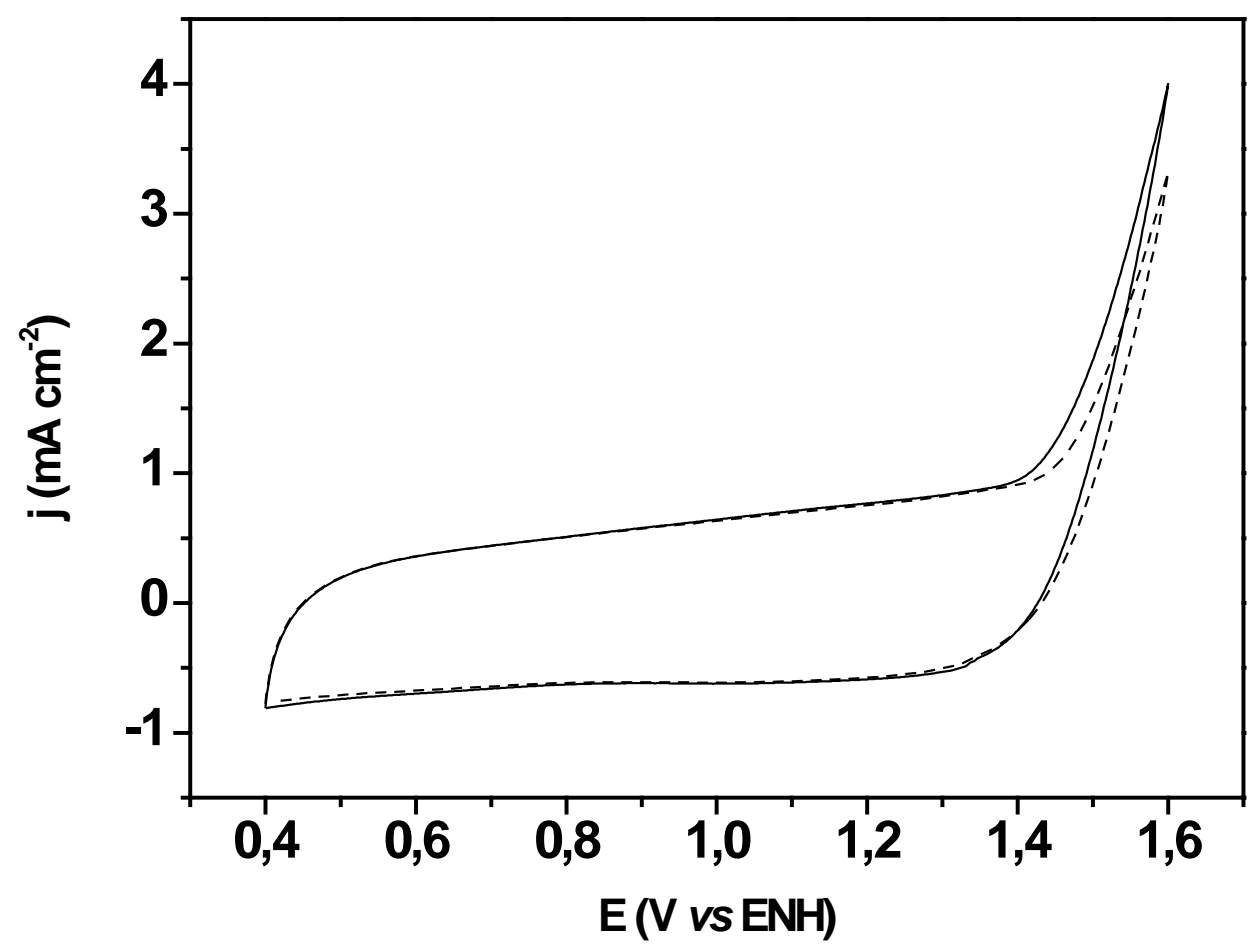

Figura 11 - Voltamograma cíclico de $\mathrm{Ti} / \mathrm{Ru}_{0,3} \mathrm{Ti}_{0,7} \mathrm{O}_{2}, \mathrm{v}=50 \mathrm{mV} \mathrm{s}{ }^{-1}$, (一) solução salina e (---) solução salina e $200 \mathrm{mg} \mathrm{L}^{-1} \mathrm{TeC}$.

\subsubsection{CARACTERIZAÇÃo eletroquímica na PRESENÇA dos demais COMPOSTOS ORGÂNICOS}

A Figura 12 mostra que a medida que a VC é realizada na presença da TeC, uréia e creatinina, esses compostos também não sofrem oxidação no intervalo correspondente as transições internas dos óxidos metálicos. Contudo da mesma forma que a $\mathrm{TeC}$ a presença dessas substâncias influenciam a RDO, ou seja, a adição desses compostos acentuou ainda mais a diminuição na RDO quando comparado com o resultado obtido na presença apenas da $\mathrm{TeC}$ indicando que esses compostos também se adsorvem sob a superfície podendo competir com o oxigênio eletrogerado e também, com a reação de desprendimento de cloreto, diminuindo assim, a formação de espécies de cloro ativo e consequente a oxidação por processo indireto. Tais fenômenos reduzem ainda mais a eficiência dos processos individuais, ficando claro que a presença de interferentes dificulta a degradação de moléculas alvo específicas em resíduos naturais. 


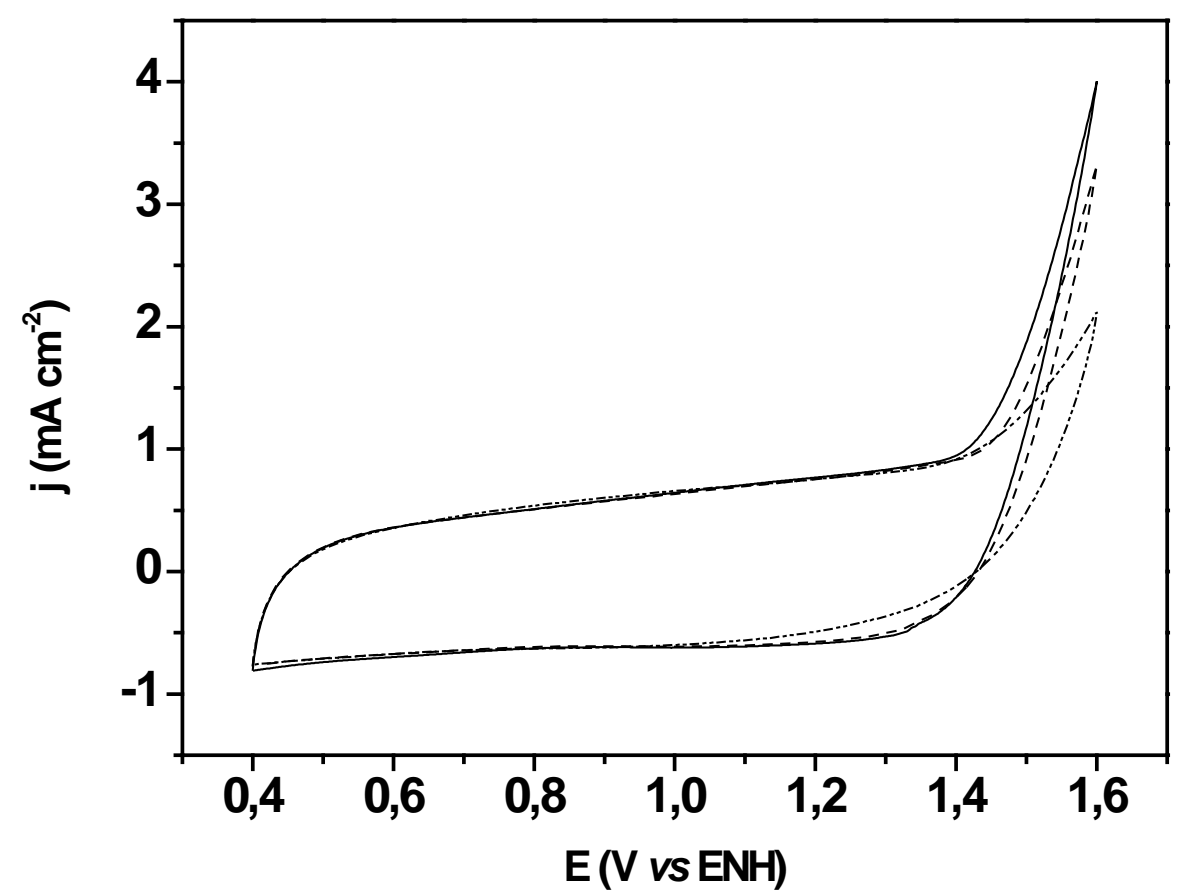

Figura 12 - Voltamograma cíclico de $\mathrm{Ti} / \mathrm{Ru}_{0,3} \mathrm{Ti}_{0,7} \mathrm{O}_{2}, \mathrm{v}=50 \mathrm{mV} \mathrm{s}{ }^{-1}$, (一) solução salina, (--) TeC $200 \mathrm{mg} \mathrm{L}^{-1}$ em solução salina (---) creatinina $1,1 \mathrm{~g} \mathrm{~L}^{-1}$ e uréia $25 \mathrm{~g} \mathrm{~L}^{-1} \mathrm{em}$ solução salina.

Nas Figuras 13 (a) e 13 (b), observa-se que ocorre diminuição da área superficial ativa do eletrodo com uma diminuição da corrente anódica a medida que o número de ciclos aumenta.

O mesmo ocorre na presença dos demais compostos orgânicos como mostram as Figuras 14 (a) e 14 (b). À medida que o número de ciclos aumenta, a corrente de oxidação diminui devido à redução de sítios ativos pela adsorção de polímeros de cadeia curta. 

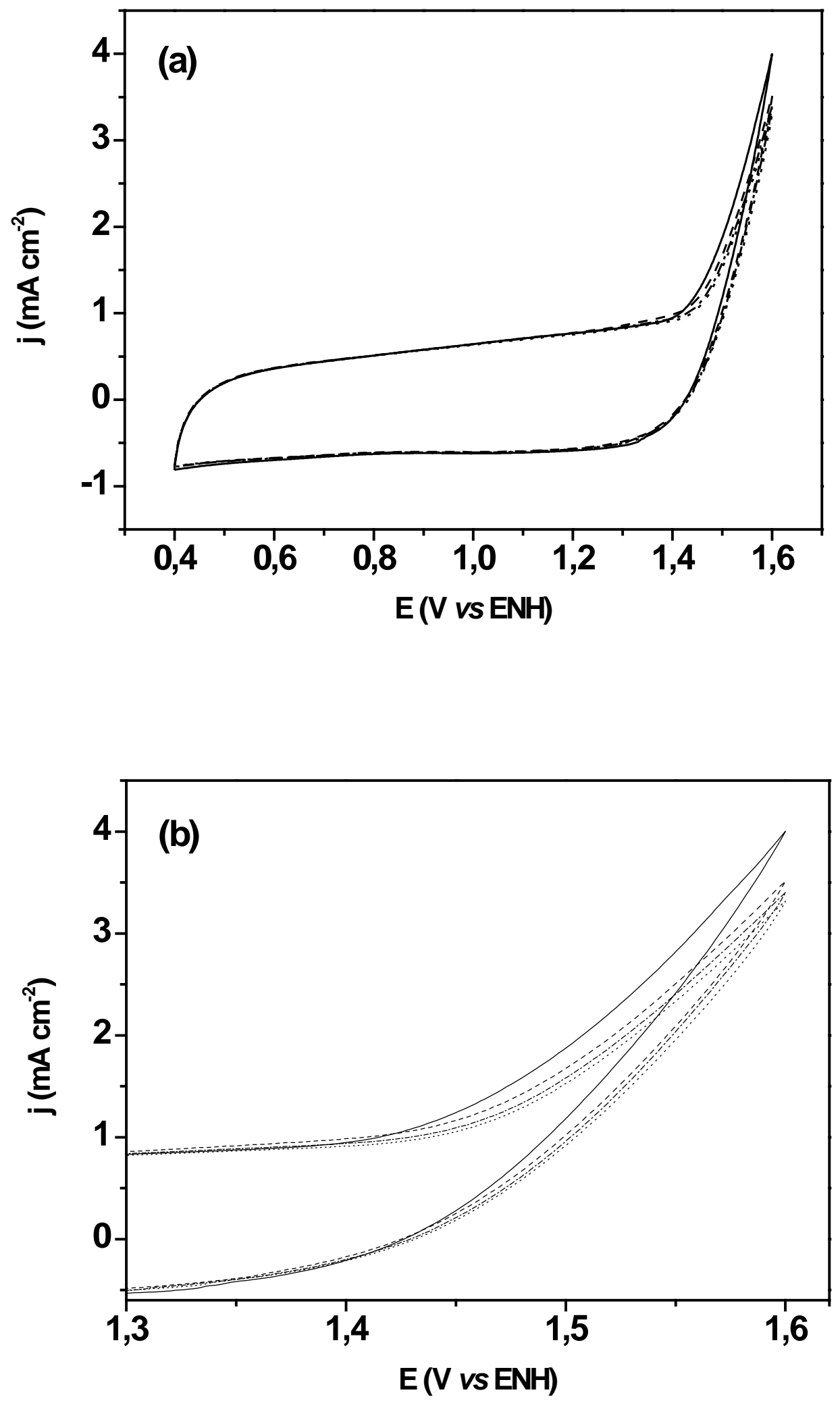

Figura 4 - (a) Voltamograma cíclico de Ti/ $\mathrm{Ru}_{0,3} \mathrm{Ti}_{0,7} \mathrm{O}_{2}, \mathrm{v}=50 \mathrm{mV} \mathrm{s}^{-1}$ (b) ampliação do voltamograma no intervalo compreendido entre 1,3 e 1,6 V, (-) solução salina, (---)

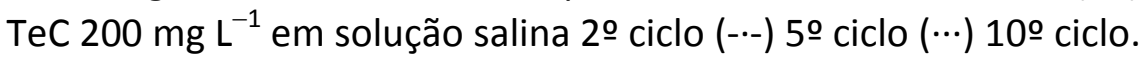



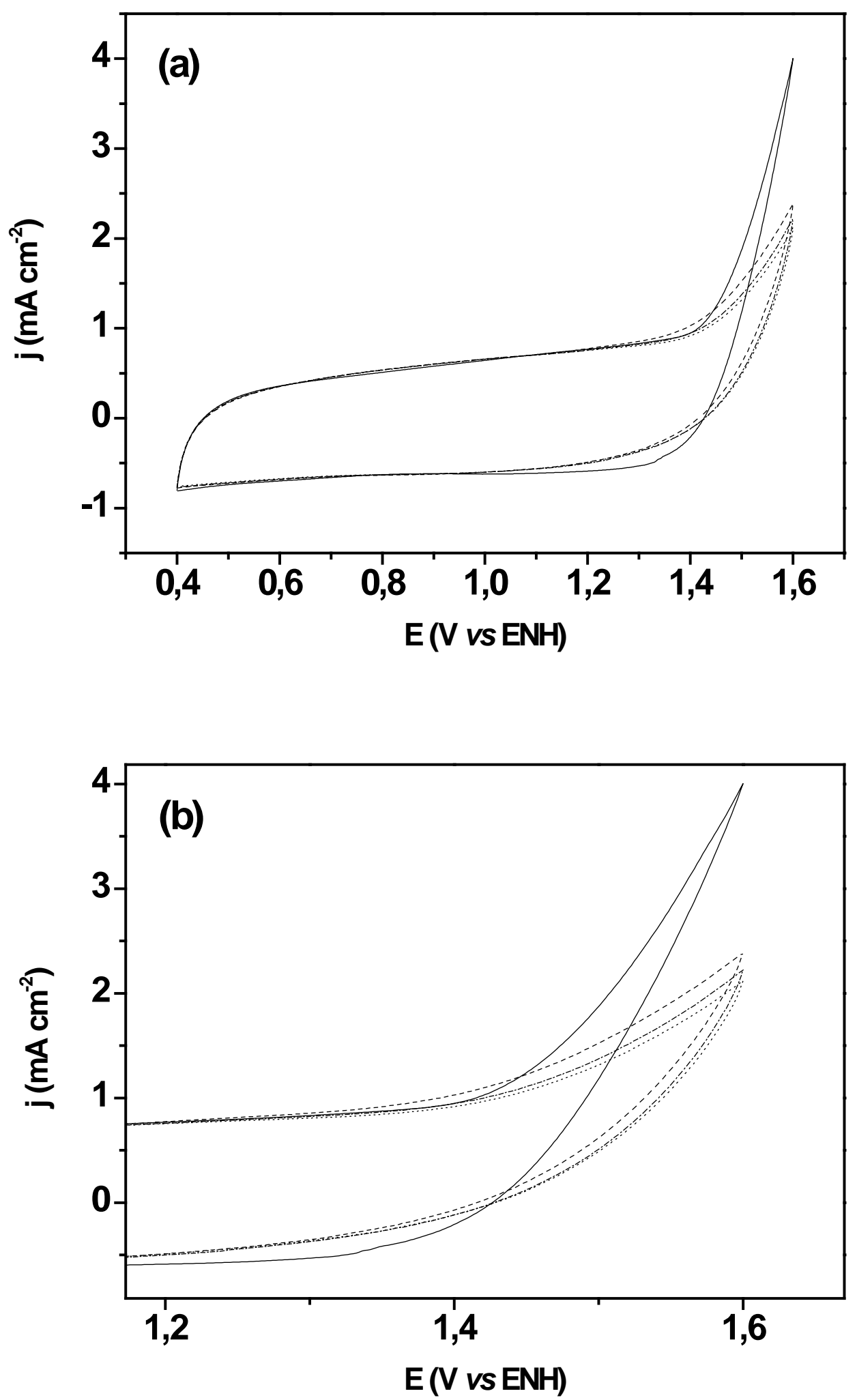

Figura 5 - (a) Voltamograma cíclico de $\mathrm{Ti} / \mathrm{Ru}_{0,3} \mathrm{Ti}_{0,7} \mathrm{O}_{2}, \mathrm{v}=50 \mathrm{mV} \mathrm{s}^{-1}$ (b) ampliação do voltamograma no intervalo compreendido entre 1,2 e 1,6 V, (-) solução salina, (---) TeC $200 \mathrm{mg} \mathrm{L}^{-1}$, creatinina $1,1 \mathrm{~g} \mathrm{~L}^{-1}$ e uréia $25 \mathrm{~g} \mathrm{~L}^{-1}$ em solução salina 2o ciclo (-·-) 5o ciclo $(\cdots) 10$ e ciclo. 
No trabalho citado anteriormente ${ }^{65}$, os autores também observaram tal comportamento do cloridrato de oxitetraciclina em eletrodo de $\mathrm{RuO}_{2}$ que pode ser atribuído a adsorção de depósitos orgânicos formados por dímeros, trímeros ou produtos intermediários que reduzem a superfície ativa de eletrodos óxidos.

\subsection{ANÁLISE DO CLORIDRATO DE TETRACICLINA}

O espectro de absorção da TeC possui dois máximos de absorção como mostra a Figura 15. A máxima absorção da TeC em 276 nm está relacionada à parte cromófora da molécula representada pelo anel A (Figura 1). O sistema hidroxiceto em C10, C10a, C11, C11a e C12 é a parte cromófora dos anéis $\mathrm{BCD}$ da $\mathrm{TeC}$, sendo responsável pela sua absorção em $\lambda=358 \mathrm{~nm}$.

A Figura 16 mostra os espectros de absorção no UV da TeC em meio de urina artificial em diferentes tempos de eletrólise, nos quais fica evidenciado o decaimento do pico em $\lambda=358 \mathrm{~nm}$.

Assim como em outro estudo envolvendo a degradação eletroquímica da oxitetraciclina empregando eletrodo de $\mathrm{RuO}_{2}{ }^{65}$, foi observado que ao longo da eletrólise, houve mudança na coloração da solução, através de seu escurecimento como pode ser visualizado na Figura 17. 


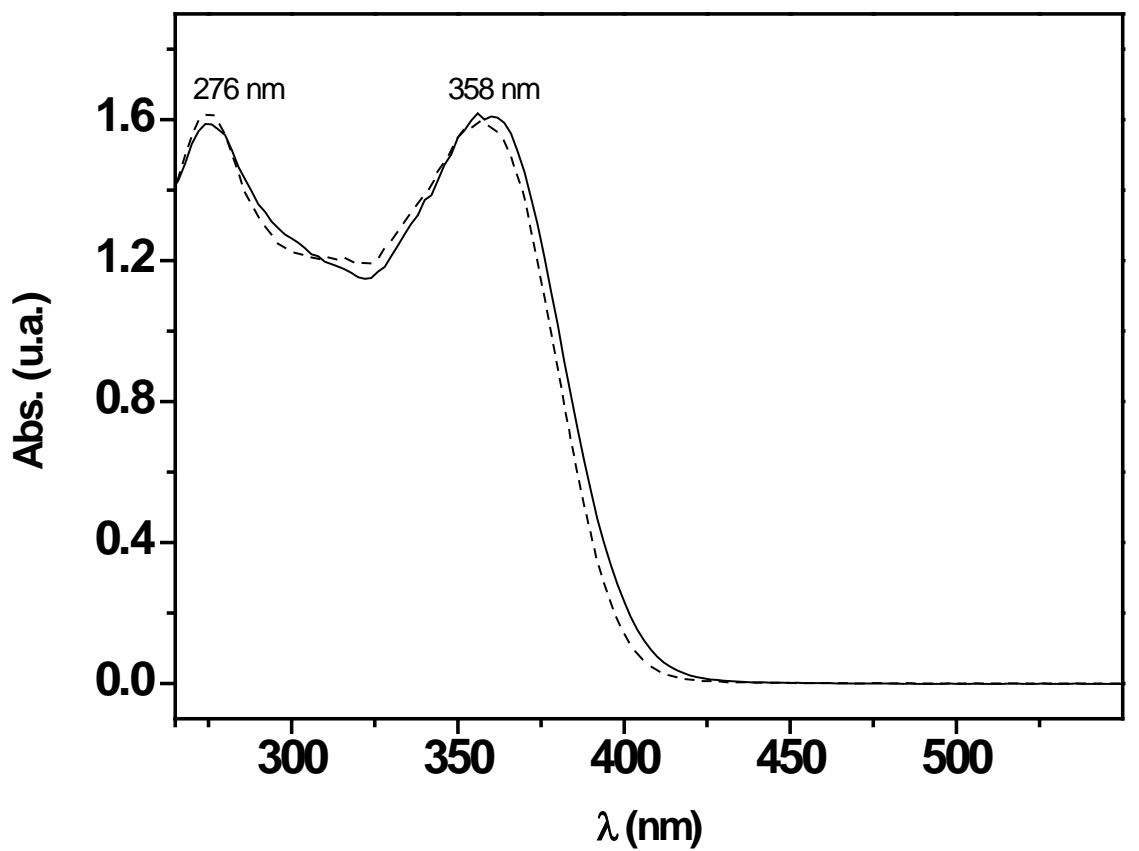

Figura 15 - Espectro de absorção no UV da TeC $50 \mathrm{mg} \mathrm{L}^{-1}(---)$ meio aquoso, (-) meio de urina artificial.

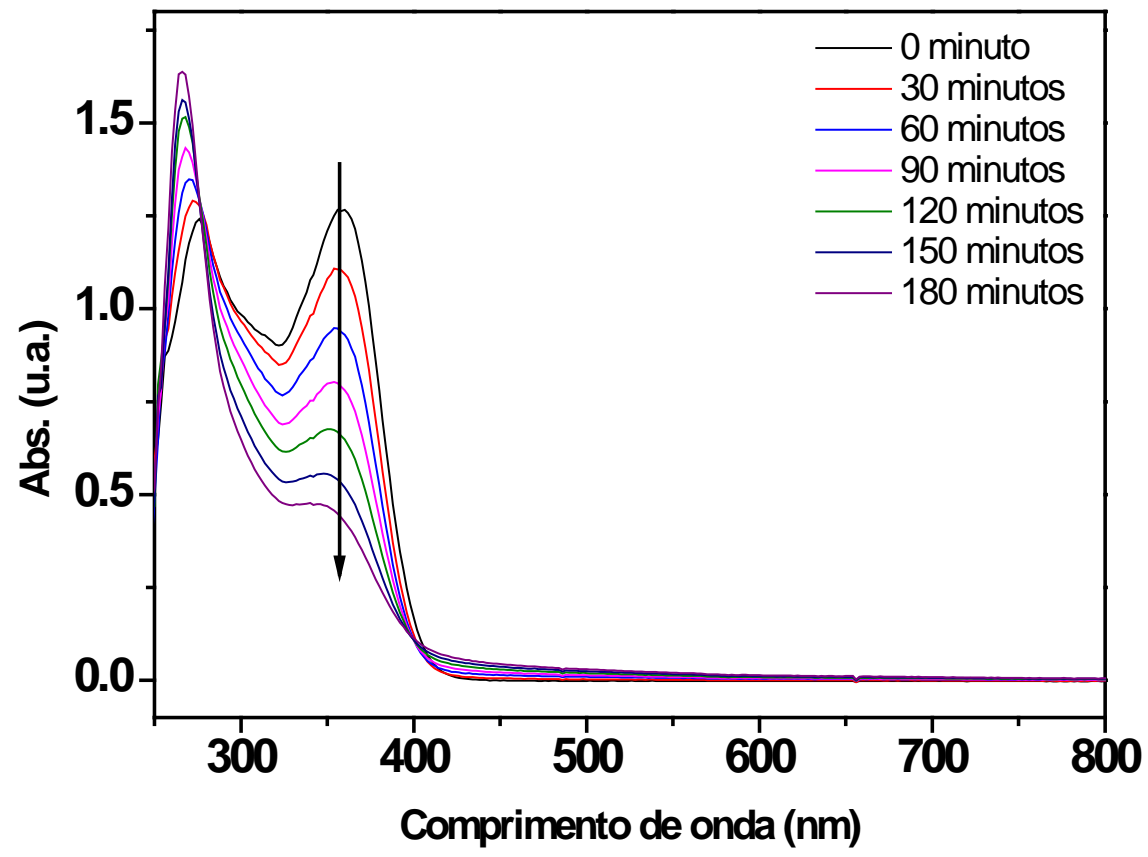

Figura 16 - Espectro de absorção no UV da TeC em meio de urina artificial em diferentes tempos de eletrólise. $\left([\mathrm{TeC}]_{\mathrm{i}}=200 \mathrm{mg} \mathrm{L}^{-1}, \mathrm{~T}=25^{\circ} \mathrm{C}, \mathrm{pH}_{\mathrm{i}}=6,0\right.$ e j $=30 \mathrm{~mA}$ $\mathrm{cm}^{-2}$ ). 

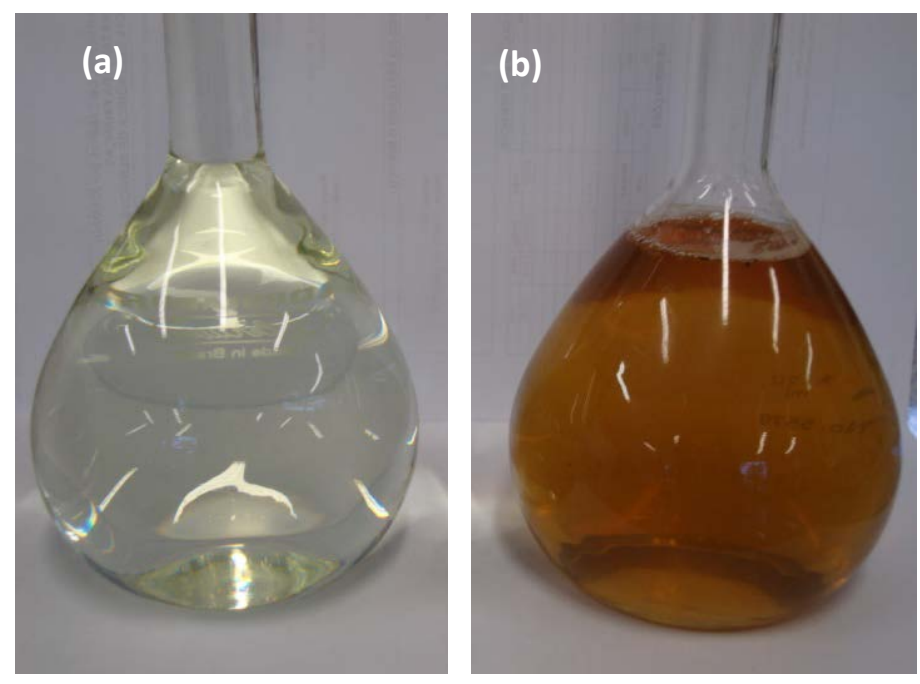

Figura 17 - Aspecto visual das soluções de TeC em meio de urina artificial. (a) antes do tratamento eletroquímico (b) depois do tratamento eletroquímico. ([TeC $]_{\mathrm{i}}=200 \mathrm{mg} \mathrm{L}^{-1}$ , j $\left.=30 \mathrm{~mA} \mathrm{~cm}^{-2}, \mathrm{~T}=25^{\circ} \mathrm{Ce}_{\mathrm{pH}}=6,0\right)$.

Como pode ser observado houve também a intensificação do pico localizado em aproximadamente $\lambda=276 \mathrm{~nm}$, fato também evidenciado em um estudo sobre a remoção da TeC por ozônio em solução aquosa ${ }^{67}$. Nessa região houve um deslocamento batocrômico que para os autores está relacionado à remoção da TeC com concomitante produção de intermediários com estruturas similares.

Nos estudos cromatográficos, no detector UV-Vis modulado ao equipamento de CLAE, os sinais de maiores intensidades foram em $\lambda=270$ e $360 \mathrm{~nm}$ e assim, a absorção da TeC foi avaliada nesses dois comprimentos de onda durante todas as oxidações eletroquímicas, porém, apenas os dados em $\lambda=360 \mathrm{~nm}$ foram utilizados para análise do decaimento da TeC.

Os valores de LD e LQ determinados para a TeC, a partir dos dados da curva de calibração obtida em $\lambda=360 \mathrm{~nm}$ foram: $0,73 \mathrm{mg} \mathrm{L}^{-1}$ e $2,23 \mathrm{mg} \mathrm{L}^{-1}$, respectivamente.

Os cartuchos Sep-Pack C18 Waters (100 mg) foram previamente condicionados com $5 \mathrm{~mL}$ de metanol, $5 \mathrm{~mL}$ de água em seguida $1 \mathrm{~mL}$ de amostra foi adicionado e a eluição foi feita com $1 \mathrm{~mL}$ de metanol. Testes de extração envolvendo adição de uma solução saturada de $\mathrm{Na}_{2}$ EDTA, com agente quelante, foram realizados, porém não foram obtidas diferenças significativas. Embora tenham atingido $72,7 \pm 2,0 \%$ de recuperação, esse valor foi superir ao obtido por Bautitz ${ }^{68}$ (43\%) em um estudo que 
envolvia a degradação da TeC por método foto-Fenton e avaliação da extração da TeC em diferentes cartuchos.

\subsection{ESTUDO DA DENSIDADE DE CORRENTE}

Como observado na Figura 18 ocorre o decaimento da concentração da TeC em função do tempo de eletrólise para todas as densidades de correntes empregadas. Tal decaimento é mais acentuado para as densidades de 30 e $40 \mathrm{~mA} \mathrm{~cm}^{-2}$, sendo que em 2 horas de eletrólise a concentração da TeC caiu para aproximadamente 10 e 1\%, respectivamente.

A equação cinética de pseudo 1a ordem representada na equação 19,

$\frac{\mathrm{dC}_{\mathrm{t}}}{\mathrm{d}_{\mathrm{t}}}=-\mathrm{kC}_{\mathrm{t}}$

onde $C_{t}$ é a concentração de TeC no tempo $t$ e $k$ é a constante de velocidade, foi a que melhor se ajustou aos dados de remoção. Na Figura 19 pode ser observada a relação linear entre a constante de velocidade e a densidade de corrente. 


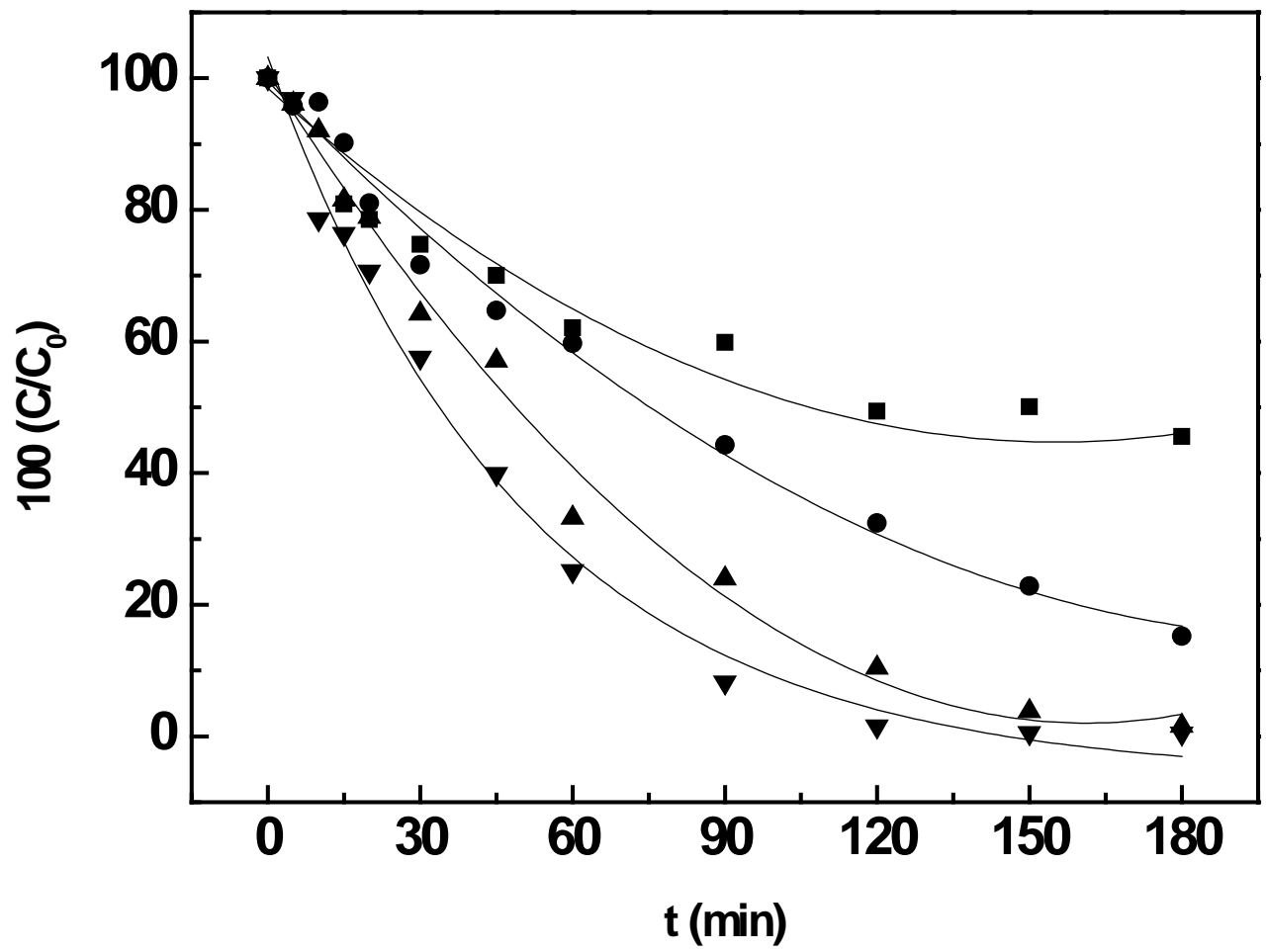

Figura 18 - Decaimento da $\mathrm{TeC}$ ao longo do tempo de eletrólise em diferentes

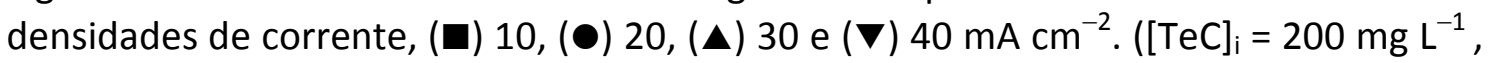
$\mathrm{T}=25^{\circ} \mathrm{C}$ e $\left.\mathrm{pH}_{\mathrm{i}}=6,0\right)$.

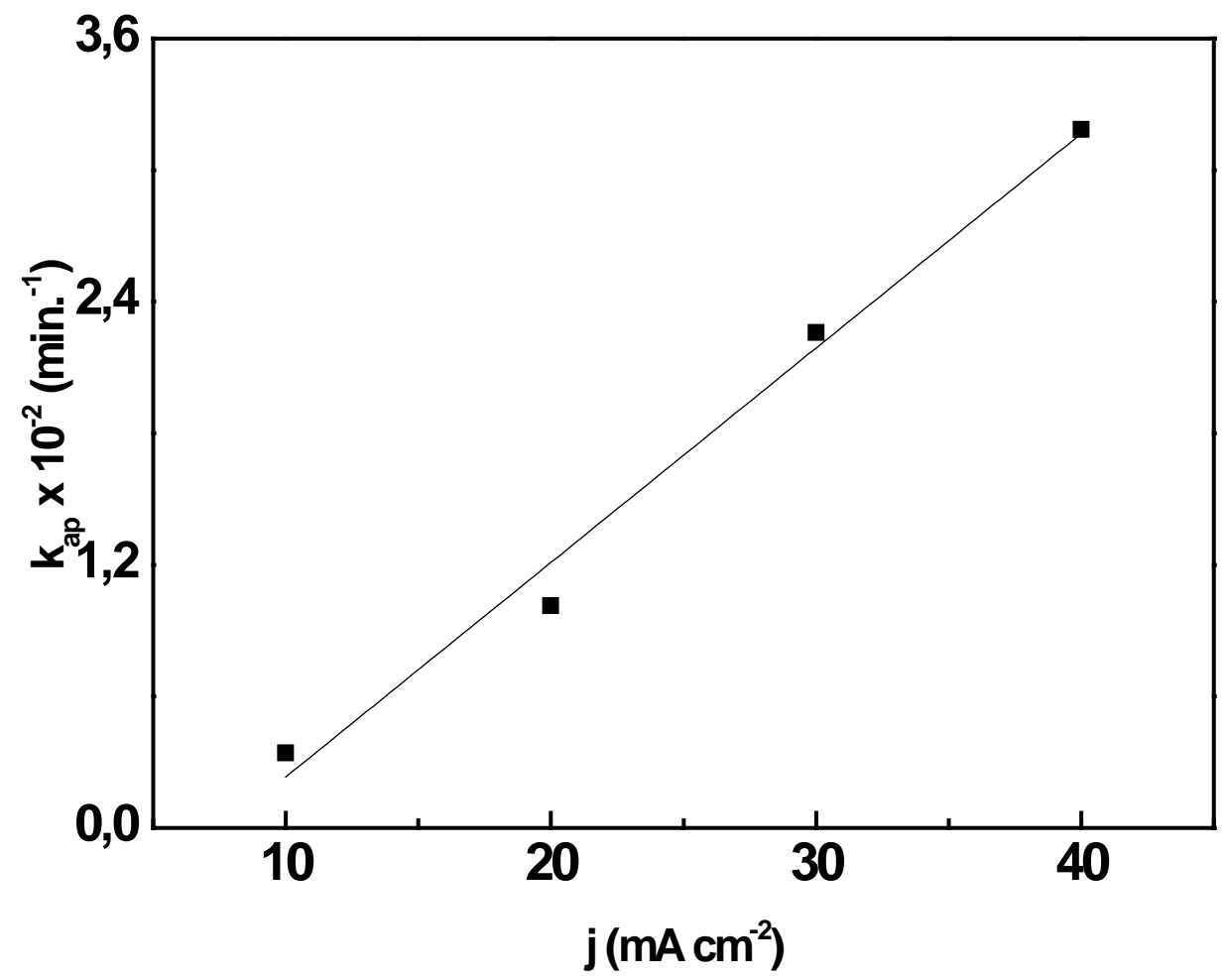

Figura 19 - Constante de velocidade de pseudo-primeira ordem em função da densidade de corrente. 
De modo geral, a oxidação de compostos orgânicos, em meios contendo cloreto, pode ocorrer de dois modos distintos: i) pela transferência direta de elétron do composto orgânico para o ânodo, e ii) através das espécies de cloro ativo formadas a partir da oxidação dos íons cloretos presentes no meio ${ }^{38}$. A relação crescente entre a constante de velocidade e a densidade de corrente indica que o aumento da densidade de corrente causa um aumento na quantidade de espécies de cloro ativo, aumentando assim a remoção da $\mathrm{TeC}^{64}$.

Quando o decaimento é analisado em função da carga específica ${ }^{69}$ obtida pela equação:

$\mathrm{Q}=\frac{\mathrm{It}}{\mathrm{V}}$

em que I é a corrente (A), t é o tempo (s) e $V$ é o volume de solução submetida à eletrólise (L), é obtido um perfil de remoção semelhante para todos os casos, independentemente da densidade de corrente (Figura 20). 


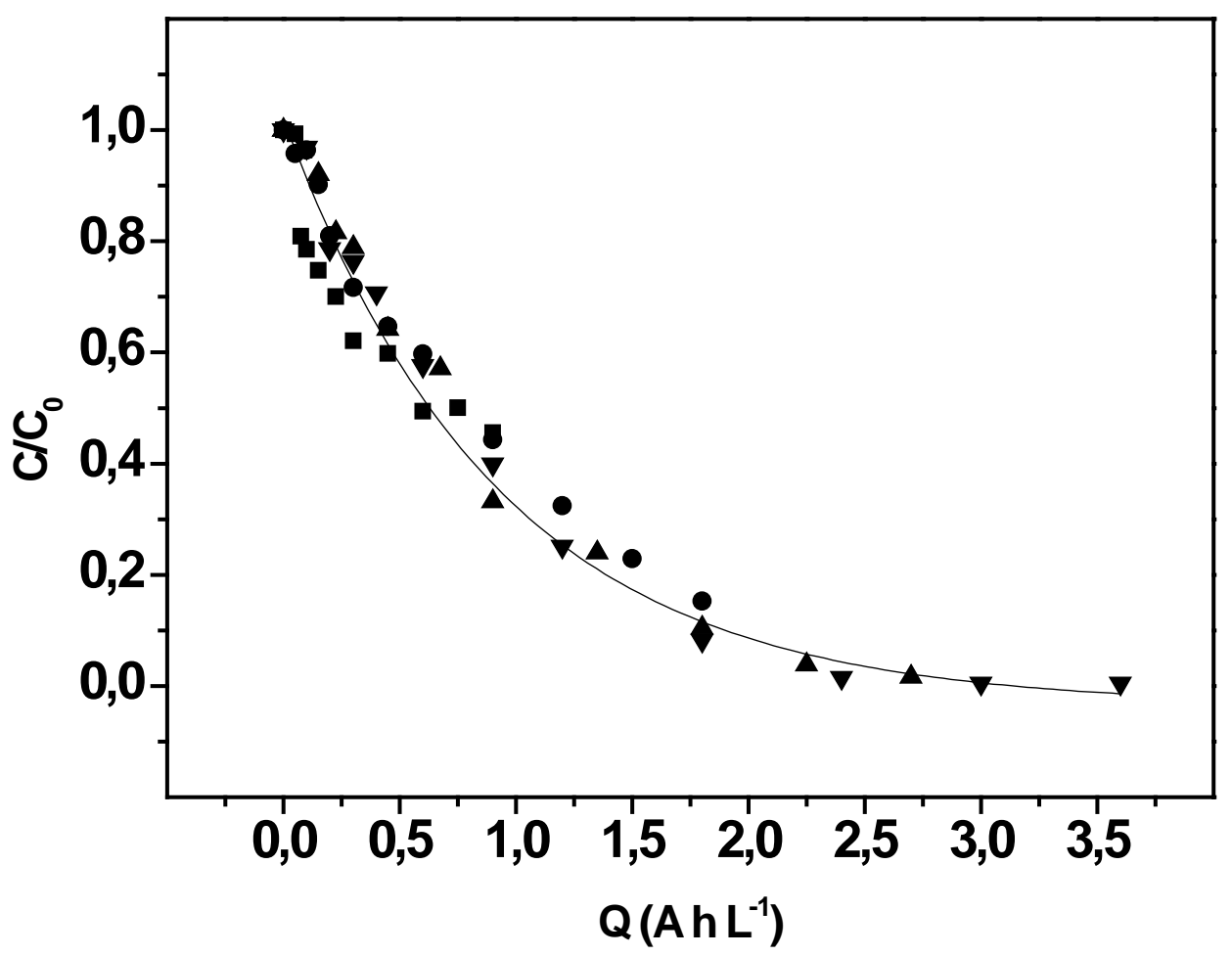

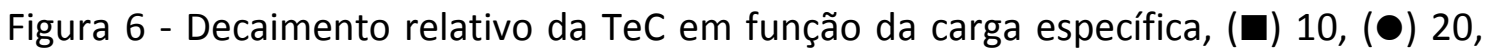

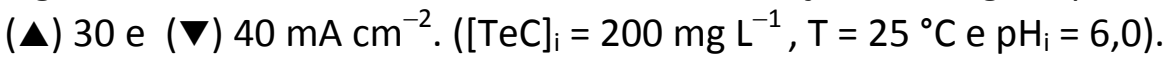

Assim, este não é um parâmetro determinante para a degradação da TeC, uma vez que para se atingir determinada porcentagem de remoção, qualquer densidade de corrente estudada demandaria semelhante carga aplicada. Deve-se salientar, entretanto, que o tempo de degradação varia, aumentando com a diminuição da densidade de corrente.

Zhang et $a .^{38}$ observaram a mesma dependência da carga específica para qualquer um dos valores de densidade de corrente utilizados, ao estudar a degradação eletroquímica da $\mathrm{TeC}$ em meio aquoso, empregando $\mathrm{Na}_{2} \mathrm{SO}_{4} 0,1 \mathrm{~mol} \mathrm{~L}^{-1}$ como eletrólito suporte. Comparando esse trabalho em meio de $\mathrm{Na}_{2} \mathrm{SO}_{4}$ com o presente estudo, em meio de urina artificial com concentração de cloreto igual a $0,1 \mathrm{~mol} \mathrm{~L}^{-1}$, observa-se, porém, que para se atingir níveis mais elevados de degradação é necessária maior carga em meio de $\mathrm{Na}_{2} \mathrm{SO}_{4}$ do em meio de urina artificial. Esta diferença entre os dois casos pode ser atribuída ao maior poder oxidante das espécies de cloro ativo, eletrogeradas durante o tratamento eletroquímico em meio de urina artificial, 
enquanto que em meio aquoso, contendo $\mathrm{Na}_{2} \mathrm{SO}_{4}$, as espécies geradas têm menor poder oxidante ${ }^{42}$.

Com relação ao teor de carbono orgânico total, tem-se que este não é alterado significativamente durante as eletrólises. Porém, como foi observado um decaimento mais acentuado do COT nos últimos $30 \mathrm{~min}$ de tratamento eletroquímico, foram efetuadas novas eletrólises para comprovar essa mudança, contudo, o tempo de tratamento foi duplicado, ou seja, elevado para 360 min. A Figura 21 mostra a comparação do decaimento relativo do COT para 180 e 360 min de tratamento.

É possível observar que em ambos os casos houve um decaimento mais acentuado nos últimos 30 min de eletrólise que não acompanharam a tendência de decaimento ao longo do tempo.

Ao efetuar mudanças na forma de diluição, de automática para manual, mantendo-se o mesmo fator de diluição, foi observado, nesse caso, melhora na resposta do equipamento, que mostrou que a remoção de COT é muito baixa e não atingiu $5 \%$ em todos os casos.

O baixo decaimento do COT durante as eletrólises foi comprovado pelas pequenas variações nas concentrações de uréia e creatinina também monitoradas, sendo, ambos, os principais compostos responsáveis pelo alto teor do COT, conforme observado na Tabela 5. 


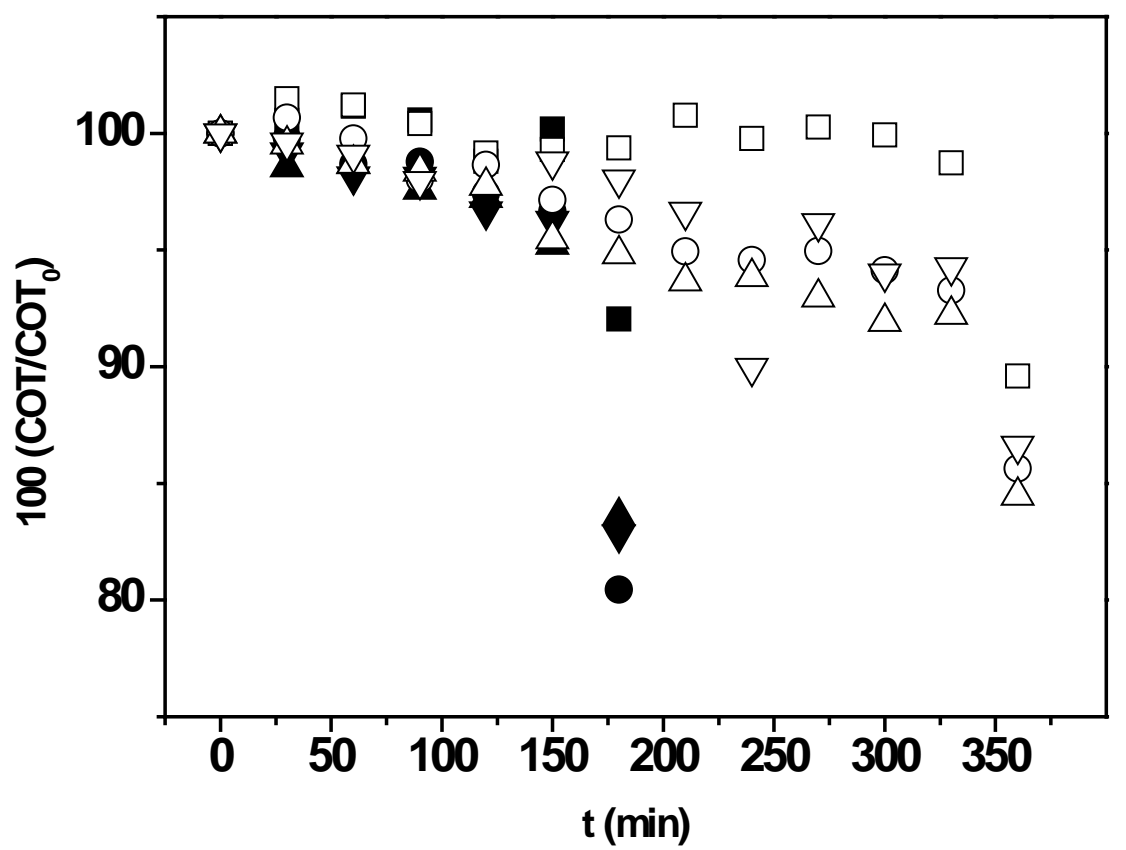

Figura 7 - Análise do teor de COT para todas as densidades de corrente com diluição automática, símbolos cheios: tempo total $=180 \mathrm{~min}$; símbolos vazios: tempo total $=360 \mathrm{~min}$ $(\boldsymbol{\square}, \square) 10,(\bullet, O) 20,(\mathbf{\Delta}, \triangle) 30$ e $(\boldsymbol{\nabla}, \nabla) 40 \mathrm{~mA} \mathrm{~cm}^{-2}$. ([TeC $\left.]_{\mathrm{i}}=200 \mathrm{mg} \mathrm{L}^{-1}, \mathrm{~T}=25^{\circ} \mathrm{Ce} \mathrm{pH}_{\mathrm{i}}=6,0\right)$.

Tabela 6 - Percentagem remanescente de uréia e creatinina para cada densidade de corrente

\begin{tabular}{|c|c|c|c|c|}
\hline \multirow{2}{*}{ \% Remanescente } & \multicolumn{4}{|c|}{ Densidade de corrente $\left(\mathrm{mA} \mathrm{cm}^{\mathbf{- 2}}\right.$ ) } \\
\cline { 2 - 5 } & $\mathbf{1 0}$ & $\mathbf{2 0}$ & $\mathbf{3 0}$ & $\mathbf{4 0}$ \\
\hline Uréia & 100 & 98,7 & 94,4 & 89,0 \\
\hline Creatinina & 100 & 100 & 100 & 96 \\
\hline
\end{tabular}

O resultado em percentagem remanescente de cada composto reflete a baixa remoção da uréia e creatinina de 11 e 4 \%, respectivamente, após 180 min de eletrólise. Isto pode ser atribuído à maior dificuldade de degradação desses compostos orgânicos, que estão em concentrações muito superiores à da $\mathrm{TeC}$, em serem degradados pelo método eletroquímico.

Assim, avaliando o decaimento tanto da TeC, quanto do COT, uréia e creatinina de modo a linearizar as concentrações em função do tempo de eletrólise ( $\log \left(100 \mathrm{C}_{\text {rel. }}\right)$ vs. tempo), é observado que as concentrações de COT, uréia e creatinina se mantém constantes enquanto que há um decaimento da $\mathrm{TeC}$ ao longo de toda a eletrólise, indicando seletividade da TeC entre todos os compostos presentes (Figura 22). 


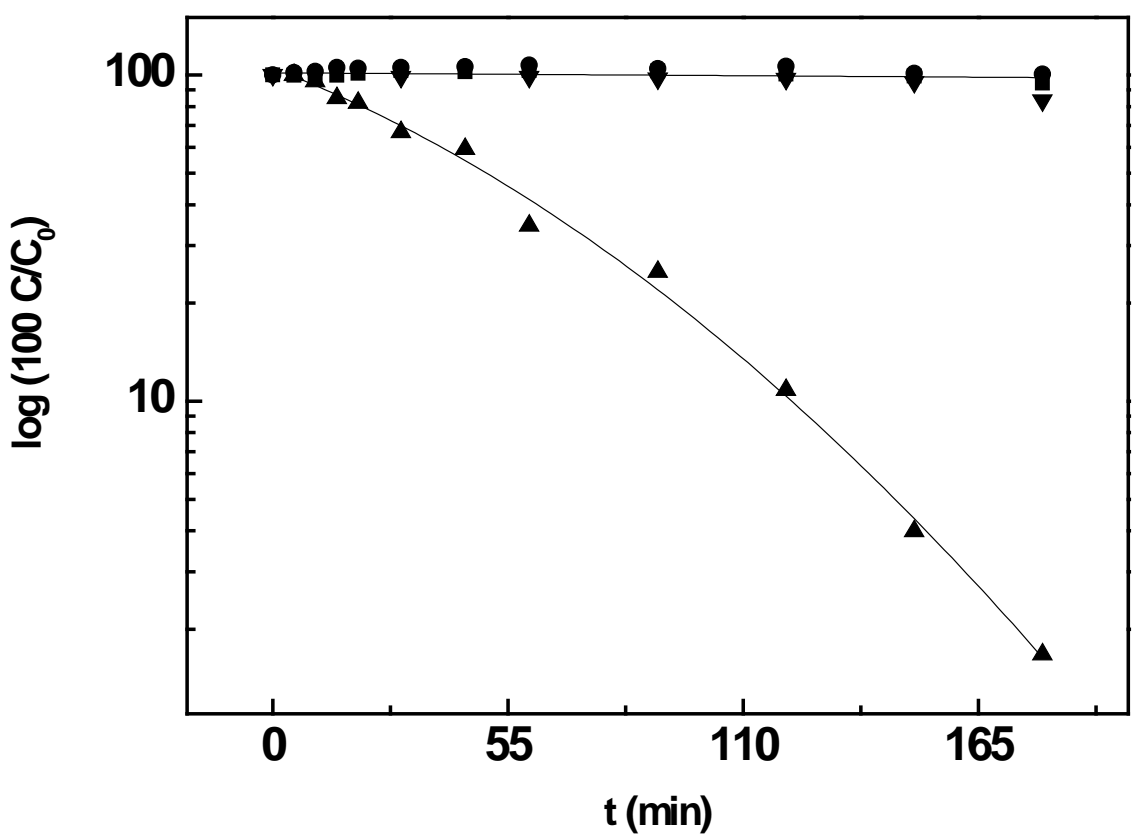

Figura 8 - Decaimento ao longo do tempo de eletrólise para j $=30 \mathrm{~mA} \mathrm{~cm}{ }^{-2}$, ( $\left.\mathbf{\square}\right)$ uréia,

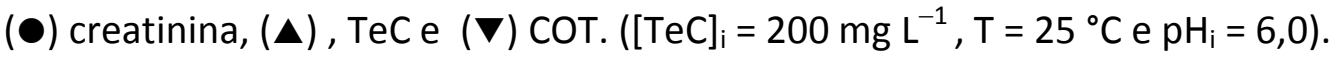

Na Figura 22 foi tomado o estudo da densidade de $30 \mathrm{~mA} \mathrm{~cm}^{-2}$ como exemplo, entretanto, tal perfil é observado para todas as demais densidades de corrente, mudando apenas a concentração final da $\mathrm{TeC}$ para cada densidade de corrente, conforme discutido anteriormente.

Para os 180 min de eletrólise pode-se observar que a medida que a densidade de corrente aumenta o consumo energético (CE) ${ }^{69}$ dado pela eq. 21 também aumenta (Figura 23).

$$
\mathrm{CE}=\frac{\mathrm{UIt}}{\mathrm{V}}
$$

em que CE é o consumo energético $\left(\mathrm{kW} \mathrm{h} \mathrm{m}^{-3}\right)$, $\mathrm{U}$ é o potencial $(\mathrm{V})$, I é a corrente $(A), \mathrm{t}$ é o tempo de eletrólise (s) e $V$ é o volume da solução em $\left(\mathrm{m}^{3}\right)$

O aumento de CE é devido a reações como desprendimento de oxigênio, redução de hipoclorito e formação de clorato que consomem cada vez mais agentes oxidantes em densidades de correntes mais elevadas. 


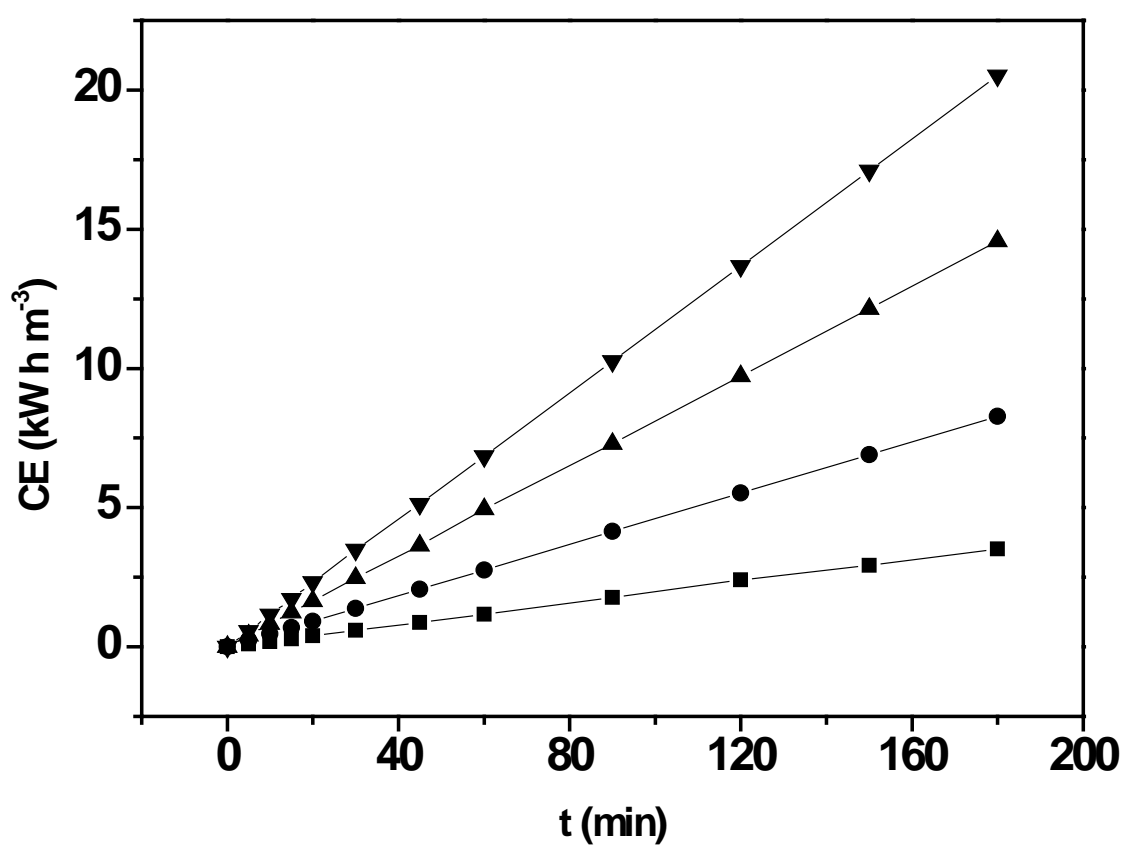

Figura 9 - Consumo energético para todas as densidades de corrente, (ם) $10,(\boldsymbol{0}) 20$,

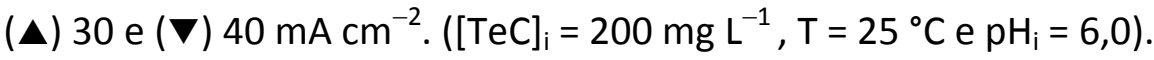

A partir desses dados e da análise do decaimento da TeC, composto alvo do presente trabalho, em função da carga aplicada e do consumo energético foi observado que as densidades de corrente de 30 e $40 \mathrm{~mA} \mathrm{~cm}{ }^{-2}$ apresentaram as maiores remoções. Porém, a densidade de corrente de $30 \mathrm{~mA} \mathrm{~cm}{ }^{-2}$ apresentou menor consumo energético sendo assim, selecionada para o estudo do $\mathrm{pH}$ inicial nos experimentos posteriores.

\subsection{COMPARAÇÃo dO ESTUDO DA DENSIDADE DE CORRENTE EM DIFERENTES MEIOS}

Para comparar a influência do meio da urina artificial durante a remoção de TeC e, considerando que em presença de cloreto as espécies de cloro ativo são as principais responsáveis pela oxidação da matéria orgânica em ADE, foram realizadas degradações em meio aquoso contendo $\mathrm{NaCl}$ como eletrólito suporte, em concentração $0,1 \mathrm{~mol} \mathrm{~L}^{-1}$, semelhante à concentração total de cloreto presente na urina artificial.

Os resultados mostraram que o decaimento da TeC também se ajustou a uma cinética de pseudo-primeira ordem e que os valores das constantes de velocidade 
foram superiores aos obtidos em meio de urina artificial (aproximadamente 16 vezes). Isto se deve ao fato desse meio proporcionar maior quantidade de espécies de cloro ativo eletrogeradas livres para reagir apenas com a TeC como composto orgânico e também, a menor obstrução dos sítios ativos em meio aquoso, uma vez que creatinina e uréia estão ausentes. Assim, foram alcançadas remoções superiores a 98 \% em apenas 45 e $10 \mathrm{~min}$ nas densidades de correntes 10 e $40 \mathrm{~mA} \mathrm{~cm}{ }^{-2}$, respectivamente, como mostra a Figura 24.

Do mesmo modo que para o meio de urina artificial, em meio aquoso com $\mathrm{NaCl}$ houve aumento da constante de velocidade, com o aumento da densidade de corrente, como observado na Figura 25 estando de acordo com aqueles relatados na literatura $^{39}$. 


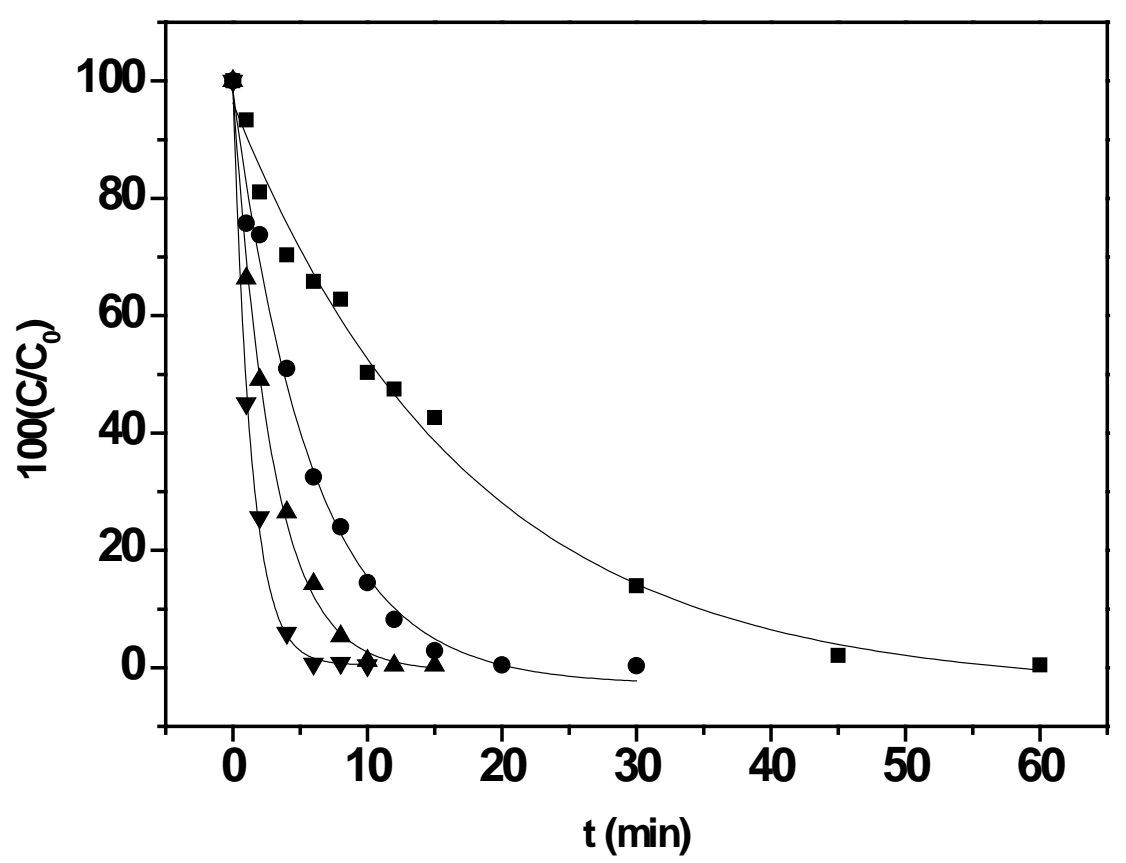

Figura 24 - Decaimento relativo da $\mathrm{TeC}$ ao longo do tempo de eletrólise em meio de $\mathrm{NaCl}$ 0,1 $\mathrm{mol} \mathrm{L}^{-1}$ em diferentes densidades de corrente, ( $\boldsymbol{( \nabla )} 10,(\bullet) 20,(\mathbf{\Delta}) 30$ e ( $\left.\mathbf{\nabla}\right) 40$ $\mathrm{mA} \mathrm{cm}{ }^{-2} .\left([\mathrm{TeC}]_{\mathrm{i}}=200 \mathrm{mg} \mathrm{L}^{-1}, \mathrm{~T}=25^{\circ} \mathrm{Ce} \mathrm{pH}_{\mathrm{i}}=6,0\right)$.

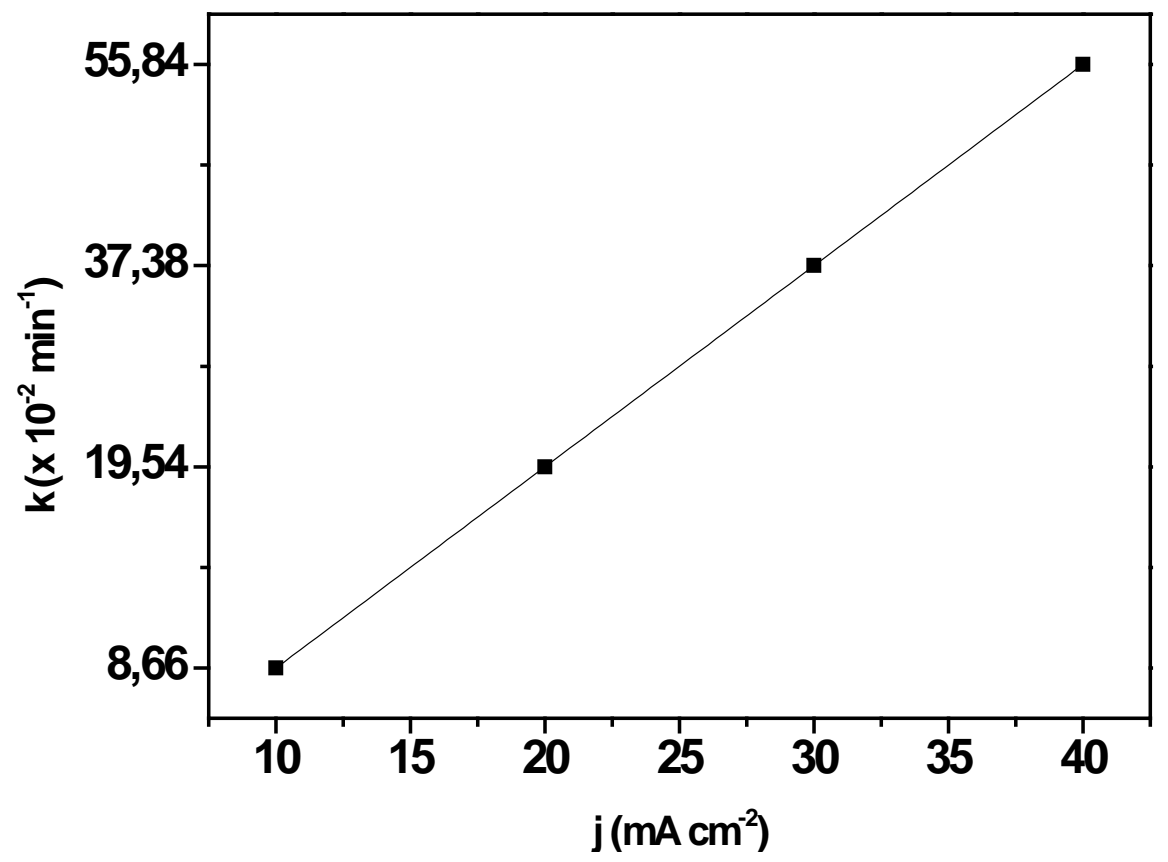

Figura 25 - Constante de velocidade de pseudo-primeira ordem em função da densidade de corrente em meio de $\mathrm{NaCl} 0,1 \mathrm{~mol} \mathrm{~L}^{-1}$. ([TeC $]_{i}=200 \mathrm{mg} \mathrm{L}^{-1}, \mathrm{~T}=25^{\circ} \mathrm{C} \mathrm{e}$ $\left.\mathrm{pH}_{\mathrm{i}}=6,0\right)$.

Considerando o período de duas horas de eletrólise é possível observar pela Figura 26 o CE e a eficiência de corrente $(E C)^{69}$, dada pela eq. 22, em função da densidade de corrente aplicada. 
$\mathrm{EC}=2,67 \mathrm{FV} \frac{\left(\mathrm{COT}_{0}-\mathrm{COT}_{\mathrm{t}}\right)}{8 \mathrm{It}}$

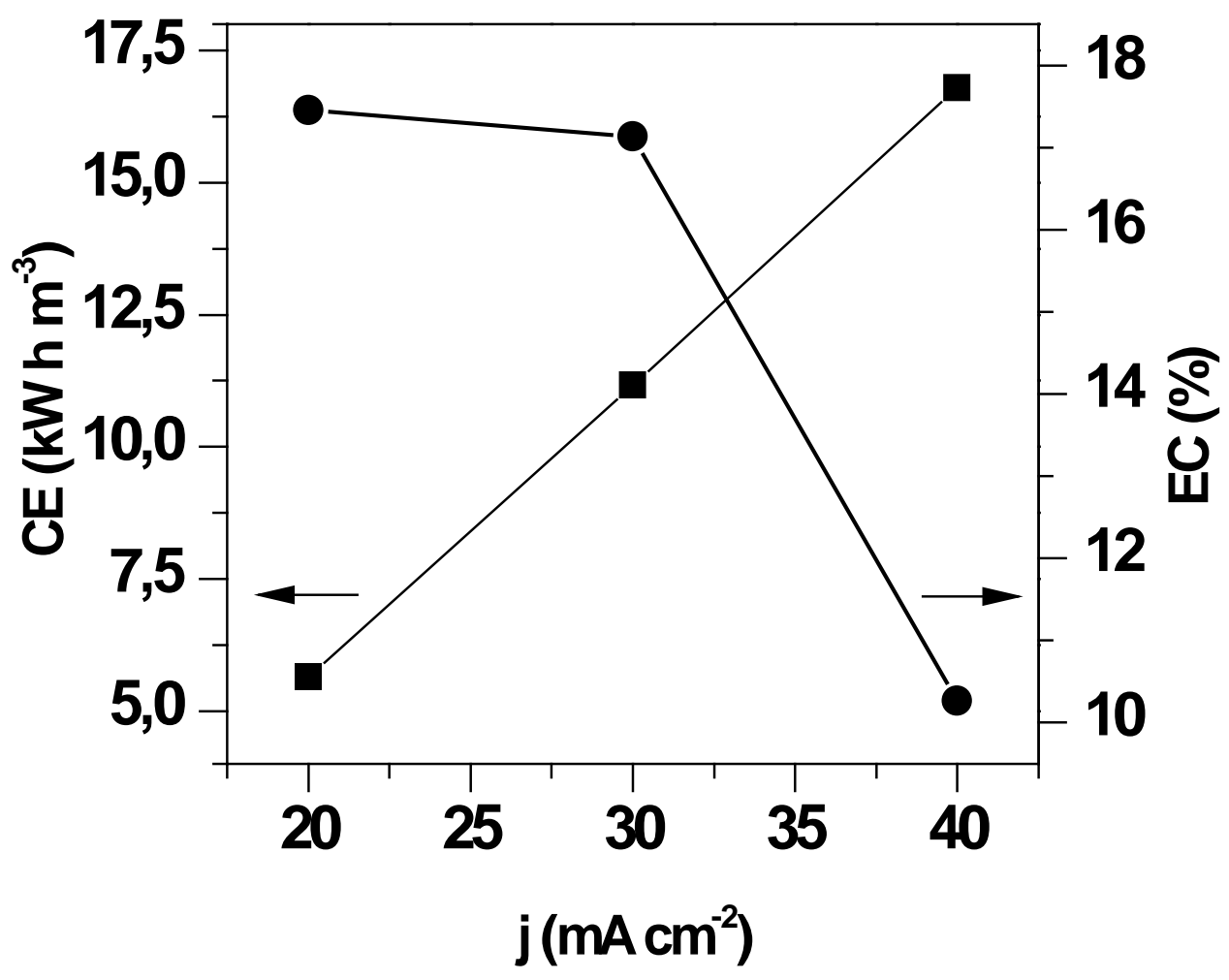

Figura 26 - (घ) CE e (๑) EC em função da densidade de corrente após duas horas de eletrólise em meio de $\mathrm{NaCl} 0,1 \mathrm{~mol} \mathrm{~L}^{-1}\left([\mathrm{TeC}]_{i}=200 \mathrm{mg} \mathrm{L}^{-1}, \mathrm{~T}=25^{\circ} \mathrm{Ce} \mathrm{pH}_{\mathrm{i}}=6,0\right)$.

À medida que a densidade de corrente aumenta o consumo energético também aumenta, uma vez que ele é proporcional a corrente aplicada e ao potencial de célula, por outro lado a eficiência de corrente diminui, pois ela é inversamente proporcional a corrente e, além disso, os valores das variações de COT para as duas horas de eletrólise mantiveram-se praticamente invariáveis.

Esses resultados indicam que por questões de consumo de energia e eficiência de corrente de mineralização para um tempo fixo de duas horas para todos os casos, é preferível trabalhar com densidades de correntes menores.

Entretanto, deve ser salientado que a constante de velocidade aparente para a degradação da TeC aumentou com a densidade de corrente, dessa forma, em tempos muito inferiores a duas horas foi possível atingir mais de $90 \%$ de remoção à medida 
que a densidade de corrente foi elevada, consumindo menos energia embora a eficiência possa cair.

Portanto, parâmetros como o tempo gasto, consumo de energia e eficiência de corrente devem ser avaliados cuidadosamente dependendo do objetivo que se deseja alcançar, por exemplo, no tratamento da solução aquosa com $0,1 \mathrm{~mol} \mathrm{~L}^{-1} \mathrm{NaCl}$ a densidade de $30 \mathrm{~mA} \mathrm{~cm}{ }^{-2}$ consome mais energia que a de 20 , porém atinge eficiência de corrente semelhante em um tempo inferior.

A Tabela 6 mostra de modo geral a constante de velocidade de pseudoprimeira ordem e consumo energético obtidos no estudo de densidade de corrente mantendo-se fixos os valores de remoção de TeC em 50 \% em diferentes meios.

Tanto para o meio de urina artificial contendo uréia e creatinina quanto para o meio de $\mathrm{NaCl}$ foi observado que houve um crescimento linear da constante de velocidade de pseudo-primeira ordem com a densidade de corrente aplicada, sendo que para o caso do meio contendo $\mathrm{NaCl}$ a constante de velocidade foi aumentada pelo menos 16 vezes, devido à ausência de compostos orgânicos como creatinina e uréia.

Do mesmo modo, o aumento da constante de velocidade, para o caso do meio contendo $\mathrm{NaCl}$, provocou a diminuição do consumo energético para obtenção de $50 \%$ de remoção da TeC. Nesse último caso não houve diferença significativa entre os valores obtidos porque a medida que houve um aumento na corrente aplicada, houve também uma diminuição na mesma proporção do tempo para se atingir $50 \%$ de remoção do antibiótico. 
Tabela 7 - Constantes de velocidade e consumo energético $\left(\mathrm{kW} \mathrm{h} \mathrm{m}^{-3}\right)$ para remoção de $50 \%$ de TeC para cada uma das densidades de corrente estudadas em meio de urina artificial e de $\mathrm{NaCl} 0,1 \mathrm{~mol} \mathrm{~L}^{-1}$. (Condições: $[\mathrm{TeC}]_{\mathrm{i}}=200 \mathrm{mg} \mathrm{L}^{-1}, \mathrm{~T}=25^{\circ} \mathrm{C}, \mathrm{pH}_{\mathrm{i}}=$ $6,0)$

\begin{tabular}{|c|c|c|c|c|}
\hline $\begin{array}{c}\mathbf{j} \\
(\mathrm{mA} \mathrm{cm}\end{array}$ & $\begin{array}{c}\mathrm{k} \times 10^{-2} \mathrm{~min}^{-1} \\
\text { urina artificial }\end{array}$ & $\begin{array}{c}\mathrm{k} \times 10^{-2} \mathrm{~min}^{-1} \\
\mathrm{NaCl}\end{array}$ & $\begin{array}{c}\mathrm{CE} \\
\text { urina artificial }\end{array}$ & $\begin{array}{c}\mathrm{CE} \\
\mathrm{NaCl}\end{array}$ \\
\hline 10 & 0,34 & 8,66 & 2,85 & 0,18 \\
\hline 20 & 1,01 & 19,54 & 3,68 & 0,19 \\
\hline 30 & 2,26 & 37,38 & 4,05 & 0,18 \\
\hline 40 & 3,18 & 55,84 & 4,10 & 0,14 \\
\hline
\end{tabular}

\subsection{ANÁlISE dOS PRODUTOS DE DEGRADAÇão POR CLAE}

Durante as análises de TeC por CLAE, observou-se que os picos em 270 e 360 $\mathrm{nm}$ decresceram com o tempo de eletrólise. Os cromatogramas obtidos para alíquotas coletadas em diferentes tempos de eletrólise e monitorados em $\lambda=360 \mathrm{~nm}$ estão representados nas Figuras 27 e 28. 

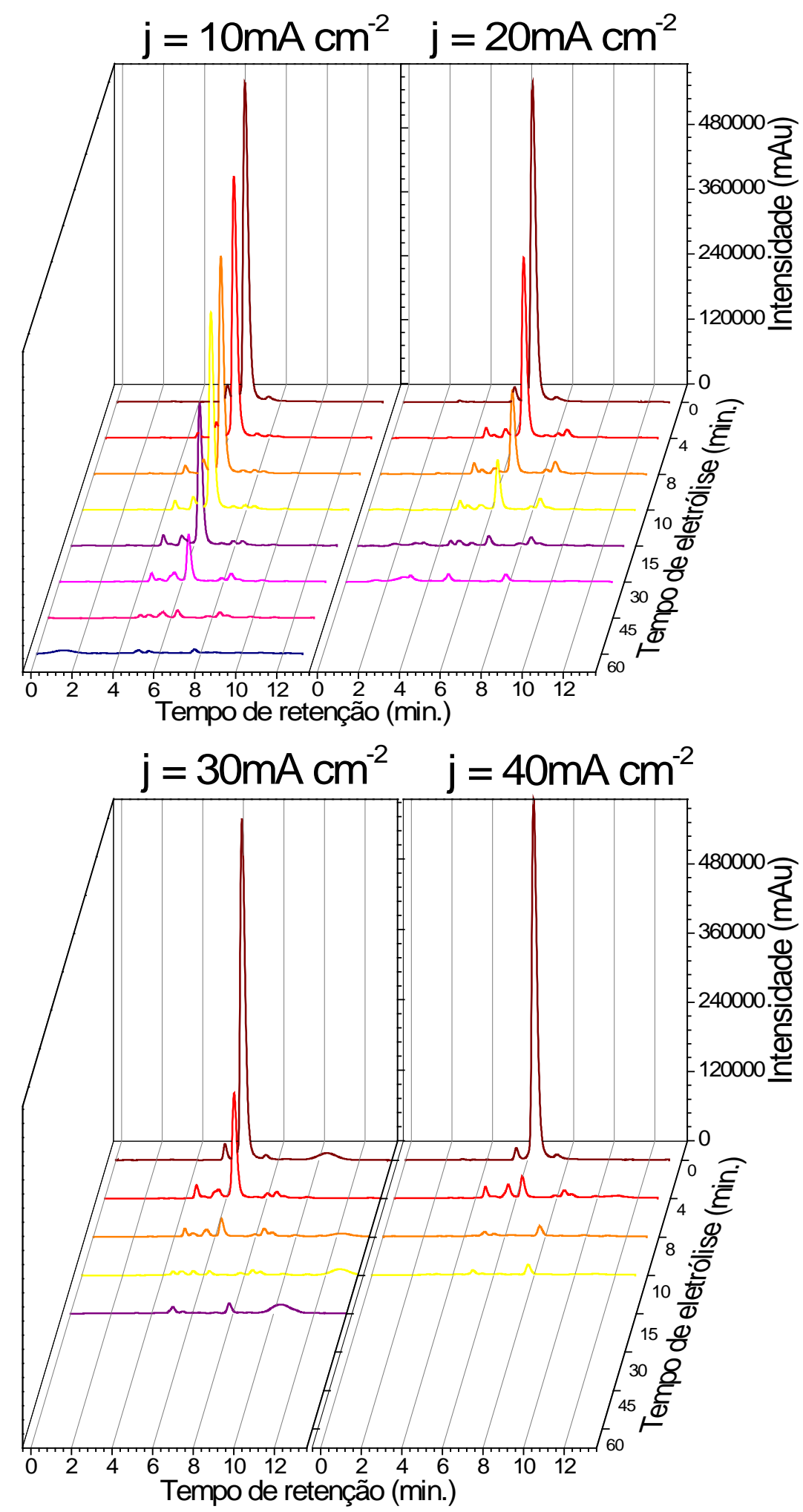

Figura 27 - Cromatogramas com detecção no UV em diferentes densidades de corrente

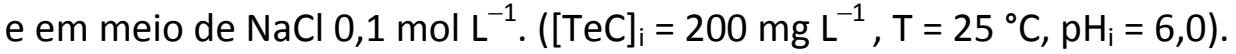




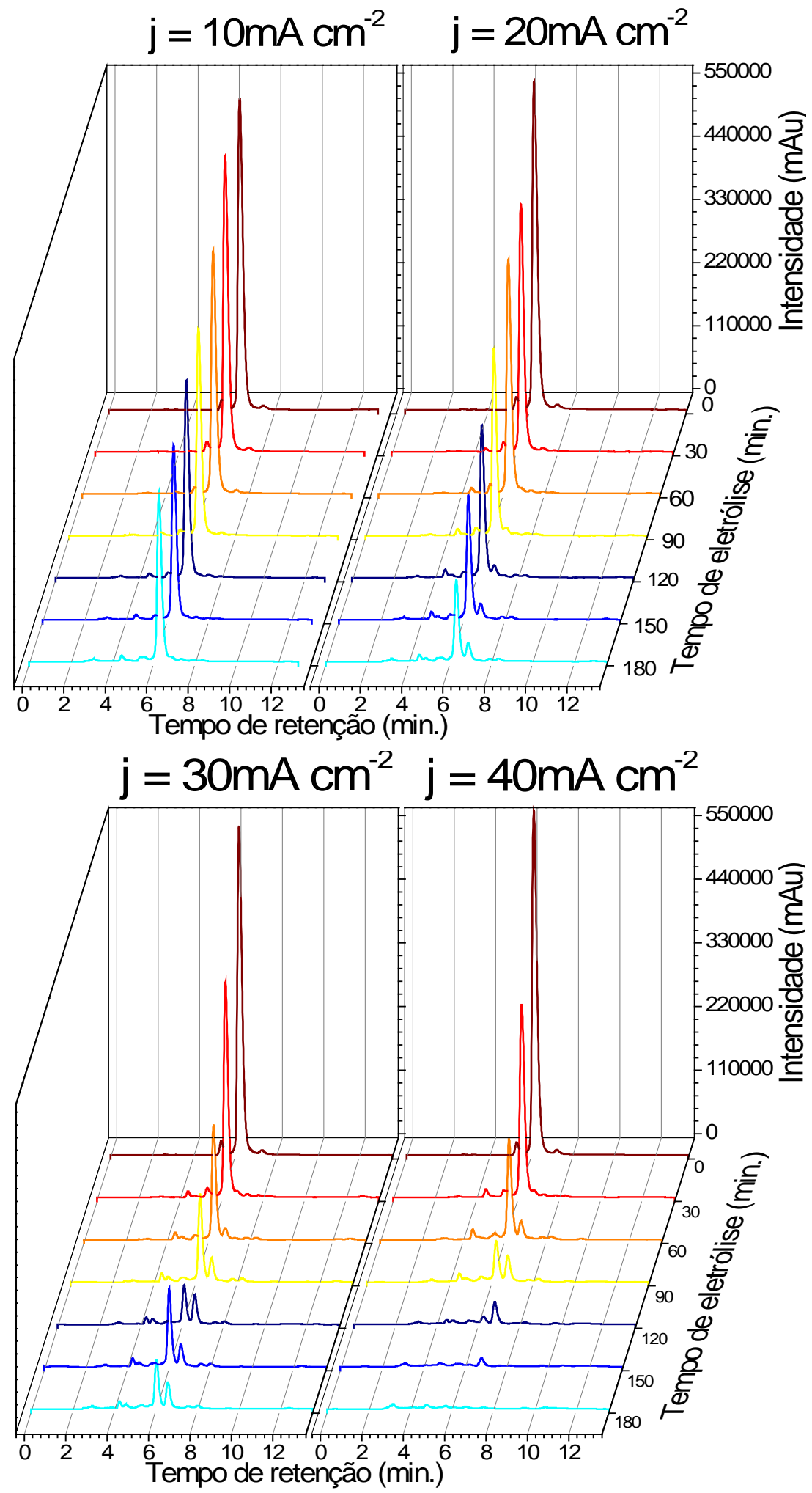

Figura 28 - Cromatogramas com detecção no UV em diferentes densidades de corrente e em meio de urina artificial. ([TeC $\left.]_{i}=200 \mathrm{mg} \mathrm{L}^{-1}, \mathrm{~T}=25^{\circ} \mathrm{C}, \mathrm{pH}_{\mathrm{i}}=6,0\right)$. 
Pode ser observado que a intensidade do pico da TeC, cujo tempo de retenção é de 5,9 min, diminui com o tempo de oxidação eletroquímica. Outros picos foram detectados, principalmente em 4,5 e 5,4 min, representando produtos de degradação de maior polaridade uma vez que possuem menor tempo de retenção do que a TeC em uma coluna cromatográfica de fase reversa. Por outro lado, produtos de menor polaridade foram retidos em 6,9 min para degradações em meio de urina artificial e 8,5 em meio de $\mathrm{NaCl} 0,1 \mathrm{~mol} \mathrm{~L}^{-1}$.

Pode-se notar pela Figura 29, que para todos os valores de densidade de corrente estudados, houve uma queda do $\mathrm{pH}$ durante as eletrólises, sendo que o decaimento aumentou com o aumento da densidade de corrente aplicada e estabilizou em aproximadamente 5.

Em ânodos ativos o processo de oxidação é parcial e seletivo, desse modo nesse processo, mediado por espécies de cloro ativo à medida que a oxidação procede, produtos ácidos são formados como intermediários de reação, sendo principalmente representados por ácidos carboxílicos, responsáveis pelo decaimento do $\mathrm{pH}$.

Um ligeiro decaimento no valor do $\mathrm{pH}$ também foi observado por Rossi et al. ${ }^{65}$ durante a eletro-oxidação da OTC utilizando um eletrodo de $\mathrm{RuO}_{2}$, o qual foi atribuído a formação de ácidos alifáticos.

Wu et $a l .{ }^{37}$, em um estudo utilizando $\mathrm{ADE}$ de composição $\mathrm{Ti} / \mathrm{RuO}_{2}-\mathrm{IrO}_{2}$, propuseram um mecanismo para a degradação oxidativa da $\mathrm{TeC}$ em que a etapa anterior a completa mineralização é caracterizada pela formação de ácidos carboxílicos de cadeia curta.

Uma vez que a degradação é realizada na presença de cloretos, não se pode descartar a possibilidade de formação de compostos clorados que possam apresentar maior toxicidade que o composto de origem, e que nesse caso não apenas a TeC pode gerar tais compostos, como também a creatinina e uréia. 


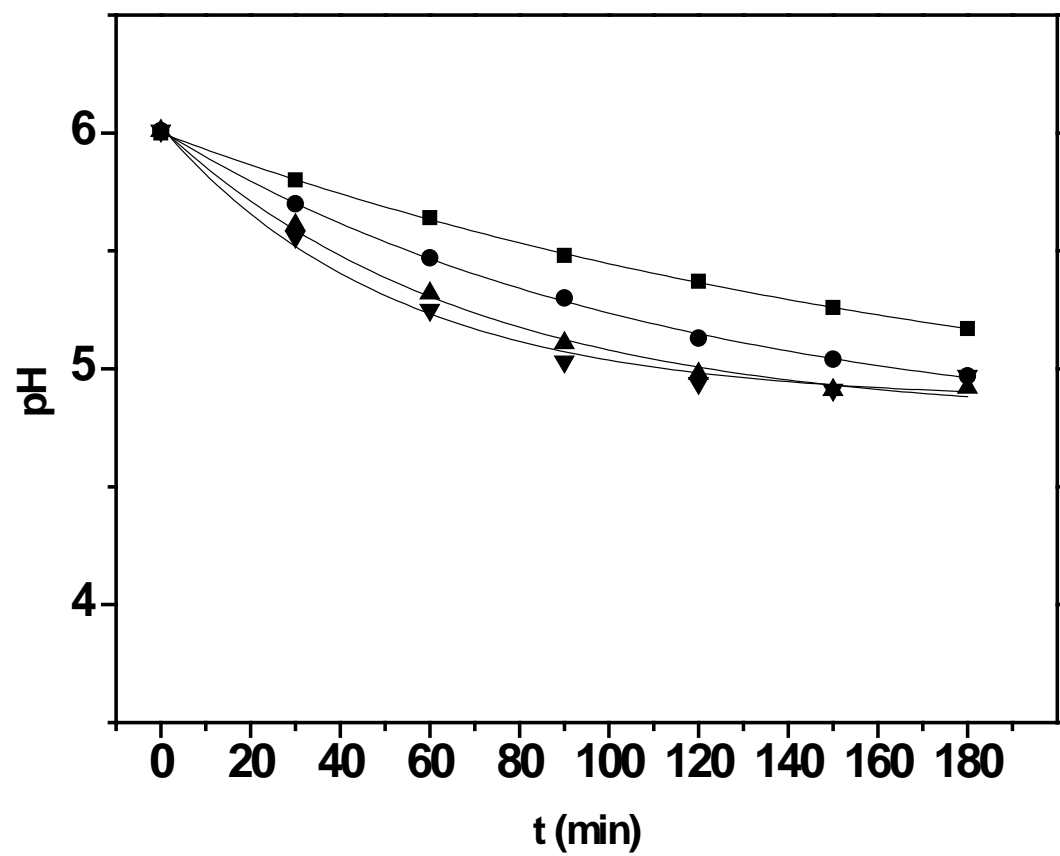

Figura 29 - Variação do pH ao longo do tempo de eletrólise em diferentes densidades

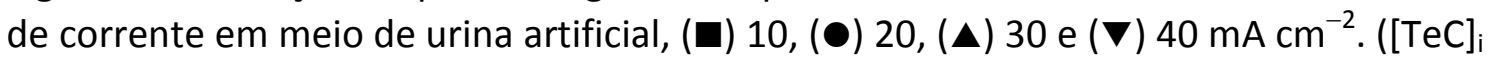
$=200 \mathrm{mg} \mathrm{L}^{-1}, \mathrm{~T}=25^{\circ} \mathrm{Ce} \mathrm{j}=30 \mathrm{~mA} \mathrm{~cm}^{-2}$ ).

De acordo com estudos desenvolvidos por Amstutz et $a l .^{48}$ a oxidação direta da uréia pode levar a formação de $\mathrm{CO}_{2}, \mathrm{~N}_{2}$ e outros produtos como $\mathrm{NO}_{2}, \mathrm{~N}_{2} \mathrm{O}$ e $\mathrm{NO}_{3}{ }^{-}$ enquanto que a oxidação indireta e mediada por espécies de cloro ativo podem gerar amônia e nitrato. A amônia formada ainda pode formar $\mathrm{N}_{2}$ e $\mathrm{NO}_{3}{ }^{-}$, porém também pode ser oxidada pelo ácido hipocloro eletrogerado e formar as cloroaminas de acordo com as Equações 23 a 25.

$\mathrm{NH}_{3}+\mathrm{HOCl} \rightarrow \mathrm{NH}_{2} \mathrm{Cl}+\mathrm{H}_{2} \mathrm{O}$

$\mathrm{NH}_{2} \mathrm{Cl}+\mathrm{HOCl} \rightarrow \mathrm{NHCl}_{2}+\mathrm{H}_{2} \mathrm{O}$

$\mathrm{NHCl}_{2}+\mathrm{HOCl} \rightarrow \mathrm{NCl}_{3}+\mathrm{H}_{2} \mathrm{O}$

Um estudo sobre a eletro-oxidação da TeC mediada por espécies de cloro ativo $^{70}$ apresentou como intermediários produtos de alto peso molecular que para os 
autores significa que não houve a quebra dos anéis, entretanto houve a formação de produtos clorados devido a reação de substituição por cloro.

Uma vez que ocorra a formação de cloroaminas, estas ainda podem reagir com a $\mathrm{TeC}$ de acordo com outro estudo mais recente ${ }^{71}$. Nele a oxidação da $\mathrm{TeC}$ foi investigada através da reação desta com cloroaminas, que servem como agentes oxidantes alternativos às espécies de cloro ativo. Nesse caso mais de 13 compostos foram identificados sendo que dentre os produtos, vários ainda continham a capacidade farmacológica da $\mathrm{TeC}$ e vários eram clorados, elevando a toxidade do meio em relação ao composto original e demonstrando que bastante atenção deve ser dada à formação desses compostos.

\subsection{ESTUDO DO PH INICIAL}

$\mathrm{O}$ estudo do $\mathrm{pH}$ em sistemas contendo tetraciclinas caracteriza-se por ser complexo uma vez que, dependendo do $\mathrm{pH}$ do meio, as tetraciclinas possuem vários grupos doadores de prótons que oferecem diferentes possibilidades de formar complexos com íons metálicos divalentes e outros compostos orgânicos ${ }^{72}$.

De acordo com Snoeyink et al. ${ }^{73}$ em águas superficiais os valores de $\mathrm{pH}$ comumente encontrados variam entre 5,5 e 8,5, além disso, as concentrações de $\mathrm{Ca}^{2+}$ e $\mathrm{Mg}^{2+}$ variam entre $10^{-4.6}-10^{-2.4}$ e $10^{-4.5}-10^{-2.8} \mathrm{~mol} \mathrm{~L}^{-1}$, respectivamente, sendo que entre os vários íons presentes em águas naturais, esses se destacam por geralmente formarem, dependendo do $\mathrm{pH}$, complexos com alguns fármacos, como a TeC por exemplo.

O meio de urina, por sua vez, situa-se em valores próximos do $\mathrm{pH}$ neutro ou levemente ácido e, além disso, costumam apresentar altas concentrações de $\mathrm{Ca}^{2+} \mathrm{e}$ $\mathrm{Mg}^{2+}$, requerendo dessa forma atenção aos estudos da variação do $\mathrm{pH}$ nesse meio. Dessa forma, os valores de $\mathrm{pH}$ estudados foram 5,0 , 6,0 e 7,0.

Ao ajustar o pH da urina artificial para 7,0 através da adição de hidróxido de sódio $5,0 \mathrm{~mol} \mathrm{~L}^{-1}$, verificou-se que a solução adquiriu coloração turva a medida que o $\mathrm{pH}$ foi sendo elevado e lentamente foi decantando um sólido de coloração mais clara e, com o tempo, a solução perdeu a homogeneidade, conforme mostra a Figura 30. 

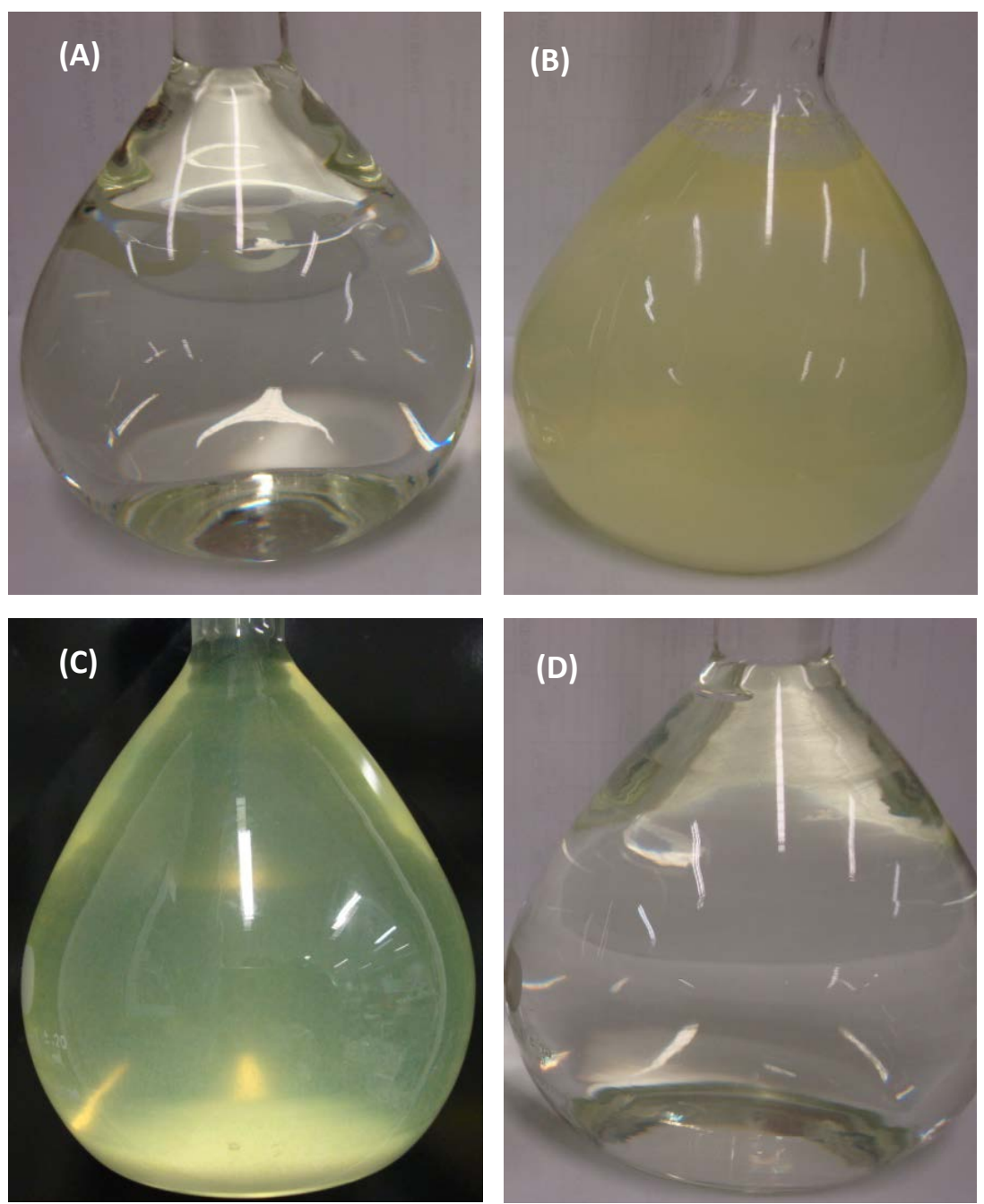

Figura 30 - Aspecto visual das soluções de $\mathrm{TeC}$ em meio de urina artificial. (a) $\mathrm{pH}=6,0$. (b) $\mathrm{pH}=7,0$ antes de decantar o precipitado. (c) $\mathrm{pH}=7,0$ após decantação em fundo preto. (d) $\mathrm{pH}=7,0$ após adição de $\mathrm{Na}_{2}$ EDTA. 
Um fator que pode ter contribuído para esse fenômeno é a complexação em valores de $\mathrm{pH}$ acima de $6 \mathrm{da} \mathrm{TeC}$ em meio que contenha $\mathrm{Ca}^{2+}$, como é o caso do meio de urina.

Um estudo sobre a influência do $\mathrm{Ca}^{2+}$ na adsorção da $\mathrm{TeC}$ em montimorilonita ${ }^{74}$, mostrou que reações de dissociação da TeC levam a formação de quatro espécies distintas de $\mathrm{TeC}$ em meio aquoso, sendo elas: catiônica $\left(\mathrm{TeCH}_{3}^{+}\right)$, zwitteriônica $\left(\mathrm{TeCH}_{2}^{ \pm}\right)$, e duas aniônicas $\left(\mathrm{TeCH}^{-}\right)$e $\left(\mathrm{TeC}^{2-}\right)$, em meio ácido, levemente ácido à neutro e alcalino, respectivamente. Entretanto, devido alguns grupos doadores de elétrons da molécula de $\mathrm{TeC}$, na presença de $\mathrm{Ca}^{2+}$ espécies adicionais surgem, em um processo dependente do $\mathrm{pH}$. Desse modo, observa-se que até $\mathrm{pH}$ próximo de 6 não há formação de complexos $\mathrm{Ca}-\mathrm{TeC}$, porém, acima desse valor várias espécies de complexos podem coexistir com predominância do complexo $\mathrm{Ca}(\mathrm{TCH})_{2}$ em pH 7 .

A partir disso, para pH inicial de 7,0 foi decidido adicionar um sal sódico de etilenodiaminotetraacético ( $\mathrm{Na}_{2} \mathrm{EDTA}$ ) como agente quelante, capaz de formar um quelato com o $\mathrm{Ca}^{2+}$ do meio, como mostrado na Figura 31.

É possível observar pela Figura 32 que o espectro de absorção da TeC foi modificado a pH 7,0 apresentando efeito hipercrômico, que após adição de $\mathrm{Na}_{2} \mathrm{EDTA}$ retorna ao original. 


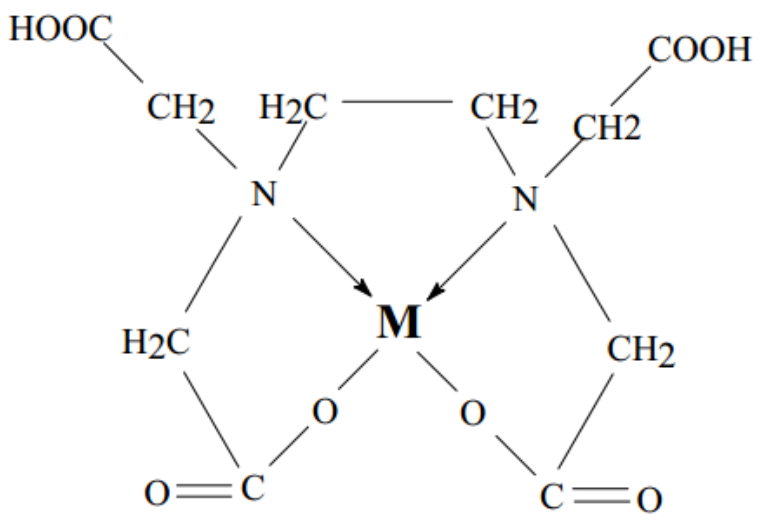

Figura 10 - Representação esquemática do quelato formado entre EDTA e um cátion bivalente $\left(\mathrm{M}=\mathrm{Ca}^{2+}, \mathrm{Mg}^{2+}, \mathrm{Zn}^{2+} \text { etc. }\right)^{75}$.

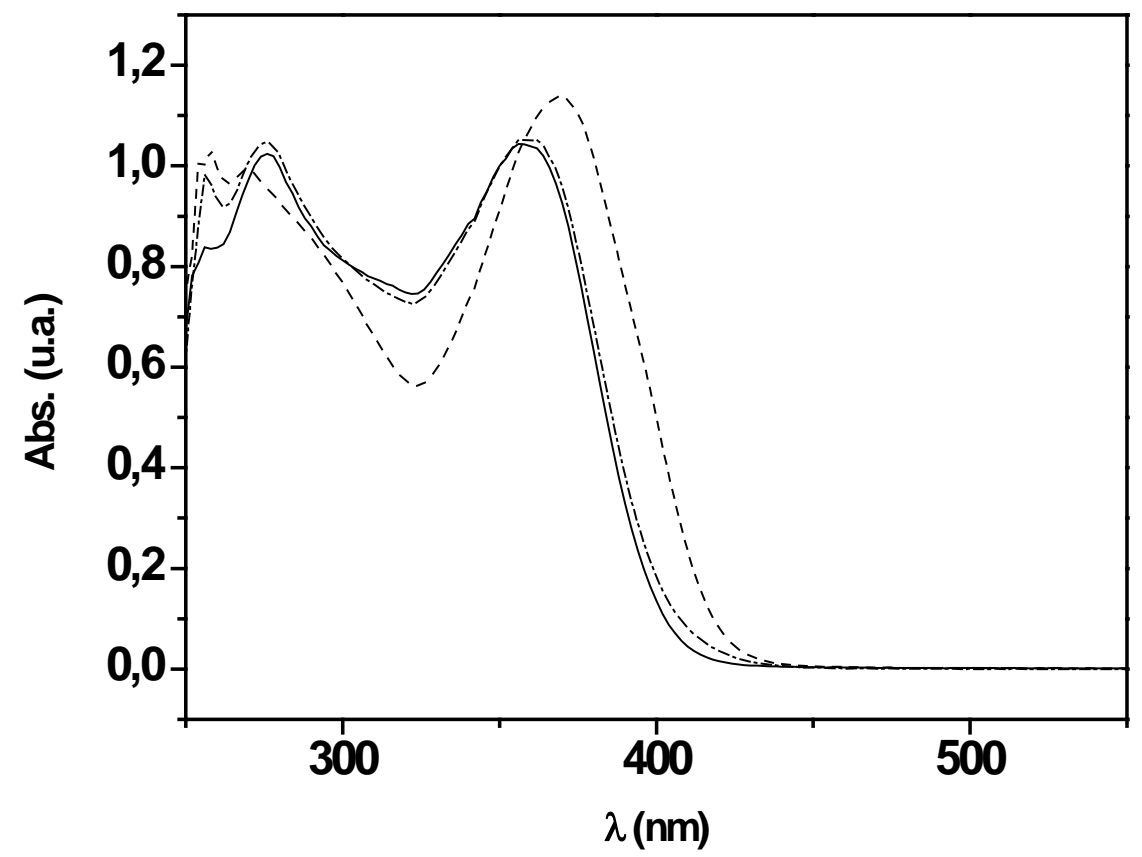

Figura 11 - Espectro de absorção no UV da TeC em meio de urina artificial em diferentes valores de $\mathrm{pH}$ inicial, (-) pHi $=6,0$, (---) $\mathrm{pHi}=7,0$ antes da adição de $\mathrm{Na}_{2}$ EDTA (---) pHi $=7,0$ após adição de $\mathrm{Na}_{2}$ EDTA. ([TeC $]_{i}=200 \mathrm{mg} \mathrm{L}^{-1}, \mathrm{~T}=25^{\circ} \mathrm{C}$ ).

Desse modo, após adição de $\mathrm{Na}_{2} \mathrm{EDTA}$, ajuste do $\mathrm{pH}$ para 7,0 e tratamento eletroquímico por três horas em meio de urina artificial foi observado que houve pequena diferença na remoção do antibiótico com a variação do pH inicial, sendo que o aumento do pH inicial provocou remoção mais rápida (Figura 33). 


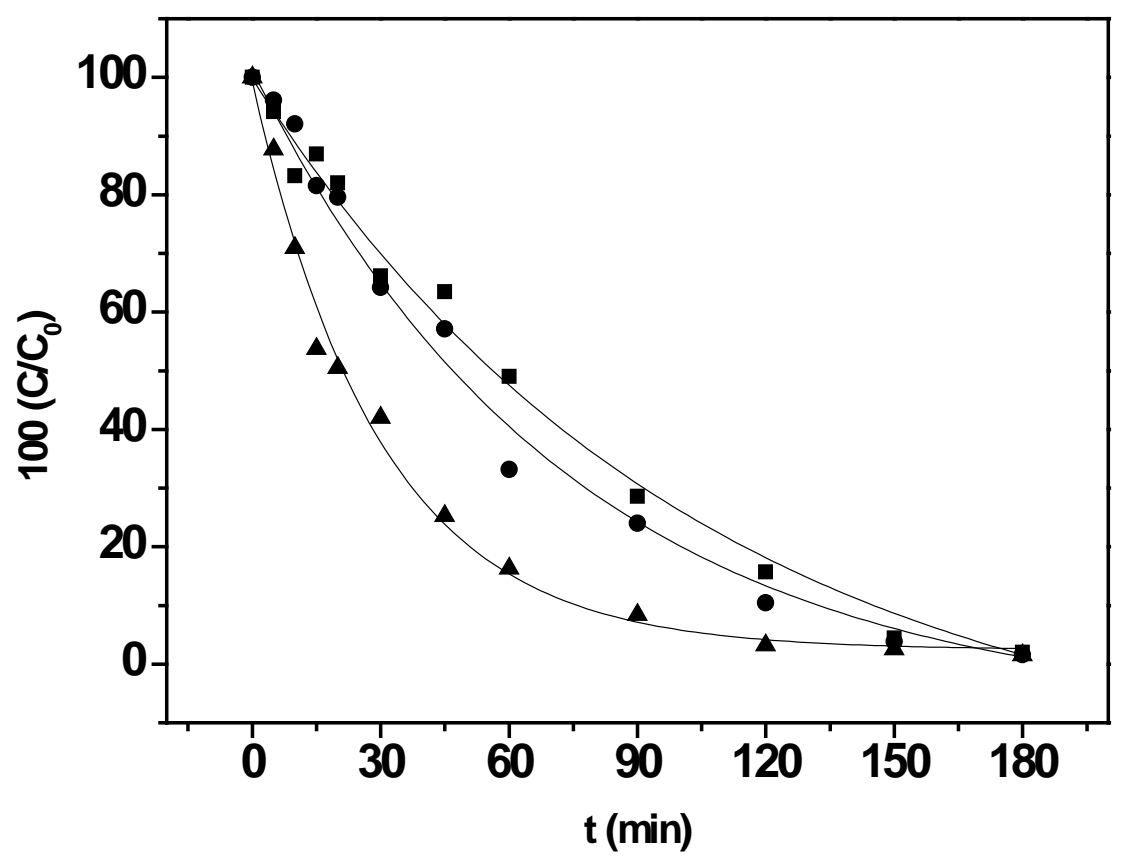

Figura 33 - Decaimento da $\mathrm{TeC}$ ao longo do tempo de eletrólise em diferentes valores de $\mathrm{pH}$ inicial, (ם) $\mathrm{pHi}=5,0,(\bullet) \mathrm{pHi}=6,0$ e $(\mathbf{\Delta}) \mathrm{pHi}=7,0$ após adição de $\mathrm{Na}_{2} \mathrm{EDTA}$. $\left([\mathrm{TeC}]_{\mathrm{i}}=200 \mathrm{mg} \mathrm{L}^{-1}, \mathrm{~T}=25^{\circ} \mathrm{Ce} \mathrm{j}=30 \mathrm{~mA} \mathrm{~cm}^{-2}\right)$.

Tendo em vista que o pH inicial igual a 7,0 provocou uma degradação ligeiramente mais rápida em relação aos outros valores, levantou-se a hipótese de que a presença desse agente complexante tenha interferido no processo. Então, realizouse também eletrólises nos pH iniciais iguais a 5,0 e 6,0, adicionando-se EDTA.

Considerando que não houve alteração significativa nas velocidades de reação, também de pseudo-primeira ordem, conforme observado na Figura 34, verificou-se que a adição de $\mathrm{Na}_{2}$ EDTA na urina artificial a ser tratada não interferiu na velocidade de degradação da TeC.

A Tabela 7 mostra as constantes cinéticas de pseudo 1a ordem. À medida que o potencial hidrogeniônico foi elevado, notou-se um ligeiro aumento na velocidade de reação. 


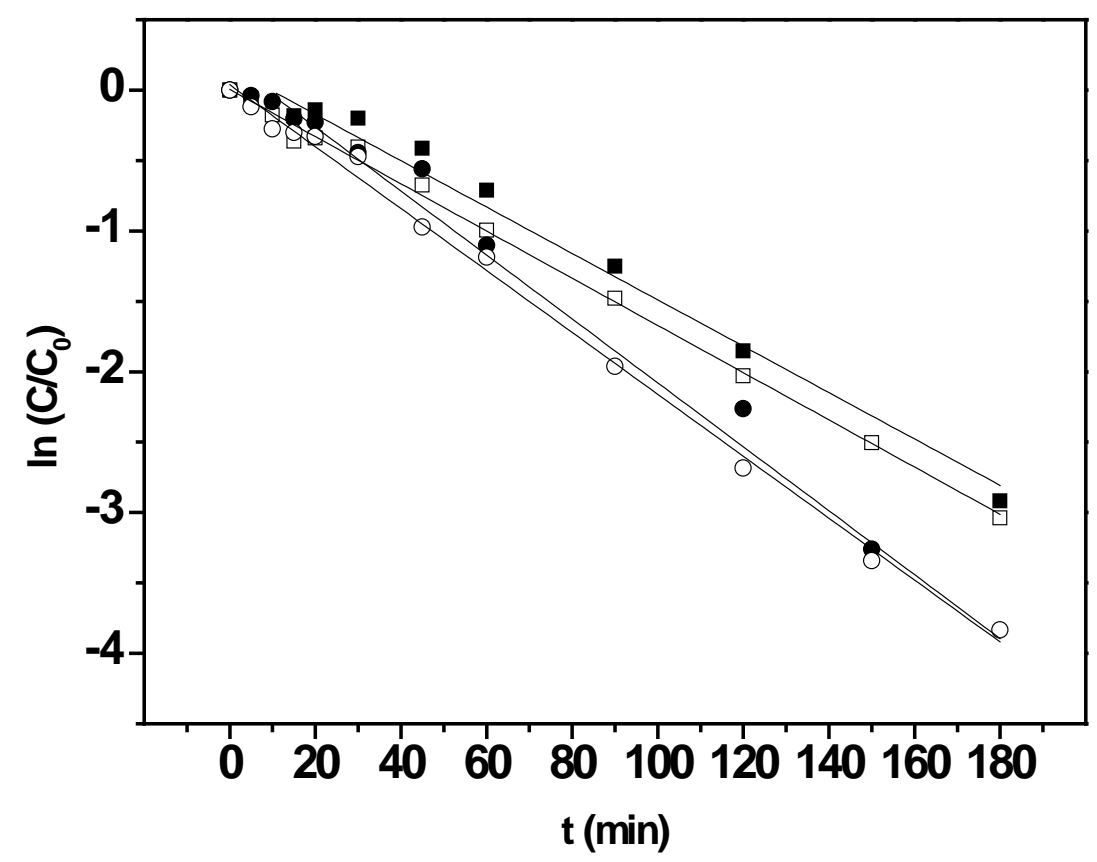

Figura 34 - Ajuste da constante cinética de pseudo-primeira ordem para as concentrações relativas em diferentes valores de $\mathrm{pH}$ inicial, $(\square) \mathrm{pHi}=5,0,(\square) \mathrm{pHi}=5,0$ com adição de $\mathrm{Na}_{2}$ EDTA, (๑) pHi = 6,0 e (O) pHi = 6,0 com adição de $\mathrm{Na}_{2}$ EDTA.

Tabela 8 - Constantes cinéticas de pseudo 1ao ordem

\begin{tabular}{|c|c|c|}
\hline $\mathrm{pH}_{\text {inicial }}$ & $\begin{array}{l}\text { k } \times 10^{-2} \min ^{-1} \\
\left(\text { sem } \mathrm{Na}_{2} \text { EDTA) }\right.\end{array}$ & $\begin{array}{l}\mathrm{k} \times 10^{-2} \mathrm{~min}^{-1} \\
\left(\mathrm{com} \mathrm{Na}{ }_{2} \mathrm{EDTA}\right)\end{array}$ \\
\hline 5 & 1,58 & 1,68 \\
\hline 6 & 2,27 & 2,20 \\
\hline 7 & -------- & 2,50 \\
\hline
\end{tabular}

Considerando o intervalo de $\mathrm{pH}$ estudado, foi possível concluir que o aumento deste causa aumento na velocidade de reação, mas sem influência na taxa de remoção do antibiótico durante três horas de eletrólise. Além disso, a adição de $\mathrm{Na}_{2}$ EDTA não causa interferência na eletro-oxidação, uma vez que para os pH iniciais iguais a 5 e 6 , não houve alteração significativa nas constantes de velocidade de pseudo primeira ordem. 
Resultados contraditórios tem sido obtidos em trabalhos envolvendo a variação do $\mathrm{pH}$ durante processos eletroquímicos. Um estudo sobre a eletro-oxidação da TeC direta em ânodo de $\mathrm{Ti} / \mathrm{RuO}_{2}-\mathrm{IO}_{2}$ em meio de $\mathrm{Na}_{2} \mathrm{SO}_{4}$ mostrou que ampla variação do $\mathrm{pH}$ não interferiu significativamente na remoção do antibiótico ${ }^{38}$. Entretanto, Wu et al. ${ }^{37}$, ao utilizarem o mesmo eletrólito suporte, observaram efeito negativo do $\mathrm{pH}$ durante o tratamento eletroquímico, ou seja, a remoção é favorecida em valores de $\mathrm{pH}$ mais baixos.

Entretanto, no presente meio estudado contendo cloreto, os resultados obtidos são consistentes com o fato de que tanto a TeC quanto as espécies de cloro ativo podem se apresentar como diferentes espécies dependendo do $\mathrm{pH}$ do meio. Assim, em um processo mediado por espécies de cloro ativo eletrogeradas, a variação na constante de velocidade com o pH pode ser atribuída a reações ácido-base específicas entre espécies de TeC e de cloro ativo.

Tal fenômeno pode ser melhor compreendido através da análise da Figura 35 e 36. A primeira mostra o perfil das espécies de cloro ativo em função do $\mathrm{pH}^{76}$ e a segunda mostra as reações entre várias tetraciclinas com dióxido de cloro e espécies de cloro ativo em um trabalho desenvolvido por Wang et al. ${ }^{70}$.

De acordo com a Figura 36, a constante de velocidade de segunda ordem (círculos pretos) é caracterizada por conter um máximo em pH aproximadamente 7 e um mínimo em aproximadamente 4. De acordo com os autores, em um sistema contendo $\mathrm{TeC}$ e espécies de cloro ativo, a medida que o $\mathrm{pH}$ torna-se superior a 4 a velocidade de remoção aumenta. Isso se deve porque a TeC passa a predominar na forma zeuteriônica $(3,3<\mathrm{pH}<7,6)$ e a espécie de cloro ativo predominante nessa faixa é a $\mathrm{HClO}$ (Figura 36), o qual é um bom eletrófilo reagindo com o grupo dimetilamino grupos fenólicos e cetônicos desprotonados da TeC. Porém, em valores de $\mathrm{pH}$ acima de 7,6 embora a TeC se apresente predominantemente nas formas aniônicas, a espécie de cloro ativo predominante é a $\mathrm{ClO}^{-}$, que em geral é um eletrófilo mais fraco que o $\mathrm{HClO}$ e assim a degradação diminui. Por outro lado, em valores de $\mathrm{pH}$ abaixo de 4,5 ocorre a formação de $\mathrm{H}_{2} \mathrm{OCl}^{+}$e $\mathrm{Cl}_{2}$ que são eletrófilos mais fortes que $\mathrm{HClO}$. Assim, de modo geral a constante de velocidade possui valor mais elevados em $\mathrm{pH}$ aproximadamente 2 e um máximo perto de 7,5 como é observado na Figura 36. 


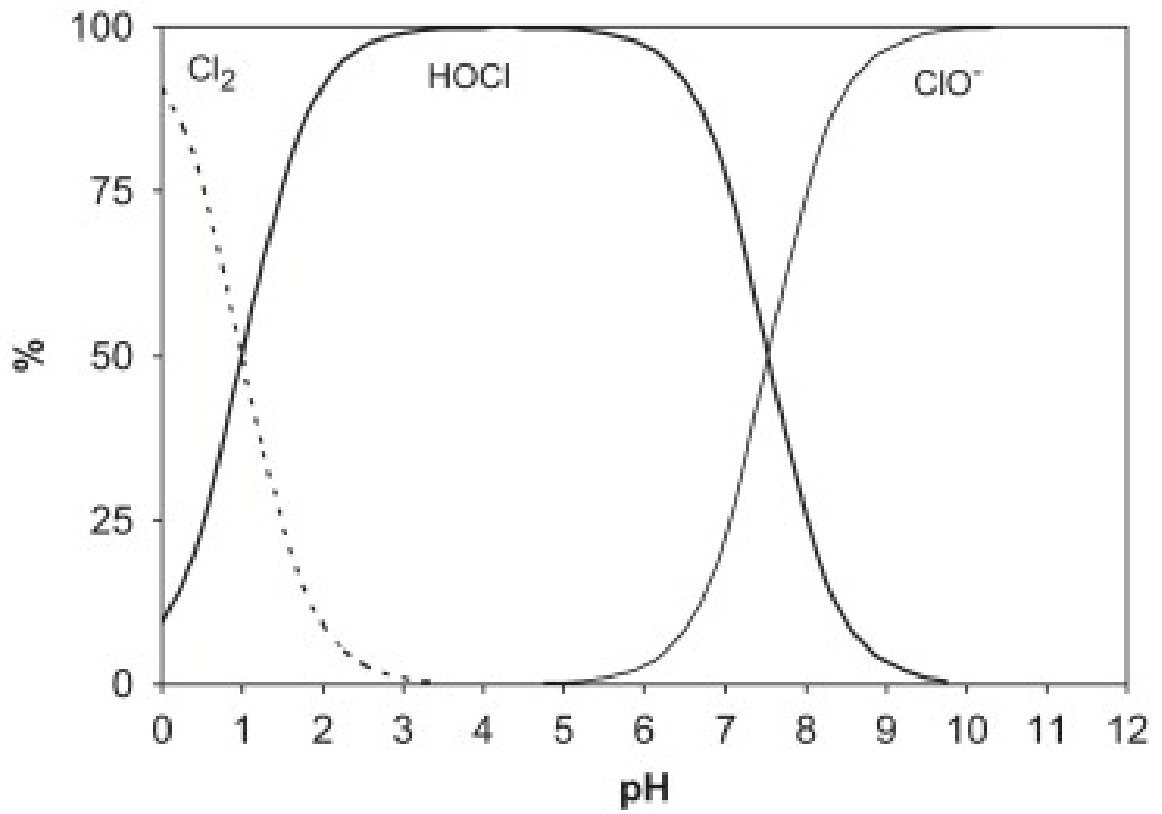

Figura 35 - Perfil das espécies de cloro ativo em função do $\mathrm{pH}^{76}$.

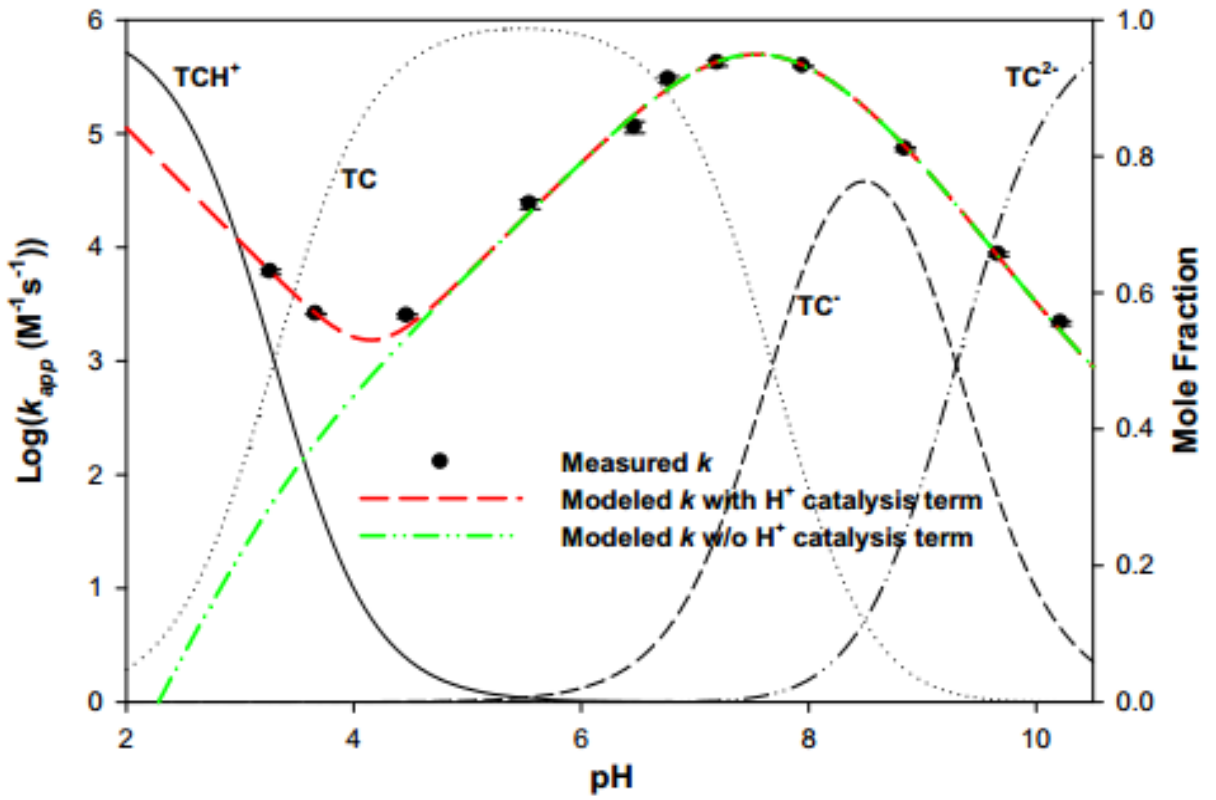

Figura 36 - Efeito do pH e modelo cinético para as constantes de velocidade de reação entre TeC e espécies de cloro ativo

Pode-se notar também pela Figura 37, que em pH iniciais de 5 e 6 na ausência de $\mathrm{Na}_{2} \mathrm{EDTA}$, houve uma queda de $\mathrm{pH}$ durante as eletrólises seguido de um ligeiro aumento ao final. Na presença de $\mathrm{Na}_{2} \mathrm{EDTA}$, foi observado que o $\mathrm{pH}$ inicial igual a 6 , manteve-se praticamente constante durante as 3 horas de degradação enquanto que o pH inicial igual a 7 caiu e o pH inicial igual a 5 aumentou, indicando uma tendência em aproximar-se de 6 para os casos. 


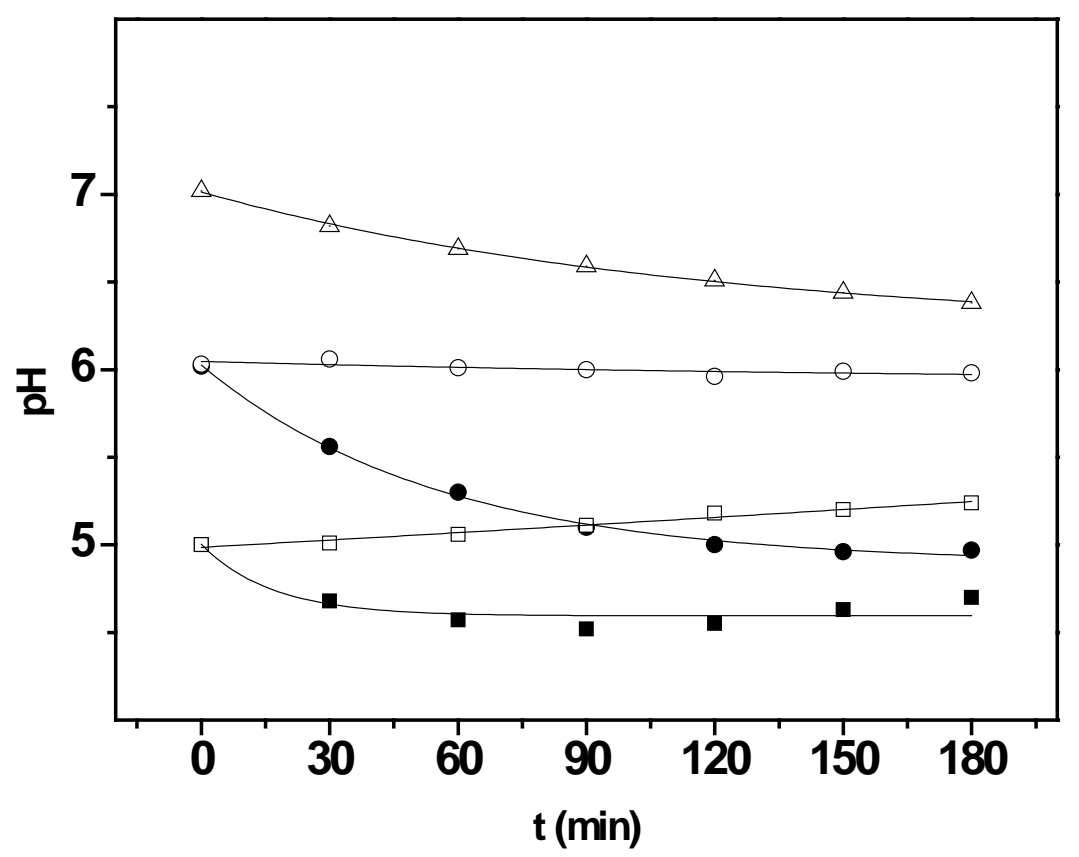

Figura 37 - Variação do $\mathrm{pH}$ ao longo do tempo de eletrólise a partir de diferentes valores de $\mathrm{pH}$ inicial. Símbolos cheios: sem adição de $\mathrm{Na}_{2} \mathrm{EDTA}$; símbolos vazios: com adição de $\mathrm{Na}_{2} \mathrm{EDTA},(\boldsymbol{\square}, \square) \mathrm{pHi}=5,00,(\bullet, 0) \mathrm{pHi}=6,00,(\triangle) \mathrm{pHi}=7,00 .\left([\mathrm{TeC}]_{\mathrm{i}}=200 \mathrm{mg}\right.$ $\mathrm{L}^{-1}, \mathrm{~T}=25^{\circ} \mathrm{Ce} \mathrm{j}=30 \mathrm{~mA} \mathrm{~cm}{ }^{-2}$ ).

É provável que durante a degradação, semelhantes intermediários foram formados, sendo eles os principais responsáveis pela alteração do pH. Assim, intermediários mais ácidos foram produzidos a taxas semelhantes no meio sem EDTA, porém maiores que no meio com EDTA, por isso houve maior variação de pH nos estudo sem a presença de EDTA.

Na faixa de $\mathrm{pH}$ estudada (5 - 7) a formação de $\mathrm{HClO}$ (forte agente oxidante) é superior a de $\mathrm{OCl}^{-}$resultando em porcentagens de remoção superiores a 98 \% em todos os casos e velocidades de degradação semelhante para todos os casos.

Do mesmo modo que para o estudo de densidade de corrente, durante a análise do pH inicial, também não houve, para todos os casos, variação significativa, ao longo do tempo, das concentrações de creatinina e uréia, e consequentemente, do teor de carbono orgânico total, como é observado na Figura 38. 


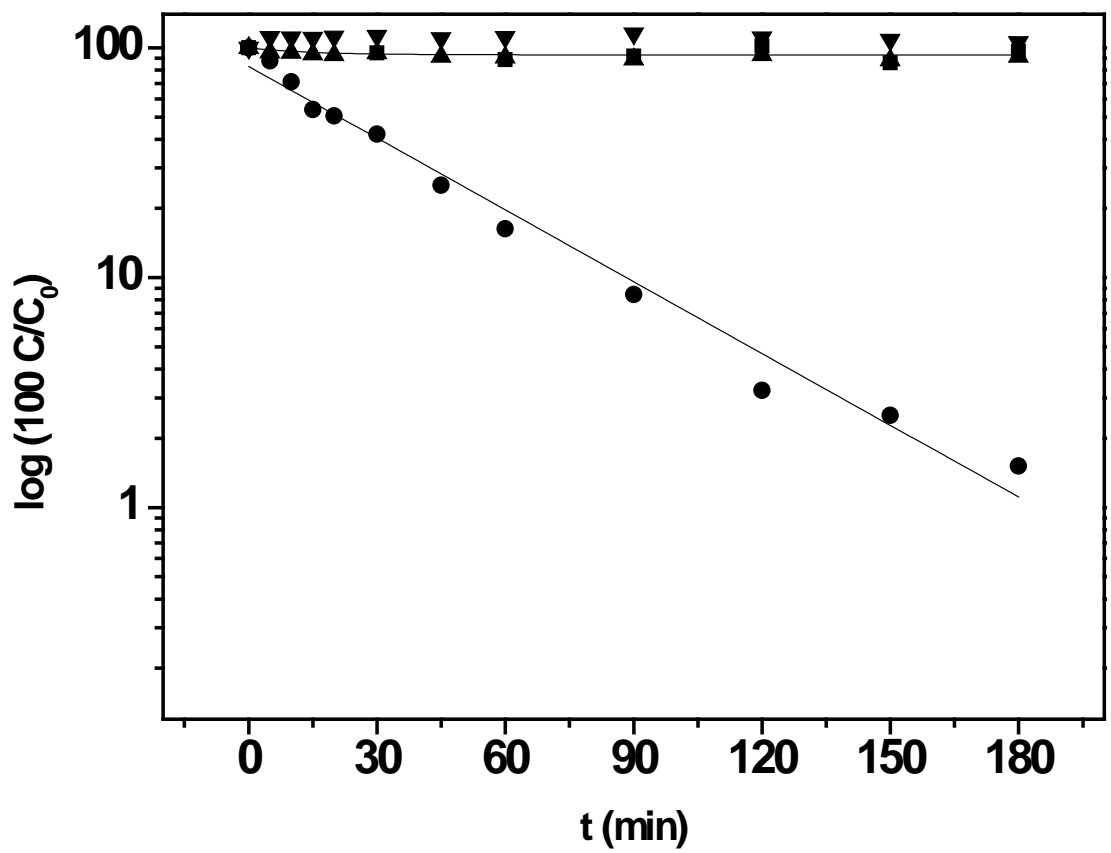

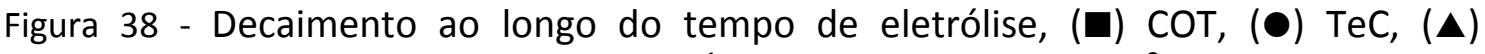
creatinina e $(\nabla)$ uréia. $\left([\mathrm{TeC}]_{i}=200 \mathrm{mg} \mathrm{L}^{-1}, \mathrm{~T}=25^{\circ} \mathrm{C}, \mathrm{j}=30 \mathrm{~mA} \mathrm{~cm}^{-2}\right.$ e pHi $\left.=7,0\right)$.

Vale ressaltar, porém, que a presença de $\mathrm{Na}_{2} \mathrm{EDTA}$, não interferiu na análise da TeC, creatinina e uréia, porém, elevou o teor de carbono orgânico total, que foi de aproximadamente 5,5 para $6 \mathrm{~g} \mathrm{~L}^{-1}$.

Assim, conclui-se que a TeC pode ser degradada seletivamente pelo método eletroquímico em valores de $\mathrm{pH}$ iniciais próximos ao $\mathrm{pH}$ da urina (6) em um tempo total de 3 horas, devido a atuação das espécies de cloro ativo eletrogeradas em meio de urina artificial que atuam sob a eletro-oxidação do composto de interesse mesmo sob a presença de creatinina, uréia e até mesmo EDTA, sendo que a TeC na forma zeuteriônica e a maior proporção de $\mathrm{HOCl}$ em pH igual a 7, favorecem a degradação. 


\section{Conclusões e Perspectivas Futuras}

Considerando os dados obtidos a partir do presente estudo, conclui-se que a TeC sofre degradação eletroquímica mesmo em um meio mais complexo em relação ao meio aquoso, como é o meio de urina artificial.

A remoção desse antibiótico, utilizando um ADE, provou ser possível e seletiva devido à eletrogeração de espécies oxidantes de cloro ativo a partir do cloreto presente no meio.

O decaimento da concentração da TeC ajustou-se a uma cinética de pseudoprimeira ordem e aumentou como o aumento da densidade de corrente aplicada, sendo que o perfil do decaimento em função da carga específica foi o mesmo para todas as densidades de corrente.

Devido à baixa mineralização apresentada, a degradação da TeC ocorreu por meio da geração de intermediários de reação com maior polaridade.

$\mathrm{O}$ tratamento eletroquímico pode ser realizado em valores de $\mathrm{pH}$ próximos ao neutro, em que a TeC na forma zeuteriônica e a espécie $\mathrm{HOCl}$, favorecem a degradação, mesmo na presença de EDTA, porém a adição deste último composto, eleva o teor de carbono orgânico do meio, não sendo assim recomendado.

A presença de creatinina e uréia interferem no processo eletroquímico, devido a diminuição dos sítios eletroativos do eletrodo e fazem com que a degradação da TeC apresente velocidades de reação mais baixas e o consumo energético do processo é mais elevado do que em meio aquoso contendo $\mathrm{NaCl}$.

Considerando a importância de estudos de degradação de fármacos por métodos eletroquímicos, as particularidades da $\mathrm{TeC}$ tanto em solução aquosa quanto em outras matrizes como urina artificial e os resultados obtidos até o momento, temse que futuramente é interessante e relevante a extensão desse estudo para avaliação de fatores como:

- A extensão da mineralização pela produção de nitrogênio total, amônia total, nitrato e nitrito.

- Diminuir a concentração inicial da TeC;

- Após avaliação dos processos eletroquímicos, deve-se investigar a rota de degradação da TeC, entendendo o mecanismo de degradação, principais 
intermediários formados e possibilidade de formação de produtos clorados. Para isso, análises de cromatografia gasosa ou cromatografia líquida com detecção por espectrometria de massa, devem ser realizadas;

- É de suma importância realizar estudos de toxicidade nas soluções tratadas, para avaliação de formação de intermediário com potencial antimicrobiano semelhante ou ainda maior que o composto de origem, principalmente ao realizar o tratamento eletroquímico em um meio com alta concentração de cloreto;

- Analisar a aplicação do método eletroquímico no tratamento de urina contendo mistura de antibióticos. 


\section{REFERÊNCIAS BIBLIOGRÁFICAS}

1. ONESIOS, K.; YU, J.; BOUWER, E. Biodegradation and removal of pharmaceuticals and personal care products in treatment systems: a review. Biodegradation, v. 20, n. 4, p. 441-466, 2009.

2. BOYD, G. R.; PALMERI, J. M.; ZHANG, S.; GRIMM, D. A. Pharmaceuticals and personal care products (PPCPs) and endocrine disrupting chemicals (EDCs) in stormwater canals and Bayou St. John in New Orleans, Louisiana, USA. Science of The Total Environment, v. 333, n. 1-3, p. 137-148, 2004.

3. DU, L.; LIU, W. Occurrence, fate, and ecotoxicity of antibiotics in agro-ecosystems. A review. Agronomy for Sustainable Development, v. 32, n. 2, p. 309, 2012.

4. KOROLKOVAS, A.; BURCKHALTER, J. H. Química farmacêutica. Rio de Janeiro: Guanabara Dois, 1982.782 p.

5. NOGRADY, T.; WEAVER, D. F. Medicinal chemistry: a molecular and biochemical approach. 3rd ed. New York: Oxford University Press, 2005. 649 p.

6. SARMAH, A. K.; MEYER, M. T.; BOXALL, A. B. A. A global perspective on the use, sales, exposure pathways, occurrence, fate and effects of veterinary antibiotics (VAs) in the environment. Chemosphere, v. 65, n. 5, p. 725-759, 2006.

7. MITEMA, E. S. KIKUVI, G. M.; WEGENER, H. C.; STOHR, K. An assessment of antimicrobial consumption in food producing animals in Kenya. Journal Of Veterinary Pharmacology And Therapeutics, v. 24, n. 6, p. 385-390, 2001.

8. NELSON, M. L.; LEVY, S. B. The history of the tetracyclines. Annals of the New York Academy of Sciences, v. 1241, n. 1, p. 17-32, 2011.

9.CHAREST, M. G.; LERNER, C. D.; BRUBAKER, J. D.; SIEGEL, D. R.; MYERS, A. G. A. Convergent enantioselective route to structurally diverse 6-deoxytetracycline antibiotics. Science, v. 308, n. 5720, p. 395-398, 2005.

10. CHEN, Y. C.; LIN, C. E. Migration behavior and separation of tetracycline antibiotics by micellar electrokinetic chromatography. Journal of Chromatography A, v. 802, n. 1, p. 95-105, 1998.

11. RIGLER, N. E.; BAG, S. P.; LEYDEN, D. E.; SUDMEIER, J. L.; REILLEY, C. N. Determination of a protonation scheme of tetracycline using nuclear magnetic resonance. Analytical Chemistry, $v$. 37, n. 7, p. 872-875, 1965.

12. CAÇO, A. I.; VARANDA, F. T.; PRATAS DE MELO, M. J.; DIAS, A. M. A.; DOHRN, R.; MARRUCHO, I. M. Solubility of antibiotics in different solvents. Part II. non-hydrochloride forms of tetracycline and ciprofloxacin. Industrial \& Engineering Chemistry Research, v. 47, n. 21 , p. 8083-8089, 2008

13. VARANDA, F.; PRATAS DE MELO, M. J.; CAÇO, A. I.; DOHRN, R.; MAKRYDAKI, F. A.; VOUTSAS, E.; TASSIOS, D.; MARRUCHO, I. M. Solubility of antibiotics in different solvents. 1. hydrochloride forms of tetracycline, moxifloxacin, and ciprofloxacin. Industrial \& Engineering Chemistry Research, v. 45, n. 18, p. 6368-6374, 2006. 
14. TRICANGINE-A ${ }^{\circledast}$ : creme. Farmacêutico Responsável Wilson R. Farias. Guarulhos: Ache Laboratórios Farmacêutico, 2007. Bula de remédio.

15. TETRACICLINA + ANFOTERICINA B: creme. Farmacêutico Responsável Miriam O. Fujisawa. Campinas: Medley S.A. Indústria Farmacêutica, [20--?]. Bula de remédio.

16. WILLIAMS, D. A.; LEMKE, T. L. Foye's principles of medicinal chemistry. 5th ed. Philadelphia: Lippincott Williams \& Wilkins, 1974. 1114 p.

17. CLORIDRATO DE TETRACICLINA: cápsulas. Farmacêutico Responsável Luiz Donaduzzi. Toledo: Prati-Donaduzzi, [20--?]. Bula de remédio.

18. OH, Y. H.; HAN, H. K. Pharmacokinetic interaction of tetracycline with non-steroidal antiinflammatory drugs via organic anion transporters in rats. Pharmacological Research, v. 53, n. 1, p. 75-79, 2006.

19. CUNHA, B. A.; GARABEDIAN-BUFFALO, S. M. Tetracyclines in urology: current concepts. Urology, v. 36, n. 6, p. 548-556, 1990.

20. WITTE, W. Medical consequences of antibiotic use in agriculture. Science, v. 279, n. 5353, p. 996, 1998.

21. SANTOS, N. D. Q.; CATARINA, U. F. D. S. Bacterial resistence in the context of hospital infection. Texto \& Contexto - Enfermagem, v. 13, n. SPE, p. 64-70, 2004.

22. LEAL, R. M. P. Ocorrência e comportamento ambiental de resíduos de antibióticos de uso veterinário. 2012. 134 f. Tese (Doutorado em Ciências)- Centro de Energia Nuclear na Agricultura, Universidade de São Paulo, Piracicaba, 2012.

23. WEI, X.; WU, S. C.; NIE, X. P. The effects of residual tetracycline on soil enzymatic activities and plant growth. Journal of Environmental Science \& Health, Part B: Pesticides, Food Contaminants, \& Agricultural Wastes, v. 44, n. 5, p. 461-471, 2009.

24. HUET, A. C.; CHARLIER, C.; SINGH, G.; GODEFROY, S. B.; LEIVO, J.; VEHNIÄINEN, M.; NIELEN, M. W. F.; WEIGEL, S.; DELAHAUT, P. Development of an optical surface plasmon resonance biosensor assay for (fluoro)quinolones in egg, fish, and poultry meat. Analytica Chimica Acta, v. 623 , n. 2, p. 195-203, 2008.

25. ALLISON, J. R. D. Antibiotic residues in milk. British Veterinary Journal, v. 141, n. 1, p. 9-16, 1985.

26. BRIGANTE, M.; SCHULZ, P. C. Adsorption of the antibiotic minocycline on cerium(IV) oxide: Effect of $\mathrm{pH}$, ionic strength and temperature. Microporous and Mesoporous Materials, v. 156, p. 138-144, 2012.

27. MUTHURAMAN, G.; MOON, I. S. A review on an electrochemically assisted-scrubbing process for environmental harmful pollutant's destruction. Journal of Industrial and Engineering Chemistry, v. 18, n. 5, p. 1540-1550, 2012. 
28. KORNAROS, M.; LYBERATOS, G. Biological treatment of wastewaters from a dye manufacturing company using a trickling filter. Journal of Hazardous Materials, v. 136, n. 1, p. 95-102, 2006.

29. RAJESHWAR, K.; IBANEZ, J. G.; SWAIN, G. M. Electrochemistry and the environment. Journal of Applied Electrochemistry, v. 24, n. 11, p. 1077-91, 1994.

30. COMNINELLIS, C. Electrocatalysis in the electrochemical conversion/combustion of organic pollutants for waste water treatment. Electrochimica Acta, v. 39, n. 11-12, p. 1857-1862, 1994.

31. BONFATTI, F.; FERRO, S.; LAVEZZO, F.; MALACARNE, M.; LODI, G.; DE BATTISTI, A. Electrochemical incineration of glucose as a model organic substrate. II. role of active chlorine mediation. Journal of The Electrochemical Society, v. 147, n. 2, p. 592-596, 2000.

32. SIMOND, O.; SCHALLER, V.; COMNINELLIS, C. Theoretical model for the anodic oxidation of organics on metal oxide electrodes. Electrochimica Acta, v. 42, n. 13-14, p. 2009-2012, 1997.

33. KAPALKA, A.; FOTI, G.; COMNINELLIS, C. Kinetic modelling of the electrochemical mineralization of organic pollutants for wastewater treatment. Journal of Applied Electrochemistry, v. 38, n. 1, p. 7-16, 2008.

34. TURRO, E.; GIANNIS, A.; COSSU, R.; GIDARAKOS, E.; MANTZAVINOS, D.; KATSAOUNIS, A. Reprint of: electrochemical oxidation of stabilized landfill leachate on DSA electrodes. Journal of Hazardous Materials, v. 207-208, p. 73-78, 2012.

35. MARTÍNEZ-HUITLE, C. A.; BRILLAS, E. Decontamination of wastewaters containing synthetic organic dyes by electrochemical methods: a general review. Applied Catalysis B:

Environmental, v. 87, n. 3-4, p. 105-145, 2009.

36. COMNINELLIS, C.; VERCESI, G. P. Characterization of DSA-type oxygen evolving electrodes: choice of a coating. Journal of Applied Electrochemistry, v. 21, n. 4, p. 335-45, 1991.

37. WU, J.; ZHANG, H.; OTURAN, N.; WANG, Y.; CHEN, L.; OTURAN, M. A. Application of response surface methodology to the removal of the antibiotic tetracycline by electrochemical process using carbon-felt cathode and DSA $\left(\mathrm{Ti} / \mathrm{RuO}_{2}-\mathrm{IrO}_{2}\right)$ anode. Chemosphere, v. 87, n. 6, p. 614-620, 2012.

38. ZHANG, H. ; LIU, F.; WU, X.; ZHANG, J.; ZHANG, D. Degradation of tetracycline in aqueous medium by electrochemical method. Asia-Pacific Journal of Chemical Engineering, v. 4, n. 5, p. 568-573, 2009.

39. LI, G. et al. Degradation of tetracycline by eletrochemical oxidation using dimensionally stable anode: Institute of Electrical and Electronics Engineers, 2009. 2069-2072 p.

40. CHEN, S.; ZHENG, Y.; WANG, S.; CHEN, X. Ti/ $\mathrm{RuO}_{2}-\mathrm{Sb}_{2} \mathrm{O}_{5}-\mathrm{SnO}_{2}$ electrodes for chlorine evolution from seawater. Chemical Engineering Journal, v. 172, n. 1, p. 47-51, 2011.

41. RAJKUMAR, D.; KIM, J. G. Oxidation of various reactive dyes with in situ electro-generated active chlorine for textile dyeing industry wastewater treatment. Journal of Hazardous Materials, v. 136, n. 2, p. 203-212, 2006. 
42. SCIALDONE, O.; RANDAZZO, S.; GALIA, A.; SILVESTRI, G. Electrochemical oxidation of organics in water: Role of operative parameters in the absence and in the presence of $\mathrm{NaCl}$. Water Research, v. 43, n. 8, p. 2260-2272, 2009.

43. MALPASS, G. R. P.; MIWA, D. W.; SANTOS, R. L.; VIEIRA, E. M.; MOTHEO, A. J. Unexpected toxicity decrease during photoelectrochemical degradation of atrazine with $\mathrm{NaCl}$.

Environmental Chemistry Letters, v. 10, n. 2, p. 177-182, 2012.

44. CHUTIPONGTANATE, S.; THONGBOONKERD, V. Systematic comparisons of artificial urine formulas for in vitro cellular study. Analytical Biochemistry, v. 402, n. 1, p. 110-112, 2010.

45. LAUBE, N.; MOHR, B.; HESSE, A. Laser-probe-based investigation of the evolution of particle size distributions of calcium oxalate particles formed in artificial urines. Journal of Crystal Growth, v. 233, n. 1-2, p. 367-374, 2001.

46. OPALKO, F. J.; ADAIR, J. H.; KHAN, S. R. Heterogeneous nucleation of calcium oxalate trihydrate in artificial urine by constant composition. Journal of Crystal Growth, v. 181, n. 4, p. 410-417, 1997.

47. SEMAAN, F. S. Desenvolvimento de estratégias analíticas para determinação do antihipertensivo furosemida. 2007. 112 f. Tese (Doutorado em Ciências-Química Analítica) Instituto de Química de São Carlos, Universidade de São Paulo, São Carlos, 2007.

48. AMSTUTZ, V.; KATSAOUNIS, A.; KAPALKA, A.; COMNINELLIS, C.; UDERT, K. M. Effects of carbonate on the electrolytic removal of ammonia and urea from urine with thermally prepared IrO2 electrodes. Journal of Applied Electrochemistry, v. 42, n. 9, p. 787-795, 2012.

49. LANÇAS, F. M. Cromatografia líquida moderna: HPLC/CLAE. Campinas: Editora Átomo, 2009. $382 \mathrm{p}$.

50. VISCO, G.; CAMPANELLA, L.; NOBILI, V. Organic carbons and TOC in waters: an overview of the international norm for its measurements. Microchemical Journal, v. 79, n. 1-2, p. 185-191, 2005.

51. PENA-PEREIRA, F.; COSTAS-MORA, I.; ROMERO, V.; LAVILLA, I.; BENDICHO, C. Advances in miniaturized UV-Vis spectrometric systems. TrAC Trends in Analytical Chemistry, v. 30, n. 10, p. 1637-1648, 2011.

52. CHEN, J. C.; KUMAR, A. S.; CHUNG, H. H.; CHIEN, S. H.; KUO, M. C.; ZEN, J. M. An enzymeless electrochemical sensor for the selective determination of creatinine in human urine. Sensors and Actuators B: Chemical, v. 115, n. 1, p. 473-480, 2006.

53. POOKAIYAUDOM, P.; SEELANAN, P.; LIDGEY, F. J.; HAYATLEH, K.; TOUMAZOU, C. Measurement of urea, creatinine and urea to creatinine ratio using enzyme based chemical current conveyor (CCCII ${ }^{+}$. Sensors and Actuators B: Chemical, v. 153, n. 2, p. 453-459, 2011.

54. LIOTTA, E.; GOTTARDO, R.; BONIZZATO, L.; PASCALI, J. P.; BERTASO, A. Rapid and direct determination of creatinine in urine using capillary zone electrophoresis. Clinica Chimica Acta, v. 409, n. 1-2, p. 52-55, 2009. 
55. MAZZACHI, B. C.; PEAKE, M. J.; EHRHARDT, V. Reference range and method comparison studies for enzymatic and Jaffe creatinine assays in plasma and serum and early morning urine. Clinical Laboratory, v. 46, n. 1/2, p. 53-55, 2000.

56. SOLICH, P.; POLÁŠEK, M.; KARLÍČEK, R.; VALENTOVÁ, O.; MAREK, M. Spectrophotometric flow-injection determination of urea in body fluids by using an immobilized urease reactor. Analytica Chimica Acta, v. 218, n. 0, p. 151-155, 1989.

57. GOMES, L.; MIWA, D. W.; MALPASS, G. R. P.; MOTHEO, ARTUR J. Electrochemical degradation of the dye reactive orange 16 using electrochemical flow-cell. Journal of the Brazilian Chemical Society, v. 22, n. 7, p. 1299-1306, 2011.

58. BAUTITZ, I. R.; NOGUEIRA, R. F. P. Degradation of tetracycline by photo-Fenton processSolar irradiation and matrix effects. Journal of Photochemistry and Photobiology A:

Chemistry, v. 187, n. 1, p. 33-39, 2007.

59. CAMPINS FALCÓ, P.; TORTAJADA GENARO, L. A.; MESEGER LLORET, S.; BLASCO GOMEZ, F.; SEVILLANO CABEZA, A.; MOLINS LEGUA, C. Creatinine determination in urine samples by batchwise kinetic procedure and flow injection analysis using the Jaffé reaction: chemometric study. Talanta, v. 55, n. 6, p. 1079-1089, 2001.

60. BUTLER, A. R. The Jaffé reaction. Identification of the coloured species. Clinica Chimica Acta, v. 59, n. 2, p. 227-232, 1975.

61. KNORST, M. T.; NEUBERT, R.; WOHLRAB, W. Analytical methods for measuring urea in pharmaceutical formulations. Journal of Pharmaceutical and Biomedical Analysis, v. 15, n. 11, p. 1627-1632, 1997.

62. ZERADJANIN, A. R.; MANTIA, F.; MASA, J.; SCHUHMANN, W. Utilization of the catalyst layer of dimensionally stable anodes - interplay of morphology and active surface area.

Electrochimica Acta, v. 82, p. 408-414, 2012.

63. GOMES, L. Degradação eletroquímica do corante têxtil Alaranjado Remazol 3R utilizando diferentes eletrodos. 2009. 128 f. Tese (Doutorado em Físico-Química) - Instituto de Química de São Carlos, Universidade de São Paulo, São Carlos, 2009.

64. ALVES, P. D. P.; SPAGNOL, M.; TREMILIOSI-FILHO, G.; ANDRADE. A. R. Investigation of the influence of the anode composition of DSA-type electrodes on the electrocatalytic oxidation of phenol in neutral medium. Journal of the Brazilian Chemical Society, v. 15, n. 5, p. 626-634, 2004.

65. ROSSI, A.; ALVES, V. A.; DA SILVA, L. A.; OLIVEIRA, M. A.; ASSIS, D. O. S.; SANTOS, F. A.; MIRANDA, R. R. S. Electrooxidation and inhibition of the antibacterial activity of oxytetracycline hydrochloride using a $\mathrm{RuO}_{2}$ electrode. Journal of Applied Electrochemistry, $\mathrm{v}$. 39, n. 3, p. 329-337, 2009.

66. CESTAROLLI, D. T. Novos materiais para eletrooxidação de substratos orgânicos: investigação da oxidação do isopulegol em eletrodos de óxidos binários de rutênio e titânio $\mathrm{Ti} / \mathbf{R u}_{\mathbf{x}} \mathrm{Ti}_{(1-\mathrm{x})} \mathbf{O}_{2}$. 1999. $101 \mathrm{f}$. Dissertação (Mestrado em Química) - Departamento de Química, Faculdade de Filosofia, Ciências e Letras de Ribeirão Preto, Universidade de São Paulo, Ribeirão Preto, 1999. 
67. DALMÁZIO, I.; ALMEIDA, M. O.; AUGUSTI, R.; ALVES, T. M. A. Monitoring the degradation of tetracycline by ozone in aqueous medium via atmospheric pressure ionization mass spectrometry. Journal of the American Society for Mass Spectrometry, v. 18, n. 4, p. 679-687, 2007.

68. BAUTITZ, I. R. Degradação de tetraciclina utilizando o processo foto-fenton. 2006. $85 \mathrm{f}$. Dissertação (Mestrado em Química) - Instituto de Química, Universidade Estadual Paulista, Araraquara, 2006.

69. MOREIRA, E. M. Tratamento eletroquímico e eletroquímico irradiado do corante vermelho de alizarina S. 2011. 143 f. Dissertação (Mestrado em Química) - Instituto de Química de São Carlos, Universidade de São Paulo, São Carlos, 2011.

70. WANG, P.; HE, Y. L.; HUANG, C.-H. Reactions of tetracycline antibiotics with chlorine dioxide and free chlorine. Water Research, v. 45, n. 4, p. 1838-1846, 2011.

71. WAN, Y.; JIA, A.; ZHU, Z.; HU, J. Transformation of tetracycline during chloramination: Kinetics, products and pathways. Chemosphere, v. 90, n. 4, p. 1427-1434, 2013.

72. COURROL, L. C.; SILVA, F. R. O.; GOMES, L.; VIEIRA JÚNIOR, N. D. Energy transfer study of europium-tetracycline complexes. Journal of Luminescence, v. 122-123, p. 288-290, 2007.

73. SNOEYINK, V. L.; JENKINS, D. Water chemistry. New York: Wiley, 1980. 463 p.

74. PAROLO, M. E.; AVENA, M. J.; PETTINARI, G. R.; BASCHINI, M. T. Influence of $\mathrm{Ca}^{2+}$ on tetracycline adsorption on montmorillonite. Journal of Colloid and Interface Science, v. 368, n. 1, p. 420-426, 2012.

75. LAVORENTI, A. Equilíbrio do complexos e quelatos. Departamento de Ciências Exatas, Escola Superior de Agricultura "Luiz de Queiroz", Universidade de São Paulo. E. U. Piracicaba, 2002. Disponível em: < http://www.Ice.esalq.usp.br/arquimedes/Atividade08.pdf>. Acesso em: 21 jun. 2013.

76. DEBORDE, M.; VON GUNTEN, U. Reactions of chlorine with inorganic and organic compounds during water treatment-kinetics and mechanisms: a critical review. Water Research, v. 42, n. 1-2, p. 13-51, 2008. 